\title{
Assessment of Surface Geophysical Methods in Geothermal Exploration and Recommendations for Future Research
} by

N. E. Goldstein, R. A. Norris, and M. J. Wilt

Lawrence Berkeley Laboratory

University of California

Berkeley, California 94720

for

U.S. Department of Energy

Division of Geothermal Energy

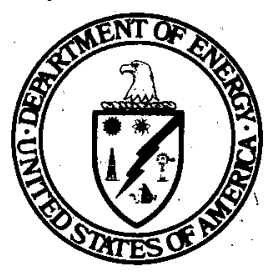

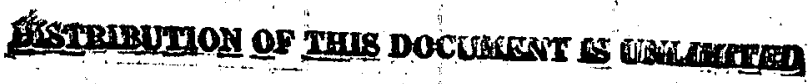

Work performed for the U.S. Department of Energy under Contract W-7405-ENG-48 
This report was prepared as an account of work sponsored by the United States Government. Neither the United States nor the Department of Energy, nor any of their employees, nor any of their contractors, subcontractors, or their employees, makes any warranty, express or implied, or assumes any legal liability or responsibility for the accuracy, completeness or usefulness of any information, apparatus, product or process disclosed, or represents that its use would not infringe privately owned rights.

Printed in the United States of America

Available from

National Téchnical Information Service

U. S. Department of Commerce

5285 Port Royal Road

Springfield, VA 22161

Price: Printed Copy, \$ 8.00 Domestic; \$16.00 Foreign

Microfiche, \$3.00 Domestic; \$4.50 Foreign 


\section{DISCLAIMER}

This report was prepared as an account of work sponsored by an agency of the United States Government. Neither the United States Government nor any agency Thereof, nor any of their employees, makes any warranty, express or implied, or assumes any legal liability or responsibility for the accuracy, completeness, or usefulness of any information, apparatus, product, or process disclosed, or represents that its use would not infringe privately owned rights. Reference herein to any specific commercial product, process, or service by trade name, trademark, manufacturer, or otherwise does not necessarily constitute or imply its endorsement, recommendation, or favoring by the United States Government or any agency thereof. The views and opinions of authors expressed herein do not necessarily state or reflect those of the United States Government or any agency thereof. 


\section{DISCLAIMER}

Portions of this document may be illegible in electronic image products. Images are produced from the best available original document. 


\section{Assessment of Surface Geophysical Methods \\ in Geothermal Exploration and \\ Recommendations for Future Research*}

by

N. E. Goldstein, R. A. Norris, M. J. Wilt

Lawrence Berkeley Laboratory

University of California

Berkeley, California 94720

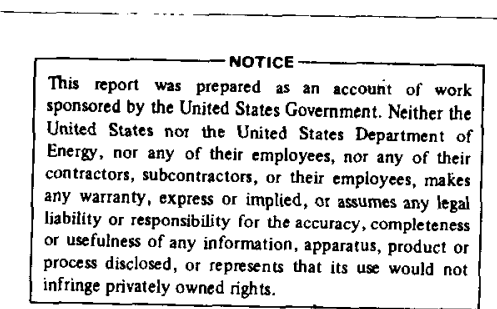

* This work was done with support from the U.S. Department of Energy. 



\section{ACKNOWLEDGMENTS}

The authors wish to acknowledge the support and guidance of several co-workers at the University of California, Berkeley who assisted in the preparation of this report. T. V. McEvilly contributed valuable discussions and review of the Passive and Active Seismic sections. H. F. Morrison provided similar important help on the Natural and Controlled-Source Electrical and Electromagnetic sections, and contributed some of the material on Controlled-Source EM systems. R. F. Corwin's work is the basis for the Self-Potential section. The authors would also like to thank the many geophysicists, listed in the Appendices, who were contacted via telephone or in person and who provided us with constructive information.

The authors also wish to acknowledge the useful suggestions of Peter Klock, consultant, who helped develop the planning approach, methodology and research matrices used in this report. 

Table of Contents

summary .................... 1

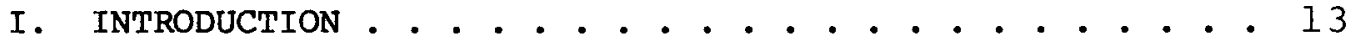

II. PLANNING APPROACH AND METHODOLOGY . . . . . . . 17

1. State-of-the-Art Assessment. . . . . . . . 17

2. Geophysical Research Needs: The Research Matrix . . 17

3. Review Task Force. . . . . . . . . 20

III. PASSIVE SEISMIC METHODS. . . . . . . . . . 21

1. Exploration Techniques .......... 21

a. Microseisms ........... 21

b. Microearthquake Studies (MEQ) . . . . . 22

c. Teleseismic Earthquake Studies ....... 23

2. Research Areas ........... 24

a. Area I: Seismic Data Acquisition and Processing $2 \dot{4}$

b. Area II: Ground Noise Studies....... 28

c. Area III: Magma Chamber Mapping ...... 32

d. Area IV: Microearthquakes and Fault Mapping . . 34

3. References ............. 36

IV. ACTIVE SEISMIC METHODS ................. 39

1. Exploration Techniques .......... 39

a. Refraction ........... 39

b. Reflection ..............41

2. Research Areas ............ 45

a. Area I: Seismic Refraction Studies ..... 47

b. Area II: Fault Mapping ........ 49

c. Area III: $v_{\mathrm{P}} / \mathrm{v}_{\mathrm{S}}$ or Poisson's Ratio Sections . 50 
d. Area IV: Deep Crustal Studies . . . . . . 53

e. Area V: Laboratory Studies ........ 55

3. References ................ 61

v. NATURAL FIELD ELECTRICAL AND ELECTROMAGNETIC METHODS • • • 67

Self-Potential . . . . . . . . . . . . . . 67

1. Background ................ 67

2. Research Areas.............. 70

a. Area I: Self-Potential Data Base ..... . 70

b. Area II: Origin of Self-Potential Anomalies . 72

c. Area III: Electrode Studies . . . . . . 73

3. References ................ 75

Tellurics . . . . . . . . . . . . . . . . 77

1. Exploration Techniques ........... 77

a. Vector Tellurics ............ 77

b. Profile Tellurics . . . . . . . . 79

2. Research Areas . . . . . . . . . 81

a. Area I: The Separation of Local From Regional Effects .............. 81

b. Area II: Updating Vector Telluric Recording Systems ................ 83

c. Area III: Data Interpretation . . . . . 86

3. References ................ 87 
Magnetotellurics/Audio-Frequency Magnetotellurics . . . . 89

1. Exploration Techniques . . . . . . . . . 89

a. Scalar MT/AMT .............. 94

b. Tensor MT/AMT .............. 95

c. Remote Telluric-Magnetotellurics . . . . . 99

d. Dual Station Magnetotellurics ...... . 100

2. Research Areas ............... 101

a. Area I: Effects of Geologic and Man-Made Noise 102

b. Area II: Data Processing and Noise Reduction • 106

c. Area III: Remote Telluric-Magnetotellurics . 110

d. Area IV: Modeling and Interpretation . . . 112

e. Area V: Tipper Reconnaissance . . . . . . 115

f. Area VI: Improvement of AMT Field Systems . . 116

3. References................. 120

Audio-Frequency Magnetics (AFMAG) ........... 125

1. Background ................. 125

2. References.................. 128

VI. CONTROLLED-SOURCE ELECTRICAL AND ELECTROMAGNETIC

METHODS ...................... 129

Galvanic Electrical Resistivity . . . . . . . . . 129

1. Background ................ 129

2. Exploration Techniques ............ 132

a. Reconnaissance Mapping or Profiling . . . . 132

b. Vertical Electrical Soundings . . . . . 134

c. Electrical Sections ........... 135 
Magnetometric Resistivity . . . . . . . . . . 137

Induced Polarization . . . . . . . . . . . . 138

Electromagnetic Induction ................. 143

Research Areas for Controlled-Source Methods . . . . . . . 148

1. Area I: Two-Dimensional Interpretation of

Resistivity Data.............. 149

2. Area II: Magnetometric Resistivity . . . . . 152

3. Area III: Inductive Coupling Effects in Induced

Polarization ............. . 153

4. Area IV: Controlled-Source Electromagnetic

Surveying . . . . . . . . . . . 155

References for Controlled Source Methods . . . . . . . 158

APPENDIX I: Geophysicists Consulted for Seismic Methods . . 163

APPENDIX II: Geophysicists Consulted on Electrical and

Electromagnetic Methods . . . . . . . 165 


\section{SUMMARY}

Four classes of geophysical methods have been considered in this report and for each, we have identified several research areas where effort is needed to improve the various techniques for geothermal exploration. These areas are briefly summarized here; the more detailed discussions, background and suggested solutions are presented in the body of the report.

\section{Passive Seismic}

Area I: Seismic Data Acquisition and Processing

Passive seismic exploration would be more effective if industry had a system with large data-gathering capacity but low operating cost. The system would be able to sample an entire prospect area $(10 \times 10 \mathrm{~km})$ in one set-up with many geophones and have the capability for some automatic in-field data processing, tape recording and information storage for post-field processing. The ideal system should have provision for:

(a) Microearthquake detection and location,

(b) Ground noise mapping, both amplitude spectra and array processing.

Selected information from teleseismic or regional earthquake signals might be stored for post-field processing for

(c) P-wave delay mapping,

(d) Attenuation (Q) mapping. 
Area II: Ground Noise Studies

An effort should be made to determine whether ground noise studies have a direct application in geothermal exploration, i.e., to determine whether certain types of near-surface geothermal regimes radiate body wave energy, and if so, to define the source mechanism. This information could be used to improve data acquisition and processing procedures. This research might be conducted over a number of reservoir areas using commercial seismic reflection equipment, minus the source, to record noise from a two-dimensional spread.

\section{Area III: Magma Chamber Mapping}

A careful study of teleseismic $\mathrm{P}$ - and S-wave arrival times and attenuations and a study of Rayleigh-wave phase velocity can help determine the presence of molten or partially molten rocks underlying certain geothermal areas.

\section{Area IV: Microearthquakes and Fault Mapping}

The question of whether thermal conditions (e.g., hydrothermal convection) cause "geothermal earthquakes" with identifiable characteristics has not been adequately answered. This would require careful microearthquake studies within and outside known geothermal areas. Systematic differences in source characteristics would be sought.

\section{Active Seismic}

There may be far more active seismic exploration work being done than is commonly known and reported in the open literature. For this reason, segments of the geothermal industry, particularly smaller 
companies with little background in seismology, may have scant appreciation for active seismic applications to their exploration problems. A one- or two-day symposium on this subject is recommended, the success of which would be largely dependent on the participation of the oil companies experienced in this area.

Specific active seismic research areas identified are as follows:

Area I: Seismic Refraction Studies

The usefulness of $\mathrm{P}$-wave delay and $\mathrm{P}$ - and S-wave attenuation mapping for geothermal exploration should be tested by means of largescale experiments at several geothermal systems. Both large magnitude distant earthquakes and explosion sources would be utilized. The objectives would be to determine whether mineralogical/physical property differences of the reservoir regions cause perturbations in seismic wave characteristics and to relate this information to reservoir character istics.

\section{Area II: Fault Mapping}

Improved high-resolution seismic reflection data acquisition and processing techniques should be tested at geothermal reservoirs where faults and fault-controlled permeability are important. Tests should be designed to determine procedures for extracting accurate information on fault location and geometry.

\section{Area III: $V_{P} / V_{S}$, Poisson's Ratio Sections}

Additional work is needed to investigate the usefulness of $v_{\mathrm{P}} / \mathrm{v}_{\mathrm{S}}$ sections for geothermal exploration and reservoir delineation. Laboratory 
evidence suggests that small amounts of steam will lower $\mathrm{V}_{\mathrm{P}} / \mathrm{v}_{\mathrm{S}}$ but field evidence at The Geysers is conflicting. Additional field work is needed, utilizing large-force shear-wave generators as well as local microearthquakes. Development of an efficient, combined SH- and P-wave energy source is also a worthwhile adjunct to this work.

Area IV: Deep Crustal Studies

The value of deep crustal (low resolution) reflection soundings for geothermal exploration is largely unknown. Surveys of the type being performed under the present COCORP Project may provide some important information on this subject and may be useful as a guide to future research.

\section{Area V: Laboratory Studies}

Additional laboratory studies of rocks under simulated geothermal reservoir conditions are needed for an understanding of elastic wave propagation in these environments. These studies must be carefully made, researchers must be mindful of irreversible changes that can take place once the sample is extracted from the earth, and the results must be studied in relation to well logs and surface measurements. 
Natural Field Electrical and Electromagnetic Methods

A. Self-Potential (SP)

Area I: Self-Potential Data Base

Acceptance of SP as an important exploration technique may depend on the acquisition and publication of an adequate laboratory and field data base. A catalogue of field results, supported by other surface and subsurface geological and geophysical information, is needed for anomalies of both geothermal and non-geothermal origin.

Area II: Origin of Self-Potential Anomalies

There is insufficient understanding of the causes of natural SP anomalies related to geothermal processes. Process information is needed to determine whether discrimination between geothermal and non-geothermal SP anomalies is possible. Laboratory studies on rocks and cores are needed to obtain magnitude estimates of streaming and thermoelectric potentials under geothermal conditions.

Area III: Electrode Studies

Self-potential measurements can be improved by finding ways to avoid the electrochemical effects (noise) that occur between electrode and ground. Proper electrode selection may be helpful because certain type(s) of electrodes may be more stable than others depending on local conditions, e.g., soil moisture, saturation, soil chemistry, temperature changes, moisture transpiration rate. 
B. Tellurics

Area I: The Separation of Local from Regional Effects

Regional structure may induce nonuniformity to the telluric field, thus obscuring smaller, local effects. There is no way to eliminate this problem, but effects can be studied and compensations estimated by means of calculations for two- and three-dimensional structures.

Area II: Updating Vector Telluric Recording Systems

The vector telluric survey system can be improved to varying degrees. Maximum improvement would be achieved if most of the usual post-field data processing were eliminated by means of an in-field data acquisition and processing system designed around a minicomputer. Alternatively, simpler systems based on microprocessors could be used to obtain some of the numerical parameters, which after being recorded, could be more fully processed in the laboratory. Lastly, the option requiring the least development is a system in which total post-field processing is retained, but made more effective by recording data on digital cassette recorders.

\section{Area III: Data Interpretation}

Interpretation of vector telluric data in geologically complex areas requires the numerical solution for the electromagnetic response of inhomogeneous half-spaces. Suitable computer programs are developed and used for magnetotelluric interpretation but have not as yet been applied to the telluric cases. 


\section{Magnetotellurics/Audio-Frequency Magnetotellurics (MT/AMT)}

Area I: Effects of Geologic and Man-Made Noise

Data can be influenced by natural and man-made noise which is sometimes difficult to recognize, and leads to improper interpretation of impedance estimates. Among these effects are large-scale field distortion caused by regional geology, non-planar signals caused by local atmospheric and man-made electrical disturbances, and local geologic inhomogeneities whose effects depend on the length of electric dipole used. These problems are serious and difficult to address. Suggestions for additional and/or continued effort include:

(1) Analog and mathematical models for representative regional geologic structures.

(2) Collection of regional MT data in areas of geothermal interest.

(3) A study and categorization of local man-made noise disturbances.

(4) More detailed studies of electric dipole length on impedance estimates in areas of geothermal interest.

\section{Area II: Data Processing and Noise Reduction}

Standard processing techniques will give biased and scattered estimates whenever electromagnetic noise is present. Thus, better data acquisition and processing techniques are needed. In addition, an understanding of the nature of electromagnetic noise is important, and may have significance to geothermal exploration as well. Efforts in these areas have begun and should be continued. Among the ongoing activities are attempts to find impedance calculations that are less sensitive to noise or that only require short data segments, and to 
develop new data acquisition techniques that allow one to recognize and compensate for certain types of noise.

\section{Area III: Remote Telluric-Magnetotellurics}

The remote telluric-magnetotelluric ( $\mathrm{T}-\mathrm{MT}$ ) method offers one means for improving the speed and cost-effectiveness of MT surveys. Whether this approach is only effective in areas of homogeneous, layered structures or may be applied to more complex areas as well is a subject that needs to be studied and evaluated. Also, because many simultaneous channels of data are collected in the T-MT technique, an on-site data processing system is a desirable adjunct.

\section{Area IV: Modeling and Interpretation}

The magnetotelluric method is severely handicapped by the user's inability to interpret results in geologically complex areas, where the one-dimensional model does not yield meaningful results. Accurate and efficient two- and three-dimensional computer programs are slowly being developed, but more effort is needed in this direction as many existing computer codes are expensive and difficult to use, requiring machines with large memories. MT/AMT interpretations can also be improved by means of joint inversion techniques involving complementary geophysical data sets. The question of whether the MT method is actually capable of detecting a zone of partial melt within the crust needs further study and clarification based on a combination of rock property studies and computer modeling. 
Area V: Tipper Reconnaissance

Planning an MT survey in a geologically complex area might be made easier if the work were preceded by a rapid reconnaissance, using only the magnetic field components to obtain tipper information. Theoretical calculations indicate that one can use tipper amplitude and direction to locate two-dimensional vertical discontinuities and determine whether three-dimensional structures are present.

Area VI: Improvement of AMT Field Systems

Present AMT field systems have limited capabilities and should be improved. In particular, AMT data acquisition and processing systems are needed which can evaluate data quality, calculate impedance phases, and obtain apparent resistivities down to frequencies approaching

$1 \mathrm{~Hz}$. For these capabilities the system requires microprocessor technology for on-site data processing and interpretation, digital recording on magnetic cassettes for post-field processing (optional), and highsensitivity portable magnetometers with a wider frequency range than currently available.

\section{Audio-Frequency Magnetics (AFMAG)}

The AFMAG method has not been used in geothermal exploration, and the development of improved AMT field systems will eventually supplant whatever applications exist for AFMAG. For the sake of scientific inquiry, however, it would be interesting to test AFMAG at selected geothermal reservoirs to determine and demonstrate its applicability. 
Controlled-Source Electrical and Electromagnetic Methods

Under this class of methods we consider galvanic electrical resistivity, induced polarization and electromagnetic induction. The research areas identified are as follows:

\section{Area I: Two-Dimensional Interpretation of Resistivity Data}

Most apparent resistivity data, whether from galvanic or inductive methods, must be interpreted in terms of two- or even three-dimensional models; the easy-to-use one-dimensional interpretations are usually inadequate. Despite many recent advances in computer programming, interpretation based on two-dimensional models is slow and arduous, based on trial-and-error forward calculations. Interpretations for three-dimensional models are in their infancy, limited to simple structures. For these reasons, we suspect that much of the resistivity data collected by industry has not been properly interpreted. The waning interest in resistivity methods may be due in part to industry's inability to allocate the proper amount of effort to interpretation. Faster, more automatic two-dimensional methods must be developed, and work must continue to optimize three-dimensional model algorithms.

\section{Area II: Magnetometric Resistivity}

The magnetometric resistivity method (MMR) is not known to have been applied to geothermal exploration. Compared to galvanic resistivity, MMR has certain advantages in terms of speed, less sensitivity to surface inhomogeneities, and greater sensitivity to bedrock conductors beneath overburden. MMR should be evaluated by means of field tests at several geothermal areas where supporting information exists. 
At the same time it is worthwhile to study the magnetic induced polarization (MIP) effect for this approach may be less sensitive to inductive coupling effects than conventional IP (see Area III).

\section{Area III: Inductive Coupling Effects in Induced Polarization}

Despite geological arguments for the use of induced polarization

(IP) in certain geothermal regimes, the technique is not being used. of the several possible reasons, one of the likelier is that inductive coupling errors, which have the appearance of true IP anomalies, are large in conductive areas and can neither be avoided by proper field procedures nor easily and accurately corrected by post-field processing. Research is needed to find a procedure whereby the inductive coupling effect can be determined directly and specifically for each group of implanted electrodes.

Area IV: Controlled-Source Electromagnetic Surveying

Controlled-source electromagnetic techniques have advantages over both dc resistivity and natural field resistivity techniques. The development and demonstration of controlled source methods for exploration at depths of several kilometers has been impeded for several reasons. Among these are instrumental and procedural difficulties in generating and measuring the low-frequency fields, and the difficulty of interpreting the results when the earth cannot be approximated by a simple model. Advances in technology now make it possible to build a practical large-moment system covering the $10^{-3}-10^{3} \mathrm{~Hz}$ range and to interpret results from more complex areas. One problem is the source; ideally it should have a large moment, be easy to deploy, 
retrieve and move in the field, and be oriented for optimum signalto-noise. Although the most practical transmitter, at this time, is a relatively small-diameter, multi-turn horizontal loop, this transmitter is not ideal. A rotating dc magnet would be better but to achieve the large moment needed, a lossless dc superconducting magnet would have to be designed for this application. 


\section{INTRODUCTION}

The objective of this report is to provide the Division of Geothermal Energy (DGE), Department of Energy (DOE) with a document to assist in guiding research planning in Geothermal Exploration Technology for the next two or three years. Research planning goals are to make geophysical exploration more effective on a scientific basis and more cost-effective on a practical basis.

This study identifies gaps in specific areas of surface geophysical technology and formulates research problems and solutions that are needed to correct these deficiencies. We have investigated four general classes of surface geophysical methods (see Table 1):

- Active seismic

- Passive seismic

- Natural field electrical and electromagnetic

- Controlled-source electrical and electromagnetic

The planning approaches and methodologies are described in Section II. Research plans are presented in sections III through VI, corresponding to each class of geophysical method. The research plans include: 1) background and state-of-the-art assessment; 2) description of research areas (including statement of the problem and discussion of the solution). A discussion of research priorities is not included; this aspect could be treated by the Seismic and Electrical Methods consortia organized by the University of Utah.

The research areas recommended in this document may include research more appropriately sponsored by agencies or groups other than DOE-DGE, e.g., the U.S. Geological Survey or National Science Foundation. 
Table 1. Geophysical methods considered in research planning.

\begin{tabular}{|c|c|c|c|}
\hline \multicolumn{4}{|c|}{ SURFACE GEOPHYSICAL CLASSES } \\
\hline 1. Passive Seismic & 2. Active Seismic & $\begin{array}{l}\text { 3. Natural Field Electrical } \\
\text { and Electromagnetic }\end{array}$ & $\begin{array}{l}\text { 4. Controlled-Source } \\
\text { Electrical And } \\
\text { Electromagnetic }\end{array}$ \\
\hline $\begin{array}{l}\text { a. Microseisms } \\
\text { (ground noise) }\end{array}$ & a. Refraction & a. Self-Potential & $\begin{array}{l}\text { a. Galvanic electrical } \\
\text { resistivity }\end{array}$ \\
\hline b. Microearthquakes & b. Reflection & b. Tellurics & $\begin{array}{l}\text { b. Magnetometric } \\
\text { resistivity }\end{array}$ \\
\hline $\begin{array}{l}\text { c. Teleseismic earthquakes } \\
\text { (delay and attenuation) }\end{array}$ & & $\begin{array}{l}\text { c. Magnetotellurics/Audio- } \\
\text { frequency magnetotellurics } \\
\text { (MT/AMT) }\end{array}$ & c. Induced polarization \\
\hline & & $\begin{array}{l}\text { d. Audio-frequency } \\
\text { magnetics (AFMAG) }\end{array}$ & $\begin{array}{l}\text { d. Electromagnetic } \\
\text { induction }\end{array}$ \\
\hline
\end{tabular}


However, to present a comprehensive picture of the problems in surface geophysics and the research needed, we have included research areas that may not presently be germane to DOE's mission to accelerate the development of on-line geothermal power.

Chapters III through VI are organized in a similar fashion. Each has a general background section that includes methodologies, instrumentation and geothermal exploration applications and results, followed by a section devoted to recommended research, consisting of a problem statement, additional background if necessary, and a recommended solution or approach toward a solution. The first portion is somewhat tutorial and is included for completeness. The expert may want to scan this portion briefly before going to the second part of the chapter. 


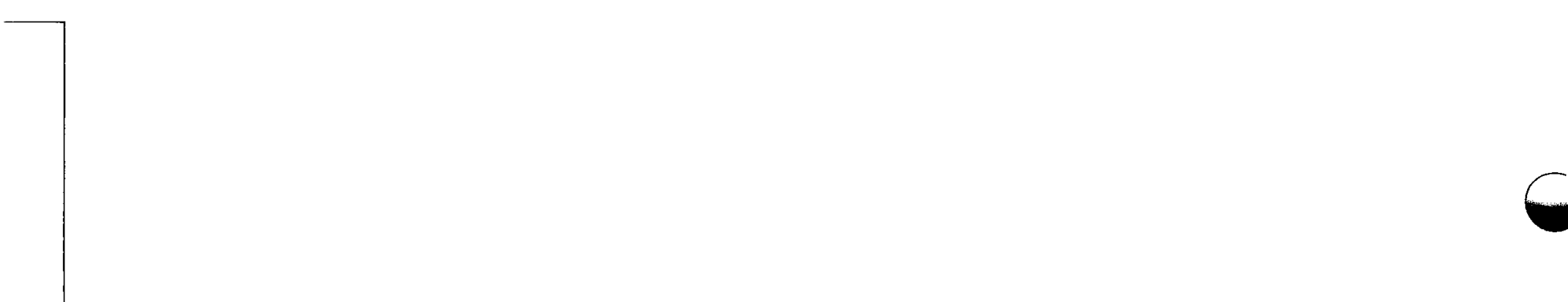

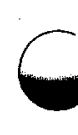




\section{PLANNING APPROACH AND METHODOLOGY}

Several approaches and methods were utilized in developing a research plan; these are discussed below.

\section{State-of-the-Art Assessment}

The assessment was designed to investigate the current state of surface geophysical technology. The investigation included: a) literature review; b) consultation with industrial, academic, and government experts; c) preparation of a state-of-the-art description for each geophysical method.

The state-of-the-art descriptions are presented in Sections III through VI, and they include pertinent sources of information and references that were reviewed. Lists of geophysicists contacted and consulted during this work are given in Appendices I and II.

\section{Geophysical Research Needs: The Research Matrix}

The state-of-the-art assessment provides a suitable basis for analyzing geophysical needs. From this analysis research areas were identified, each research area being a clearly defined problem or gap in geophysical technology for which we could present a problem statement and a recommended solution. The recommended solution consists of research activities falling into one or more of the following categories:

- Fundamental studies: The basic field and laboratory studies needed to (a) develop a missing data base, and (b) test concepts needed to improve field techniques or help develop superior instrumentation. 
- Instrument Development: The design, fabrication, and testing of new instrument prototypes needed to make exploration surveys more effective and/or less costly.

- Data Processing: The development of new approaches or new algorithms for the processing of geophysical data, reducing and presenting the data in a more interpretable form.

- Data Interpretation: The development of new approaches and algorithms to interpret geophysical results in terms of subsurface geology.

- Field Verification Surveys: Proof-of-concept and proof-of-design field surveys over geothermal environments, previously delineated and documented by geological and geophysical investigations.

In order to help visualize and analyze the components of each research area in relation to other research areas, we devised a graphical aid called the research matrix, illustrated in Fig. l. The matrix shows the five research categories, and how they fit into a larger research area. In the hypothetical example, two fundamental studies are needed to assist with instrument development. In conjunction with this, there is the need to develop software packages for data processing and for interpretation. Finally, the new hardware will be field tested, and the data collected will be interpreted by means of the interpretative schemes worked out.

Arrows between elements show the direction of information flow. In this example the flow exists only between elements of the one research area. In actuality, however, we find that flow lines may also exist between different research areas. For example, an instrument developed 
RESEARCH

CATEGORY

1. Fundamental

Studies

(Concept Testing)

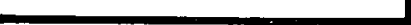

2. Instrument

Development

3. Data

Processing

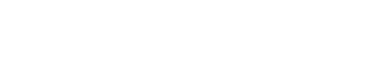

4. Data

Interpretation

5. Verification

(Proof of Concept)
RESEARCH AREA

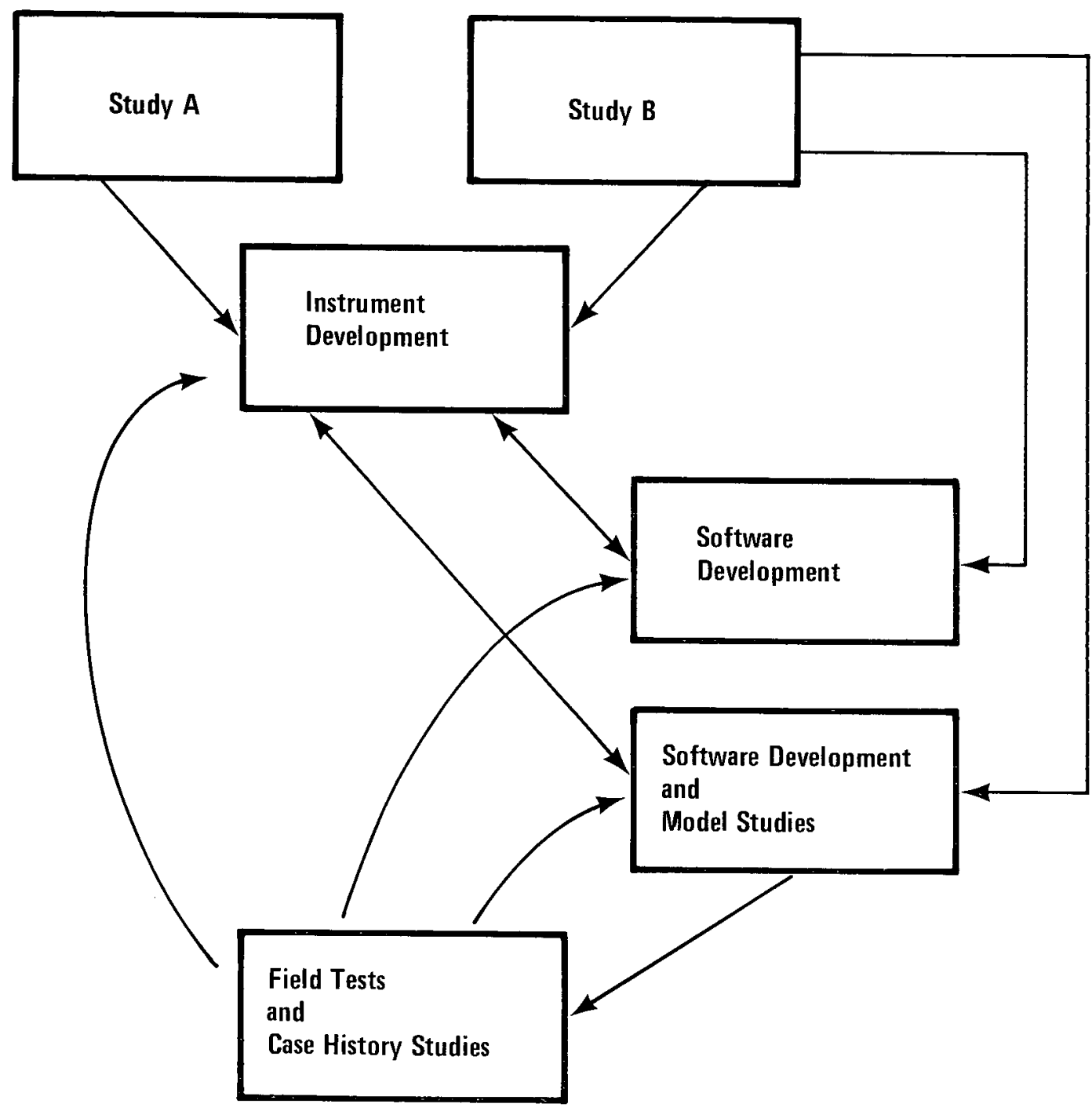

Fig. 1. Example research matrix for surface geophysical method. 
for one area of investigation might also have application in helping to resolve a problem within another area.

In each of the Sections III through VI we present research matrices that correspond to and may help to underscore the discussions given for each research area. Within each method class several research areas have been identified. Many of these are discrete, in that the research area constitutes a clearly defined and distinct unit for planning and administrative purposes. Other research areas tend to be related and, although they address separate problems, could be combined into a single programmatic effort.

Not represented in any research matrix is the existing body of knowledge, the so-called input to the research area.

A research area does not necessarily equate with a project level effort. Many of the research areas contain two or more elements, and in some areas each element could be addressed as a separate project.

\section{Review Task Force}

While planning this document it was anticipated that the finished work would eventually be submitted to a Review Task Force composed of experts chosen from industry, academia and government laboratories. This phase of work has not yet been undertaken. However, we recommend that a Task Force be selected and charged with the responsibility for reviewing the document, and reporting its recommendations to DOE/DGE. The work statements should include a description of expected results, schedules, and levels of effort. 


\section{PASSIVE SEISMIC METHODS}

In passive seismic exploration, a man-made energy source is not employed. Detectors (geophones) are laid out or arrayed over a prospect area, and the natural seismic activity usually at frequencies above $1 \mathrm{~Hz}$ is recorded, processed and studied. Passive exploration may be subdivided into three general techniques, each requiring a different approach to data collection and processing: a) microseisms, b) microearthquake studies, and c) teleseismic earthquake studies.

\section{Exploration Techniques}

\section{a. Microseisms}

The most commonly used passive seismic technique is to record and study the spatial and frequency characteristics of ambient microseisms. This is generally known as the "seismic ground noise" method. On theoretical grounds there are two reasons for investigating microseisms in geothermal exploration. First, the reservoir or heat source may behave as a seismic energy source producing a continuum of radiation in the 1 to $100 \mathrm{~Hz}$ band because of convective hydrothermal activity or thermal-stress induced microfracturing. This reasoning has resulted in the "standard" noise survey widely used in geothermal exploration, in which noise power from a listening survey is calculated and contoured.

A second method is the interpretation of noise propagation characteristics by propagating elastic waves and then inverting the observed wave characteristics to obtain the distribution of medium properties, i.e., velocity and attenuation. From the propagation parameters, one can also then locate individual energy sources. Fixed 
non-aliased arrays are needed, and when used in a beam-forming mode, can help define the source region of coherent radiation. Because the second method is complex, it is expensive to use and consequently is less well understood by the geothermal industry.

\section{b. Microearthquake Studies (MEQ)}

Another type of "listening" survey involves the detection, location, and analysis of individual microearthquakes $(M \geq-2)$. Interest in this approach began several years ago following observation that many geothermal fields have a consistent microearthquake activity of 3 to 30 events per day (Palmason, 1975). However, the frequency of events alone is not a useful exploration index because tectonically stressed areas with average heat flow will also exhibit high microearthquake activity. Therefore microearthquake studies are, at best, an indirect exploration method and cannot be used and interpreted without other geological and geophysical survey results. They do, of course, give direct evidence of active faulting.

To obtain maximum information from microearthquakes, geophysicists determine the relative arrival times of the seismic energy at a number of detectors spaced several kilometers apart. From this information a source location (hypocenter) is calculated, and the locus of many hypocenters may define a fault zone which, in certain areas, could be the conduit for hydrothermal convection. Also, using first motion polarities, a fault-plane solution will indicate the type of motion, hence the local stress state in the earth. Given good shear-wave arrivals, it is possible also to estimate the ratio of P-to-s wave 
velocities, and to detect spatial variations in Poisson's ratio, averaged over the ray path. Anomalies in Poisson's ratio may be indicative of certain types of geothermal reservoirs due to the effect of brine and steam saturation on $\mathrm{P}$ - and $\mathrm{S}$-wave velocities ( $\mathrm{V}_{\mathrm{P}}$ and $\left.\mathrm{V}_{\mathrm{S}}\right)$. Amplitudes of $\mathrm{P}-$ and S-wave provide indications of variation in attenuation throughout an area.

\section{c. Teleseismic Earthquake Studies}

The final passive seismic method involves the detection and analysis of seismic events originating from distant earthquakes or explosions. Relative P-wave arrival times, corrected for average velocity and referenced to an appropriate site, provide a delay pattern over an area which is conditioned by local velocity, and hence, geology changes. When this delay pattern, together with $\mathrm{P}$-wave attenuation and frequency content, is studied in terms of geological data and other geophysical data, the results may delineate a potential reservoir area. Negative P-wave delays (i.e., advances) have been noted over the silicified Leach Hot Springs (Beyer et al., 1976), and at The Geysers (Majer and McEvilly, 1977).

In addition to the $P$-wave arrival time and amplitude studies, valuable information is also contained in the $P$ to $S$ converted wave at the base of the crust. If this phase can be detected, it provides $S$ velocity information and the spatial variation in Poisson's ratio. This approach is seldom used in commercial geothermal exploration, primarily due to the lack of control in data acquisition, i.e., many 
field days may yield nothing. Where it has been applied, it is usually a part of more comprehensive survey programs.

\section{Research Areas}

In the following sections we describe several research areas for which additional research is needed to improve the overall stateof-the-art and effectiveness of passive seismic exploration. For each we pose a problem statement, followed by a section giving more detailed background relating to the problem, and finally a section with a proposed solution to the problem written as a general scope of work. The research areas, also shown graphically in the research matrix of Fig. 2, are the following:

- Seismic Data Acquisition and Processing

- Ground Noise Studies

- Magma Chamber Mapping

- Microearthquakes and Fault Mapping

a. Area I: Seismic Data Acquisition and Processing

Problem Statement

Workers have encountered problems in trying to obtain definitive ground noise, P-wave delay and microearthquake (MEQ) results over known geothermal areas. This situation has led to the conclusion that passive seismic methods, in general, are of marginal value and are uneconomical for the amount of useful information obtained. 
RESEARCH AREAS

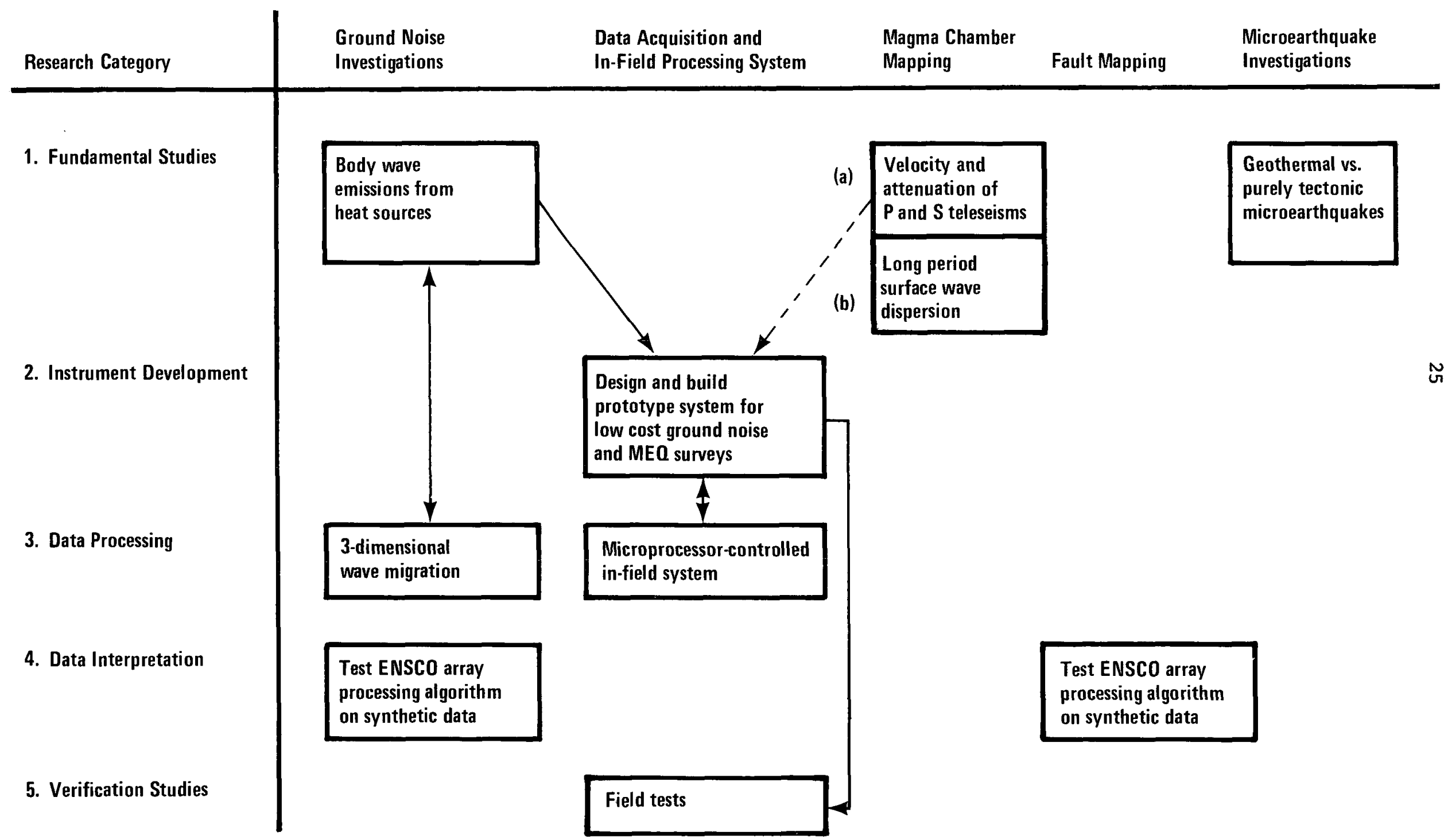

Fig. 2. Research matrix for passive seismic exploration. 
Whether this argument is justified on geological grounds has not been thoroughly evaluated, partially because our instrumental capabilities are yet too limited to deal with the problem in a systematic and efficient way.

\section{Background}

One of the principal reasons behind the questionable effectiveness of passive seismic methods is that no one at present has the capability of fielding a low-cost system that will provide both the large aerial coverage and tight resolution needed in geothermal exploration. Looking at the exploration problem in terms of a sampling exercise, we see that we should have the capability to cover a large area, $10 \mathrm{~km}$ by $10 \mathrm{~km}$, by separate arrays of the small aperture, non-aliased type. Because of the large number of data channels involved, it would also be necessary to design a system which can process the data in the field, as well as calculate and store information for later use. The U.S. Geological Survey's Centipede System, with 96 geophones, has a large data-gathering capacity, but is costly to operate and requires post-field processing. Present systems in common use are not only limited by too few data channels, resulting in geophone separations typically too wide to be useful, but also include reconnaissance systems without adequate timing accuracy for the resolution needed. Present systems require that acquisition and data processing be performed sequentially, with the processing done in the laboratory after the tapes and charts are returned from the field. This process is lengthy and expensive to the user. Furthermore, continuous monitoring over 
a long period to ensure adequate data occasionally generates an excessive amount of recording that needs to be handled, scanned and stored. Also, data processing in the laboratory means that the field crew has no way of knowing whether the measurements are adequate and if not, what should be done to modify the operations.

\section{Solution}

Based on LBL's experience in northern Nevada and at The Geysers, we believe that it is possible to obtain meaningful and useful results from passive seismic data, provided the surveys are properiy conducted and the data are properly processed. Lacking are sufficient casehistory examples, and, more importantly, a system that should be fielded for such measurements. The proposed solutions to this problem are:

1) to acquire more case-history information, making detailed measurements over perhaps an additional 12 selected hydrothermal systems;

2) to assemble the proper field system with in-field processing capability.

The first proposed solution involves designing and conducting field experiments for additional fundamental information in known geothermal areas. This work ties in with research areas covered in the sections following. Therefore, we discuss only the second proposed solution, i.e., instrument development.

As far as data acquisition and processing are concerned, there is a need for: a digital system with wide dynamic range $(\geq 60 \mathrm{~dB})$, broad bandwidth ( 1 to $100 \mathrm{~Hz}$ ), relative timing accuracy ( $1 \mathrm{~ms}$ ), and high 
gain which could be operated economically in the field (two-man operation). The system should have the capability of gathering data from a large number of geophones, arrayed in clustered centers over a typical geothermal prospect area $(10 \mathrm{~km} \times 10 \mathrm{~km})$, and have the built-in capability for automatic data processing to provide:

1) MEQ detection and location, some spectral data storage, as well as $\mathrm{P}$-wave and S-wave arrival times for post-analysis;

2) Ground noise mapping, both the simple power-spectral amplitudes, suitably referenced, and the array processing analysis to help define the source of the noise.

The system should detect teleseismic or regional earthquake P-waves and should store amplitude and time information which can later be used in post-field processing for the purpose of relative P-wave delay mapping and attenuation (or Q) mapping.

\section{b. Area II: Ground Noise Studies}

\section{Problem Statement}

Relative to Research Area I is the fundamental question of whether ground noise investigations have a direct application in geothermal exploration. That is, can we determine whether a particular geothermal reservoir, or a class of reservoirs with similar geological characteristics, behaves as a noise generator, radiating body wave energy from depth in sufficient quantity to serve as a direct exploration guide? Related problems are to define the source mechanisms and to use this information to improve data acquisition and processing procedures. 
Background

The conventional noise power mapping technique, as described by Douze and Sorrells (1972) and used for several years by researchers and industry, is considered questionable as a universally effective exploration approach. It is now becoming increasingly evident that a noise power anomaly may result not only from an active seismic source, such as hydrothermal activity near the surface and geyser eruption (Iyer and Hitchcock, 1974), but also from lateral variation in nearsurface velocity, particularly where low-velocity alluvium is involved (Liaw and McEvilly, 1977). It is also now evident that much of the observed noise once believed to indicate a seismic source at depth is from surface waves, principally fundamental-mode Rayleigh waves. This energy can be either narrow or wide band, related to natural sources such as flowing rivers, canals and waterfalls, or to man-made sources such as freeways, pumps, and pipelines.

In summary, the conventional noise mapping technique provides no information to distinguish between noise caused by buried sources emitting body waves, and noise caused by surface waves related to shallow geological and man-made effects. To make this distinction, one must use some type of array processing to determine phase velocity and propagation direction of the noise field. Phase velocity will discriminate between shallow surface waves and body waves. Whiteford (1975) located the noise source in the Wairakei area using tripartite array measurements. Iyer and Hitchcock (1976) used an L-shaped array with a 106-meter instrument spacing in Long Valley, and found that propagation azimuths for the high-velocity waves defined areas of 
surface geothermal phenomena, but propagation azimuths of low velocity waves were random. There is some question as to whether all attempts by researchers using array processing have been effective because of the large geophone separations used. Liaw and McEvilly (1977) found they had to use a small aperture array to eliminate spatial aliasing of high wavenumber components associated with the shallow, low velocity surface waves. Using a 12-element circular array with geophones tightly spaced, they were able to sample wavelengths as short as 10 to 20 meters near Leach Hot Springs, Grass Valley, Nevada. Their resulting high resolution frequency-wavenumber $(f-k)$ analysis gave no indication for a significant body wave component in the noise. However, array geometry was controlled by the high wavenumbers, significantly reducing resolution for the low wavenumber body waves, if present.

\section{Solution}

The ground noise problem may be approached in various ways. A combination of conventional noise mapping with a high-resolution, non-aliased array used in a beam-forming mode to define the source area of coherent radiation would be a reasonable approach. Spatial anti-alias fitting in sub-arrays would provide improved body wave resolution, surface wave discrimination, and the possibility of simultaneous microearthquake surveying. Spectral studies would define diurnal and secular noise variations early in the experiment.

This approach would best be effected by the development of a special-purpose seismic data acquisition and processing system (see Research Area I). With such a simplified system the cost of acquiring 
and processing the large amount of required data could be held down, and the results then assembled to provide a definitive assessment of the technique, given adequate data quality.

It would be expedient to conduct first an experiment in reconnaissance by using a commercial seismic reflection crew to perform a beam-forming type of survey, eliminating the seismic source, but recording noise data from a two-dimensional surface spread. The seismic data from geophones $110 \mathrm{ft}$ apart, recorded simultaneously for 48 to 96 groups, would be interpreted by means of three-dimensional migration software to continue the wave field back to its apparent source. Data could be collected at different gain settings and at different times of the day, and once the geophone array is laid out there is little effort required to collect the data. The entire experiment could be conducted in two days. Data interpretation, on the other hand, is nonstandard and would require special handling with available software. Surveys of this nature could be conducted over several known reservoir areas, including Roosevelt, Leach, and Long Valley. A standard seismic velocity survey, funds permitting, could also be conducted to obtain velocity data so that migration can be more reliably done. This experiment would be definitive in establishing the existence of reservoir-induced body-wave radiation from depth.

If surveys show the existence of reservoir-related body-wave generation, the data can be studied for information in the physics of the process, e.g., continuous micro (or nano) earthquakes of tectonic nature, phase changes, pore fracturing (Knapp and Knight, 1977), turbulent fluid flow, resonant chambers (plumbing noise), or these in 
combinations. Recordings should include the use of horizontal geophones (in addition to the usual vertical ones). Information gained in such a test study could be applied to the data acquisition and processing system design discussed in the Problem Statement (see Research Area I), and therefore it is recommended that this project be conducted early in the time sequence.

\section{c. Area III: Magma Chamber Mapping}

\section{Problem Statement}

A guide to geothermal exploration is the near surface magma chamber postulated to underlie many geothermal areas. Whether these magma chambers exist and can be detected is of fundamental importance to both the geological questions of origin and duration (heat content) of hydrothermal systems and to the problem of exploring for new blind systems.

\section{Background}

To date we have no direct evidence for a body of molten or partially molten rock coming close to surface (within the crust) beneath a geothermal reservoir. Indirect evidence for magma chambers include youthful rhyolitic intrusives and resurgent volcanic activity, Curie isotherm analysis of aeromagnetic data, gravity lows suggesting low density rocks at depth (The Geysers), an absence in earthquake hypocenters at depth below a reservoir area (Yellowstone Caldera), high conductive heat flow, high thermal gradients, and anomalous $\mathrm{P}-$ and S-wave characteristics. of the indirect techniques that have been or can be employed, seismic methods involving a study of $P$ and particularly $S$ waves provide an 
approach yielding less ambiguous results. Except at the Yellowstone Caldera (Steeples and Iyer, 1975; Smith et al., 1974; Eaton et al., 1975) and the Rio Grande Rift fundamental studies of this type have not been conducted in detail in geothermal areas, and most studies of this type (Steeples and Iyer, 1975) have been concerned with teleseismic P-wave arrival times only. It is important that the S-wave data be brought into the reservoir delineation studies.

\section{Solution}

In order to study the feasibility of mapping a crustal magma chamber, it is recommended that velocity variations (from $P$ - and S-wave delay times of teleseisms and local microearthquakes) and attenuation of $P$ and $S$ waves be mapped in detail over several known geothermal systems. Experiments of this type would involve installation of a tightly-spaced, wideband, three-component monitoring network during a period of four to six weeks per site. The amplitudes and arrival times of the $P$ and $S$ phases and hopefully, the $P$ to $S$ converted phase at the Moho, from teleseisms, would be used in this study.

This study for magma chamber mapping also involves ground noise measurements, extended to the longer period surface wave microseisms using the 6-8 sec period Rayleigh wave. Because of their long wavelengths, these surface waves penetrate deeply into the crust, and the phase velocity, dependent heavily on the s-wave velocity, should reflect passage through a magma chamber. 


\section{d. Area IV: Microearthquakes and Fault Mapping}

\section{Problem Statement}

Microearthquakes $(M<2)$ are often observed in geothermal areas, and this has led to the speculation that thermal stresses or conditions related to thermal energy transport causes "geothermal" earthquakes. Geothermal exploration would be greatly facilitated if it could be proved that microearthquakes related to high temperature conditions can be distinguished from microearthquakes originating from tectonic stresses. If the concept is valid, the explorationist would have a powerful tool. On the other hand, if the concept can be totally refuted, the explorationist would know to fall back on the conventional seismological methods of data interpretation.

\section{Background}

Faults and fracture zones are believed to provide major pathways for convective thermal transport, and for this reason a great deal of attention has been directed to their identification and location. This has been carried out by means of passive seismic monitoring of the often numerous microearthquakes that occur along fault zones, and calculating hypocenter locations and fault plane solutions by means of arrival times and first motions at numerous recording sites. The simplicity of the method does not, unfortunately, carry over into the interpretation, and many faults that can be mapped by the MEQ methods turn out not to be related to anomalous thermal conditions. This had opened the question of whether there exists a "geothermal microearthquake" that can be distinguished from a normal tectonic 
earthquake. According to one hypothesis, through-going faults, those with a long epicenter distribution, are classified as of tectonic origin while swarm activity is diagnostic of geothermal activity. This hypothesis has not been supported by field evidence, showing swarm, or cluster, to be part and parcel of the seismic regime.

\section{Solution}

The question of the existence of geothermal earthquakes is one of unique source characteristics. Careful microearthquake studies should be made at several known geothermal areas. Comparisons should be made of the source details, using the most sophisticated spectral and time-domain inversion techniques in all areas, as well as for similar measurements outside the geothermal areas in geologically related settings with normal heat flow.

The method would be the same as that used for deep noise source (beam-forming) search, but with additional horizontal geophones. Data would be analyzed for systematic differences between thermal and normal areas in several source parameters:

1) High frequency spectral characteristics (stress drop, attenuation, and source dimensions);

2) Occurrence rates (strain energy release);

3) Mechanism, including moment tensor study (faulting, phase change components, etc.);

4) Cluster characteristics in space and time;

5) Moment-Magnitude characteristics. 


\section{References--Passive Seismic Methods}

Beyer, H. et al., 1976, Geological and geophysical studies in Grass Valley, Nevada: Lawrence Berkeley Laboratory Report, LBL-5262, 144 pp.

Douze, E. J. and Sorrells, G. G., 1972, Geothermal ground noise surveys: Geophysics, v. 37 , p. 813-824.

Eaton, G. P. et al., 1975, Magma beneath Yellowstone National Park: Science, v. 188, p. 787 .

Iyer, H. M. and Hitchcock, T., 1974, Seismic noise measurements in Yellowstone National Park: Geophysics, v. 39, p. 389-400.

Iyer, H. M. and Hitchcock, T., 1976, Seismic noise survey in Long Valley, California: J. Geophys. Res., v. 81, p. 821-840.

Knapp, R. B. and Knight, J. E., 1977, Differential thermal expansion of pore fluids: fracture propagation and microearthquake production: J. Geophys. Res., v. 82, p. 2515-2522.

Liaw, A. A. and McEvilly, T. V., 1977, Microseisms in geothermal exploration: studies in Grass Valley, Nevada: Lawrence Berkeley Laboratory Report, LBL-6813, in preparation.

Majer, E. and McEvilly, T. V., 1977, Seismological investigations at The Geysers, California: Interim Report, Lawrence Berkeley Laboratory Report, LBL-5939, 8 pp. plus tables and illustrations.

Palmason, G., 1975, Geophysical methods in geothermal exploration: Proceedings of the Second U.N. Symposium on the Development and Use of Geothermal Resources, San Francisco, v. 2, p. 1175-1184.

Smith, R. B. et al., 1974, Yellowstone hot spot: new magnetic and seismic evidence: Geology, v. 2, p. 451. 
Steeples, D. W. and Iyer, H. M., 1975, Teleseismic P-wave delays in geothermal exploration: Second U.N. Symposium on the Development and Use of Geothermal Resources, San Francisco, v. 2, p. 1199-1206. Whiteford, P. C., 1975, Studies of the propagation and source locations of geothermal seismic noise: Second U.N. Symposium on the Development and Use of Geothermal Resources, San Francisco, v. 2, p. 1263-1271. 


\section{ACTIVE SEISMIC METHODS}

In this section we deal with the seismic refraction and reflection methods. These methods are often treated in the literature as separate and distinct exploration techniques. However, in a theoretical sense the information provided by these methods is related, occupying only a different region in time-distance space (time being the arrival time of refracted or reflected wave and distance being the shot-detector separation). Furthermore, a seismic field crew is equally capable of running both types of measurements (with minor modifications in survey procedures) and is often called upon to do so in the same area. Both methods have been used in geothermal exploration; we discuss the reported applications and survey results here.

\section{Exploration Techniques}

\section{a. Refraction}

Refraction surveys are employed to determine the thickness and velocity of the major velocity units, usually to the depth of the high velocity basement rocks. This information may be acquired for a velocity model needed to calculate more accurate hypocenter locations of microearthquakes (see Passive Seismic Methods), or it may be used more directly in geothermal exploration. For example, lateral changes in seismic velocity within a unit may be related to changes in induration (silicification) or some other form of hydrothermal alteration; fracture porosity-permeability; and type, saturation and temperature of pore fluids. 
Refraction surveys have been conducted in several geothermal areas around the world, many of which are in volcanic terrains or in geologically complex areas where reflection techniques are more difficult to apply. Williams et al. (1975) reported that refraction surveys at Raft River, Idaho provided: structural information, hydrothermal induration of the sediments, and inference for a shallow zone of warm water. By means of refraction seismic results correlated with well logs and production data, it was determined that geothermal reservoirs in the Reykjanes field (Palmason, 1975) and the Kawerau field (Macdonald and Muffler, 1972) tended to occur in the deeper, higher velocity and lower porosity rocks. This finding was contrary to initial expectations, but demonstrated the direct applicability of seismic refraction to both exploration and reservoir assessment problems.

As discussed in more detail in the preliminary section to Passive Seismic Methods, there have been several attempts in recent years to study the refracted P-wave arrival times and amplitudes from distant explosions at geothermal fields. From this information, observed at numerous stations 2 to 4 kilometers apart, it is possible to calculate and contour P-wave delay and attenuation over the area of interest. Spatial variations in these wave characteristics may provide diagnostic information on the location of geologic features, such as faults, and may also outline the reservoir area.

Because velocity and density are related through the elastic properties of rocks, refraction surveys may be helpful for interpreting gravity surveys. However, the high cost of refraction surveys means 
it is seldom used for basement mapping where gravity and aeromagnetic surveys can be taken, unless a high degree of accuracy is needed (Duprat and Omnes, 1975) .

\section{b. Reflection}

Similar to the evolutionary process in petroleum-gas exploration, refraction surveys are giving way to reflection surveys in geothermal exploration. This is simply because reflection seismology provides a degree of geometrical resolution unmatched by any other surface technique. However, as published examples of reflection seismology applied to geothermal exploration are few, a situation that may belie the state-of-the-art, reflection seismology may be unused or underused by smaller exploration groups concerned about cost and not knowledgeable about the effectiveness or application of the techniques involved.

A major reason why seismic reflection is not a more widely used technique is that the physical environments of some major geothermal areas are not well suited to it (Palmason, 1975). Complicated velocity distribution, caused by thick volcanic sequences or energy absorbing clayey sediments at surface, along with extreme heterogeneity, make interpretation difficult (Duprat and Omnes, 1975). In geologic settings better suited to the technique, such as the Basin and Range geomorphic province, and parts of California, significant amounts of seismic reflection work are being done by geothermal departments of oil companies who do not normally disclose their activities. Consequently, the industryat-large has few examples of applications and results, though these exist. 
In applying reflection seismology, one would mainly seek to identify reflectors, which in geothermal areas could relate to

1) steam-filled or water-filled fracture zones,

2) silicified cap rock,

3) basement or other reflecting horizons which provide structural information,

4) fault zones.

To conduct these surveys geophysicists have tended to follow conventional petroleum exploration practices. Because the exploration depth is usually shallow (less than $6,000 \mathrm{ft}$ ), high resolution CDP profiling survey procedures are commonly followed with small geophone intervals, and dynamite or multiple mechanical vibrators serving as the energy source. There is less but growing interest in deep surveys, for structural information to depths of 5 to $10 \mathrm{~km}$. Such studies may provide important regional information on the lateral variation in the mid-to-deep crust where heat sources may lie.

In addition to compressional wave energy sources, there has been recent interest in utilizing shear-wave vibrators for SH energy. Continental Oil Company has developed several such vibrators and one has been tested in a geothermal environment (Goupillaud and Cherry, 1977). The advantage of combined $\mathrm{P}$ and $\mathrm{SH}$ reflection surveys is that, through the calculated $\mathrm{v}_{\mathrm{P}} / \mathrm{v}_{\mathrm{SH}}$ velocity ratio, useful information can be obtained on lithology, porosity, and the nature of fluids filling pores and fractures.

The recent literature contains several accounts of how reflection seismology has been used to obtain geologic information important in 
geothermal exploration. A few of these are discussed below to illustrate the use of the technique.

One of the earliest reported successful applications of reflection seismology was Hayakawa's (1970) discussion of survey results at the Matsukawa, Otake, and Onikobe geothermal fields. Although seismic reflection prospecting in Japan dates back twenty years, it was not until the availability of modern digital data processing that suppression of noise and multiple reflections made it possible to recognize the presence of fine structure from deeper reflectors. Hayakawa reported that work done at the Matsukawa field showed that fissure zones could be located by a rapid decrease of seismic wave energy in a narrow band and also by a change of wave phase. He also noted that low frequency but high amplitude wave patterns typified the hot water reservoir. For structural control, a vibroseis (registered trade name of Continental Oil Company) survey was conducted along two lines in Grass Valley, Nevada, one of which crossed Leach Hot Springs (Beyer et al., 1976). Data quality was generally good except in the immediate Hot Springs area where the fault-related silicified section is apparent in the lack of reflections. The Hot Springs fault is evident by reflection correlation and presence of diffractions. The relative amplitude sections showed strong reflections from below the Hot Springs area in the area of the silicified sections. A velocity analysis of the better data resulted in a lithologic model which was useful for evaluating the validity of other surface geophysical techniques, mainly dipoledipole resistivity and gravity. There was excellent agreement in the 
location and dip of the Hot Springs fault determined independently from reflection seismology and gravity.

A high resolution reflection survey, also with vibroseis, over the East Mesa (Imperial Valley, California) geothermal field showed an absence of reflectivity over part of the field. This effect, plus some diffraction draping at the ends of some reflecting events, indicates a major fracture/fault zone terminated by major fractures or faults (Goupillaud and Cherry, 1977). A velocity analysis shows the fracture zone to extend from 3,000 ft below surface, downward to below 5,000$6,000 \mathrm{ft}$, the depth of the reservoir determined from drill holes a mile and more away. There are, however, no drill holes into the shallow part of the interpreted fracture zone.

Another Vibroseis survey was conducted in the vicinity of the California Geysers-Castle Rock geothermal area, to assess the applicability of seismic reflection technique to detect the fractured zones from which steam is currently being produced (Denlinger and Kovach, 1977). Because of the complex geologic structure, this area is not normally considered to be one where useful seismic data can be obtained. However, enhanced reflections were reported that correlate well with fracture zones at the base of thrust plates in the Franciscan formation. These fracture zones, in many cases, also correspond to zones of major steam entries, suggesting that the main conduits of the system can be mapped. This finding is supported by theoretical and laboratory studies which show that a steam-filled fracture zone behaves like a thin reflector for seismic wavelengths less than 12 times the width of the fracture zone (Denlinger and Kovach, 1977). 


\section{Research Areas}

It is not clear whether active seismic methods present technological problems that industry cannot solve for itself. If there is one paramount problem, it may be that reflection seismology is only now being accepted as a valuable exploration tool for geothermal reservoir exploration and delineation and more thorough discussion and dissemination of survey results are needed to keep the industry current on recent advances and accomplishments. This might be best achieved by means of a oneor two-day symposium devoted strictly to the use of active seismic techniques for geothermal exploration. The success of such a meeting would depend greatly on the participation of geophysicists from oil companies with the resources of their own seismic crews, data processing centers, and research facilities.

Several research areas have been identified, and these are now briefly discussed in the following sections. (The research areas are also shown in research matrix form in Fig. 3).

- Seismic Refraction Studies

- Fault Mapping

- $\mathrm{v}_{\mathrm{P}} / \mathrm{v}_{\mathrm{S}}$ or Poisson's Ratio Sections

- Deep Crustal Studies

- Laboratory Studies 
RESEARCH AREAS

\begin{tabular}{|c|c|c|c|c|c|}
\hline Research Category & $\begin{array}{l}\text { Seismic Refraction } \\
\text { Studies }\end{array}$ & Fault Mapping & $V_{p} V_{S}$ Sections & $\begin{array}{l}\text { Deep Crustal } \\
\text { Studies }\end{array}$ & $\begin{array}{l}\text { Laboratory } \\
\text { Studies }\end{array}$ \\
\hline $\begin{array}{l}\text { 1. Fundamental Studies } \\
\text { 2. Instrument Development }\end{array}$ & & $\begin{array}{l}\text { Apily new } \\
\text { data processing } \\
\text { techniques } \\
\text { to existing } \\
\text { data }\end{array}$ & $\begin{array}{l}\text { Large source } \\
\text { shear wave or } \\
\text { combined S- and } \\
\text { P-wave genera- } \\
\text { tor }\end{array}$ & $\begin{array}{l}\text { Regional low } \\
\text { resolution } \\
\text { reflection } \\
\text { seismology }\end{array}$ & $\begin{array}{l}\text { Seismo-elastic } \\
\text { properties of } \\
\text { large core } \\
\text { samples of } \\
\text { rocks from geo- } \\
\text { thermal environ- } \\
\text { ments }\end{array}$ \\
\hline 3. Data Processing & & $\begin{array}{l}\text { 1. Enhance dif- } \\
\text { fractions for } \\
\text { fault mapping } \\
\text { 2- and 3-dimensional } \\
\text { wave migration for } \\
\text { fault mapping }\end{array}$ & $\begin{array}{l}\text { Combined } P \text { - and } \\
\text { S-wave process- } \\
\text { ing to yield } \\
\mathrm{V}_{\mathrm{P}} / \mathrm{V}_{\mathrm{S} \text { sections }}\end{array}$ & & \\
\hline 4. Data Interpretation & & & $\begin{array}{l}\text { From } \\
\text { Laboratory Studies }\end{array}$ & & $\begin{array}{l}\text { Theoretical } \\
\text { computer- } \\
\text { assisted } \\
\text { studies of } \\
\text { chemical } \\
\text { kinetics }\end{array}$ \\
\hline 5. Verification Studies & $\begin{array}{l}\text { P-wave delay } \\
\text { P-and S- wave } \\
\text { attenuation } \\
\text { field tests }\end{array}$ & $\begin{array}{l}\text { Use new data } \\
\text { processing } \\
\text { techniques to } \\
\text { help design } \\
\text { field test. } \\
\text { Conduct ad- } \\
\text { ditional demon- } \\
\text { stration and } \\
\text { verification } \\
\text { tests. }\end{array}$ & $\begin{array}{l}\text { Demonstration } \\
\text { field tests }\end{array}$ & & \\
\hline
\end{tabular}

Fig. 3. Research matrix for active seismic exploration. 


\section{a. Area I: Seismic Refraction Studies}

\section{Problem Statement}

Seismic refraction has been used mainly as a geophysical reconnaissance method and a more direct exploration application is largely overlooked; namely, the direct identification and delineation of geothermal areas by means of velocity anomalies in the refracted $P$ and $S$ phases and the amplitude attenuations of these phases.

\section{Background}

As briefly discussed in the introductory comments to both Active and Passive Seismic Methods, there is now evidence to show that several geothermal areas seem to have been identified and delineated by P-wave delays, and attenuation of $P$ and $S$ waves of refracted waves from distant man-made explosions. LBL's seismological work at The Geysers (Majer and McEvilly, 1977) and that of the University of Texas at Coso Hot Springs (Combs and Jarzabek, 1977) show anomalous velocities and amplitudes of refracted waves passing through the reservoir region, compared to results at nearby stations outside. Limited results at hand are not easy to explain and are contradictory. At The Geysers a distinct negative P-wave delay (i.e., advance) was found to coincide with the main part of the production zone, together with a greater attenuation of $\mathrm{P}$ phase and a nearly total loss of S-phase energy. On the other hand, a positive P-wave delay (reduced $V_{P}$ ) was noted for Coso compared to its surroundings.

It has been suggested (Biehler, 1977, personal communication) that a large $\mathbf{P}$ delay implies that a geothermal area is young and hot, and that a negative $\mathrm{P}$ delay (or $\mathrm{P}$ advance) implies that the system 
is old. The hypothesis is that P-wave velocity should be low in a reservoir because of higher porosity than the adjacent rocks, but $P$-wave velocity is higher in an old system because secondary minerals have precipitated, filling pore spaces as temperature declines. Observed increases of basement velocity beneath geothermal systems may be attributed to a combination of high temperature and low porosity, due to compaction caused by deep burial, and possibly to mineralization of pore space. The results at The Geysers, of course, are in direct contradiction with this hypothesis.

\section{Solution}

To verify the usefulness of P-wave delay and $P$ - and S-wave attenuation mapping for geothermal exploration, it is recommended that surveys, similar to the one performed at The Geysers, be conducted over several other geothermal systems, e.g., Long Valley, East Mesa, Roosevelt. Experiments of this nature are best conducted with a fairly large number of recording stations in a dense array to provide both a high resolution within the area of interest as well as sufficient reference points outside. In addition to the information provided by large distant sources, explosions should be detonated at increasing distances from the test area to provide progressively deeper propagating refracted waves, and thus obtain a degree of depth discrimination. Velocities and amplitudes will need to be suitably referenced to a base station, and $\mathrm{P}$ delays corrected on the basis of an average velocity between source and each receiver. It may also be useful to locate the shot points at different azimuths. 
Because both vertical and horizontal geophones would be needed at a large number of stations (perhaps 20 or more), both multichannel and telemetry features are needed. The U.S. Geological Survey's Centipede system has these instrumental capabilities.

\section{b. Area II: Fault Mapping}

Problem Statement

It may be possible to extract a great deal more information from high resolution seismic reflection surveys than is presently being done. Some of the information that is not being recovered or displayed as well as it should is the location and geometry (strike and dip) of faults.

\section{Solutions}

Three separate solutions have been suggested.

1. It is common practice in seismic reflection profile data processing to filter out diffractions, such as occur from the end of a reflecting horizon terminated abruptly at a fault. It has been suggested that data processing can be improved by finding a means for enhancing this information and producing directly a section showing fault location and apparent dip.

2. Reflection surveys are normally run as long, continuous profiles, and depending on geologic complexity, the profiles may be many kilometers apart. The result is an unfocused picture of the structural geometry which must be reconstituted to give a more accurate picture. To focus the data from complex areas two procedures may be followed: downward continuation of move-out corrected seismograms (Claerbout and Doherty, 
1972) or digital migration (Schneider, 1971). In the geologically complex settings of some geothermal areas these procedures may be inadequate to define the geometry properly. A solution is to conduct numerous parallel profiles over a target area to obtain dense coverage and process the seismograms using three-dimensional wave migration methods (French, 1974). The result would be an estimated threedimensional structure map, showing a clear picture of the reflectors and the faults.

3. Rather than obtaining dense coverage by running numerous parallel profiles, one could conduct a survey using a cross-spread consisting of a line of sources laid out perpendicular to a line of geophone stations (Walton, 1972) or one of the many popular twodimensional surface patterns of sources and receivers. The data would then have to be reassembled to simulate a central source in a square array of geophone stations. The approach described by Walton (1972) provides extremely dense coverage on each reflecting surface within a relatively small area $(4 \mathrm{~km} \times 4 \mathrm{~km})$, and therefore would have greatest application either as a late-stage exploration or a reservoir-assessment method. The method is reported to be particularly effective for recognizing faults and showing fault directions.

\section{c. Area III: $V_{P} / V_{S}$ or Poisson's Ratio Sections}

\section{Problem Statement}

The ability to determine $V_{\mathrm{P}} / \mathrm{V}_{\mathrm{S}}$ ratio, or Poisson's ratio $(\sigma)$, from continuous seismic reflection data has not yet been demonstrated. 


\section{Background}

Laboratory measurements and theoretical calculations of compressional and shear wave velocities in porous rocks under different saturation, pressure, and temperature conditions have shown that these velocities, hence reflection coefficients and Poisson's ratio, depend on type and amount of fluid saturation (Toksoz et al., 1976). Compressional velocities $\left(V_{P}\right)$ are highest for brine saturation and lowest for gas saturation, the difference decreasing with increasing pressure. The presence of a small amount of gas or steam in the brine reduces $v_{P}$ significantly, even below that of a fully gas-saturated rock at some pressures. On the other hand, the shear wave velocity $\left(\mathrm{V}_{\mathrm{S}}\right)$ tends to increase with gas saturation, although to a lesser degree. The combined behavior of $v_{P}$ and $v_{S}$ lead to a Poisson's ratio that is higher for brine-saturated porous rock $(\sigma>0.20)$ than for the gas-saturated rock $(\sigma<0.20)$. The difference is largest at low pressures, corresponding to depths less than $2 \mathrm{~km}$, but may persist to higher pressures. The difference is most likely related to rigidity, $\mu$; rigidity is higher in a dry reservoir causing $v_{S}$ to increase more than $v_{P}$, thus giving a low value of Poisson's ratio (McEvilly, 1977, personal communication) .

Because of these laboratory findings there has been considerable interest, directed mainly toward hydrocarbon search, in measuring $V_{S}$ as well as $V_{P}$ from a velocity analysis of seismic reflection data. For this purpose at least one company, Continental oil Company, has developed shear wave vibrators, and numerous papers have been written 
on laboratory tests, e.g., Tatham and Stoffa (1976), Domenico (1976), and Gregory (1976).

At this time there is conflicting field evidence for elastic wave behavior in steam-saturated reservoirs.

The works of Hayakawa (1970) at the Matsukawa field, and Denlinger and Kovach (1977) at The Geysers, show that steam-saturated zones do appear as enhanced P-wave reflections. It is presumed that this effect is due to a higher reflection coefficent caused by the decrease of $\mathrm{V}_{\mathrm{P}}$ in the steam-saturated rocks, and is predicted by laboratory and theoretical results. On the other hand, Majer and McEvilly (1977) found evidence for decreased $V_{S}$ and increased $V_{P}$ in The Geysers steam field, using $P$ and $S$ waves from local earthquakes.

Goupillaud and Cherry (1977), using both $P$ and SH vibrators at the East Mesa geothermal anomaly, were able to obtain a profile of $V_{P}(r m s) / V_{S H}(r m s)$ as a function of depth. Unfortunately, only limited data were obtained and the S-wave data was not of high quality. It was therefore difficult for the authors to draw any definite conclusions from the results, other than to suggest the possible presence of a fracture zone.

\section{Solution}

To evaluate the usefulness of $v_{\mathrm{P}} / \mathrm{V}_{\mathrm{S}}$ sections for geothermal exploration and reservoir delineation, additional studies of the type begun by Goupillaud and Cherry will have to be conducted over other geothermal systems and careful measurements of $v_{P} / v_{S}$ using local microearthquakes must also be made where possible. There will be a need 
for a larger SH energy source than used at East Mesa, such as the large state-of-the-art devices currently in use by Conoco ( $\mathrm{K}$. Waters, 1977 , personal communication). It also will be necessary to run long, continuous profiles over the region in order to obtain comparative results away from the known reservoir.

Within this research area we should also include research into the processing of the combined $\mathrm{P}$ and $\mathrm{SH}$ reflection data for the calculation and interpretation of $\mathrm{v}_{\mathrm{P}} / \mathrm{v}_{\mathrm{SH}}$ sections.

Another related topic of research, suggested by Goupillaud and Cherry (1977), is the development of an efficient, combined SH- and P-wave energy source.

\section{d. Area IV: Deep Crustal Studies}

Problem Statement

Deep crustal reflection soundings are not a standard exploration technique, and few such tests have been made. However, deep information on physical properties of the crust, if obtained by deep sounding, may be valuable in mapping the extent of the high temperature source regions for geothermal fields.

\section{Background}

Deep crustal soundings provide fundamental regional information which, when used with crustal-scale refraction, gravity and magnetotellurics, may prove useful for resolving geological questions concerning fine structures within the crust and M-discontinuity. A notable survey of this type was conducted in the Mojave Desert (Dix, 1965), at a site chosen because the thin alluvial cover over bedrock would minimize 
interference of multiple reflections from sedimentary layers. Geophones were grouped close to the shot-point where they would be as close as possible to the reflection maximum at normal incidence, but offset far enough to minimize "noise" from surface waves. Dix found the crust to be more complicated than generally believed. He also found a group of reflectors near the M-discontinuity, suggesting that there is more fine detail than previously determined from refraction surveys. More recently, Fowler and Waters (1975) and Mair and Lyons (1976) showed that deep crustal refractions and reflections could be obtained by means of a swept frequency vibrator. These authors concluded that continuous deep basement coverage with CDP stacking can be achieved with a large source effort--many vibrators operating simultaneously, and a multichannel recording system to handle nests of geophones. T. V. McEvilly (1977, personal communication) is attempting to monitor variations in crustal rock velocities along the San Andreas fault using a Vibroseis source. Travel times for deep crustal reflectors are being monitored. These studies and similar ones in other countries form much of the basis for the current COCORP (Consortium for Continental Reflection Profiling) Project being conducted under the auspices of the U.S. Program for the Geodynamics Project, reporting under the section "Fine Structure of the Crust and Upper Mantle." Continuous seismic profiling using vibratory sources and 12-fold and 24-fold CDP stacking was applied in Hardeman County, Texas (Oliver et al., 1976) and in the Rio Grande Rift north of Socorro, New Mexico (Oliver and Kaufman, 1976). The first experiment demonstrated the usefulness 
of conventional seismic reflection techniques in obtaining deep reflections to depths of about $50 \mathrm{~km}$. The second experimental site was chosen because of its geological nature: a rift-zone, dominated by normal faulting and a crustal magnetic body reported in a nearby area (Sanford et al., 1973). The COCORP line found evidence for a strong reflector, or "bright spot", at the end of one line which may be the magma body suggested by Sanford et al. (1973).

\section{Solution}

This research area constitutes a relatively untouched avenue of long-term research into the rocks and structure of the deep crust in geothermal areas. At present, the cost of conducting these surveys is extremely high, approximately $\$ 100,000$ to $\$ 150,000$ per month for 10 to 20 linear miles of coverage. The results of the COCORP project, particularly the work in the Rio Grande Rift, will be closely watched. If geothermal exploration application is demonstrated, more surveys of this type will hopefully be planned for other geothermal areas. The extremely high cost of the surveys and processing probably precludes the acceptance of the technique by industry at this time.

\section{e. Area V: Laboratory Studies}

Problem Statement

Seismic methods are used in geothermal prospecting because seismic waves are affected by transmission through, absorption in, and reflection from the rocks of geothermal environments. The resulting seismic information can often be interpreted in terms of geological models which help define the reservoir region. However, reservoirs are quite 
different from one another and are complex within themselves. The multitude of variables makes interpretation of seismic data difficult and uncertain. Laboratory studies of rocks under simulated geothermal reservoir conditions are helping us to understand more about elastic wave propagation in these environments, but the work done thus far is preliminary and little laboratory work has dealt with rocks from actual geothermal reservoirs.

\section{Background}

Amplitudes, velocities, and spectra of compressional, shear and surface waves can be altered by propagation through a geothermal environment. For example, seismic refraction measurements at the Coso Geothermal Area showed that compressional waves ( $P$ waves) were slowed and strongly attenuated during passage through the reservoir (Combs and Jarzabek, 1977). Conversely, measurements at The Geysers showed that $P$ waves were speeded up and very weakly attenuated relative to reference sites outside the field (Majer and McEvilly, 1977). $P$ waves from distant earthquakes, which approximate plane waves arriving at near-vertical angles from beneath the crust, outline low-velocity regions at known geothermal areas at Yellowstone, Wyoming; Long Valley Caldera, California; and The Geysers, California (Steeples and Iyer, 1976). P waves from an explosion at the Nevada Test Site were severely attenuated on paths which passed nearly horizontally beneath the Yellowstone Caldera at depths of 200 and 400 kilometers (Hadley et al., 1976). Shallow guided waves passing beneath the hot springs area of Long Valley Caldera had a spectrum that was deficient in the higher 
frequencies compared to similar waves which did not pass beneath the hot springs (Hill, 1976). Velocity and attenuation anomalies were also observed in the vicinity of an active volcano (Matsumoto, 1971). An understanding of these phenomena and how they relate to the geothermal exploration problem can be approached from laboratory studies. Although numerous studies have been done, mainly with petroleum in mind, some results carry over to the geothermal exploration problem, and recent studies show a growing concern for geothermal conditions. Biot (1956) wrote on the theory of wave propagation in a fluid-saturated porous solid. Knapp and Knight (1977) made a theoretical study of fracture propagation and microearthquake production due to thermal expansion of pore fluids--a process which may contribute to the geothermal noise which is sought in ground noise surveys. Recent experimental works, on wave propagation in two- and three-phase systems composed of liquid-gas mixtures alone or in porous rocks, include that of: Kieffer (1977) on sound speeds in water-air and water-steam mixtures; Spencer and Nur (1976) on velocities in granite as functions of pressure, temperature, and pore water; O'Connell and Budiansky (1974) on the velocity effect of saturation in low porosity rocks; and Nur (1969) on the effects of stress and fluid inclusions. Other recent studies include the following: Toksoz et al. (1976) studied the velocities of seismic waves in porous rock; Gregory (1976) measured the dynamic elastic properties of sedimentary rocks as a function of fluid saturation; Tatham and Stoffa (1976) investigated the use of $\mathrm{v}_{\mathrm{P}} / \mathrm{v}_{\mathrm{S}}$ to detect zones of gas saturation--for the geothermal case the gas could be steam; and Domenico (1976) studied the effect of 
brine-gas mixture in a sand reservoir. Petroleum reservoir engineers have considered the effects of temperature on reservoir rocks (Sanyal et al., 1974; and Somerton et al., 1974).

\section{Solution}

The solution is to incorporate the results of previous work, relate them to the geothermal exploration problem, and use them to design and carry out additional laboratory experiments needed to understand wave propagation characteristics in geothermal reservoirs. For example, Kieffer's (1977) observation that a small admixture of steam into water reduces sound velocity by more than 908 relates directly to the P-delay exploration technique. The conclusion by Toksoz et al. (1976) that Poisson's ratio (an elastic constant indicated by $v_{\mathrm{P}} / \mathrm{v}_{\mathrm{S}}$ ) could be an important parameter for identifying gas-saturated formations in petroleum exploration applies also to steam-saturated formations in geothermal exploration. Indeed, Combs and Rotstein (1976) observed unusually low values of Poisson's ratio at the coso geothermal system and concluded that it was likely that the cracks were filled with steam.

Seismic measurements in the field sample the gross average properties of the three-dimensional half-space of the earth within their range, while well logs sample one-dimensional subsets of that space and the cores examined in laboratories are discrete (point) samples of it. It is necessary to improve our understanding of the relations between the results of the different sampling methods so that laboratory results can be applied to seismic measurements made 
in the field. Examination of very large cores would give results more like those of well logs and surface methods, which by their nature average out the effects of large grains and pores and cracks, but the cost probably outweighs the advantage. Laboratories must study the effects of joints and dikes, in addition to other rock properties, from samples brought from the field. Much care has to be taken with samples of all kinds to insure against irreversible changes being made during handling such as drying out, chemical reactions and effects of the release of overburden pressure. The ultrasound (megahertz) frequency measurements made in laboratories often correlate well with the seismic (hertz) frequency measurements, but they are more sensitive to small inhomogeneities. Static elastic moduli are usually smaller than the dynamic moduli, an important difference to seismic work caused by imperfections in the sample and lack of perfect elasticity under a sustained load.

Effort needs to be spent on the combined interpretation of laboratory measurements, well logs, and seismic measurements from an extensive data base gathered from geothermal reservoirs. Additional experiments should include careful study of acoustic and shear wave propagation effects in representative rock types, as functions of porosity, crack density, fluid saturation, and admixture of gas, and at the ranges of pressure and temperature of geothermal reservoirs. An important concern is nonstatic porosity (Nur, 1977, personal communication), a term used to describe modifications to a rock's bulk porosity when it is subjected to the high temperature and fluid convection conditions of a geothermal environment. Chemical reactions 
between circulating thermal water and the rock or temperature-related solubility changes cause the formation of secondary minerals that may seal pores and fractures and modify the seismo-elastic properties of the rock. These changes occur too slowly in nature to serve as an exploration guide, but the spatial variations are important to the interpretation of both passive and active seismic data and can be estimated by means of careful laboratory experiments and theoretical computer-assisted studies involving chemical kinetics.

The emphasis for exploration needs to be on large-bulk properties in order to explain and predict what happens to seismic waves in their passage through the heterogeneous mass of a geothermal reservoir and to determine what are the diagnostic properties best sought for in exploration. 


\section{References--Active Seismic Methods}

Beyer, H. et al., 1976, Geological and geophysical studies in Grass

Valley, Nevada: Lawrence Berkeley Laboratory Report, LBL-5262, p. 144.

Biehler, S., 1977, personal communication.

Biot, M. A., 1956, Theory of propagation of elastic waves in a fluidsaturated porous solid: I. low frequency range; and II. higher frequency range: J. Acoust. Soc. Am., v. 28, pp. 168-191.

Claerbout, J. F. and Doherty, S. M., 1972, Downward continuation of moveout corrected seismogram: Geophysics, v. 37, pp. 741-768. Combs, J., and Jarzabek, D., 1977, Seismic evidence for a deep heat source associated with the Coso Geothermal Area, California: Transactions, Geothermal Resources Council, v. 1, pp. 41-43. Combs, J., and Rotstein, Y., 1976, Microearthquake studies at the Coso Geothermal Area, China Lake, California: Proceedings of the Second United Nations Symposium on the Development and Use of Geothermal Resources, v. 2, p. 909-916.

Denlinger, R. P. and Kovach, R. L., 1977, Seismic reflection investigations in a geothermal area (Abstract): Trans. Geothermal Res. Council, v. 1, p. $77-78$.

Dix, C. H., 1965, Reflection seismic crustal studies: Geophysics, v. 30 , no. 6 , p. $1068-1084$.

Domenico, S. N., 1976, Effect of brine-gas mixture on velocity in an unconsolidated sand reservoir: Geophysics, v. 41, no. 5, p. $882-894$. 
Duprat, A. and Omnes, G., 1975, The cost of geophysical programs in geothermal exploration: Proceedings of the Second U.N. Symposium on the Development and Use of Geothermal Resources, San Francisco, v. 2, p. $963-970$.

Fowler, J. C. and Waters, K. H., 1975, Deep crustal reflection recordings using "Vibroseis" methods--a feasibility study: Geophysics, v. 40, p. $399-410$.

French, W. S., 1974, Two-dimensional and three-dimensional migration of model experiment reflection profiles: Geophysics, v. 39, p. 265-277.

Gregory, A. R., 1976, Fluid saturation effects on dynamic elastic properties of sedimentary rocks: Geophysics, v. 41, p. 895-921. Goupillaud, P. L. and Cherry, J. T., 1977, Utilization of seismic exploration technology for high resolution mapping of a geothermal reservoir, Final report: System, Science and Software, Report SSS-R-77-3176, p. 55 .

Hadley, D. M., Steward, G. S., and Ebel, J. E., 1976, Yellowstone: seismic evidence for a chemical mantle plume: Science, v. 193, p. 1237-1239.

Hayakawa, M., 1970, The study of underground structure and geophysical state in geothermal areas by seismic exploration: Geothermics, Special Issue 2, v. 2, pt. 1, p. 347-357.

Hill, D. P., 1976, Structure of Long Valley Caldera, California, from a seismic refraction experiment: J. Geophys. Res., v. 81, no. 5, p. 745-753. 
Kieffer, S. W., 1977, Sound speed in liquid-gas mixtures: water-air and water-stream: J. Geophys. Res., v. 82, no. 20, p. 2895-2904.

Knapp, R. B. and Knight, J. E., 1977, Differential thermal expansion of pore fluids: fracture propagation and microearthquake production in hot pluton environments: J. Geophys. Res., v. 82, no. 17, p. 2515-2522.

Macdonald, W. J. P., and Muffer, L. J. P., 1972, Recent geophysical exploration of the Kawerau geothermal field, North Island, New Zealand: New Zealand J. Geol. and Geophys., v. 15, n. 3, p. 303. Mair, J. A., and Lyons, J. A., 1976, Seismic reflection techniques for crustal structure studies: Geophysics, v. 41, p. 1272-1290. Majer, E. and McEvilly, T. V., 1977, The Geysers geothermal reservoir properties from seismological data: Transactions, Geothermal Resources Council, v. 1, p. 199.

McEvilly, T. V., 1977, personal communication. Matsumoto, T., 1971, Seismic body waves observed in the vicinity of Mount Katmai, Alaska, and evidence for the existence of molten chambers: Geol. Soc. Amer. Bull., v. 82, pp. 2905-2920.

Nur, A. M., 1977, personal communication.

Nur, A. M., 1969, Effects of stress and fluid inclusions on wave propagation in rocks: Ph. D. Thesis, M. I. T. O'Connell, R. J. and Budiansky, B., 1974, Seismic velocities in dry and saturated cracked solids, J. Geophys. Res., v. 79, pp. 5412-5426. 
Oliver, J., Dobrin, M., Kaufman, S., Meyer, R., and Phinney, R., 1976, Continuous seismic profiling of the deep basement, Hardeman County, Texas: Bull. Geol. Soc. Am., v. 87, p. 1537.

Oliver, J., and Kaufman, S., 1976, Profiling the Rio Grande Rift: Geotimes, v. 21, n. 7, p. 20.

Palmason, G., 1975, Geophysical methods in geothermal exploration: Proceedings of the Second U. N. Symposium on the Development and Use of Geothermal Resources, San Francisco, v. 2, pp. 1175-1184.

Sanford, A. R. et al., 1973, Use of reflection phases on microearthquake seismograms to map an unusual discontinuity beneath the Rio Grande Rift: Bull. Seis. Soc. Am., v. 63, p. 2021.

Sanyal, S. K., Marsden, S. S., Jr., and Ramey, H. J., Jr., 1974, Effect of temperature on petrophysical properties of reservoir rocks: Forty-ninth Ann. Fall Mtg., Soc. Petrol. Eng., Houston, SPE-4898, pp. 19.

Schneider, W. A., 1971, Developments in seismic data processing and analysis (1968-1970): Geophysics, v. 36, pp. 1043-1073.

Somerton, W. H., El-Shaarani, A. H., and Mobarak, S. M., 1974, High temperature behavior of rocks associated with geothermal type reservoirs: Forty-fourth Ann. Reg. Mtg., Soc. Petrol. Eng., San Francisco, SPE-4897, pp. 16.

Spencer, J. W., Jr., and Nur, A. M., 1976, The effects of pressure, temperature, and pore water on velocities in Westerly granite: J. Geophys. Res., no. 5, pp. 899-904. 
Steeples, D. W. and Iyer, H. M., 1976, Teleseismic P-wave delays in geothermal exploration: Proceedings of the Second United Nations Symposium on the Development and Use of Geothermal Resources: v. 2, pp. 1199-1206.

Tatham, R. H. and Stoffa, P. L., 1976, $\mathrm{V}_{\mathrm{P}} / \mathrm{V}_{\mathrm{S}^{--A}}$ potential hydrocarbon indicator: Geophysics, v. 41, pp. 873-849.

Toksoz, M. N., Cheng, C. H., and Timur, A., 1976, Velocities of seismic waves in porous rocks: Geophysics, v. 4l, no. 4, p. 621-645. Walton, G. G., 1972, Three-dimensional seismic method: Geophysics, v. 37 , pp. $417-430$.

Waters, K., 1977, personal communication.

Williams, P. L., et al., 1975, Geology and geophysics of the southern Raft River Valley geothermal area, Idaho, U.S.A.: Proceedings of the Second U. N. Symposium on the Development and Use of Geothermal Resources, San Francisco, CA, v. 2, pp. 1273-1282. 


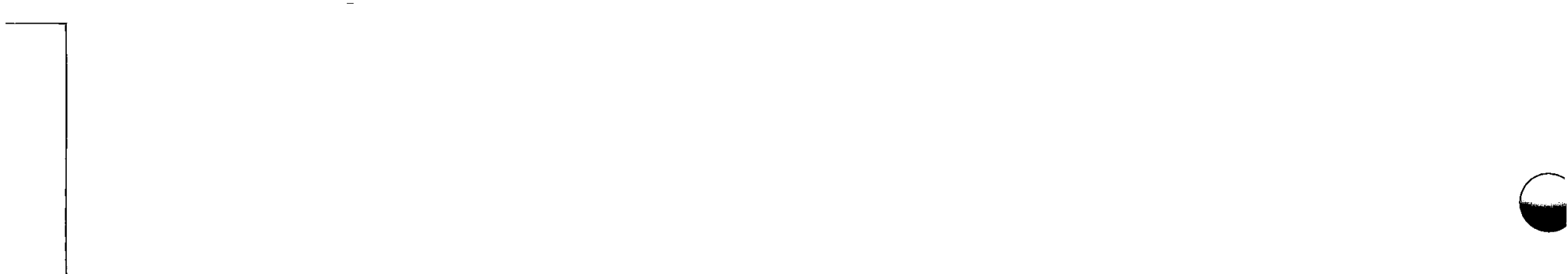

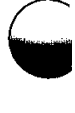

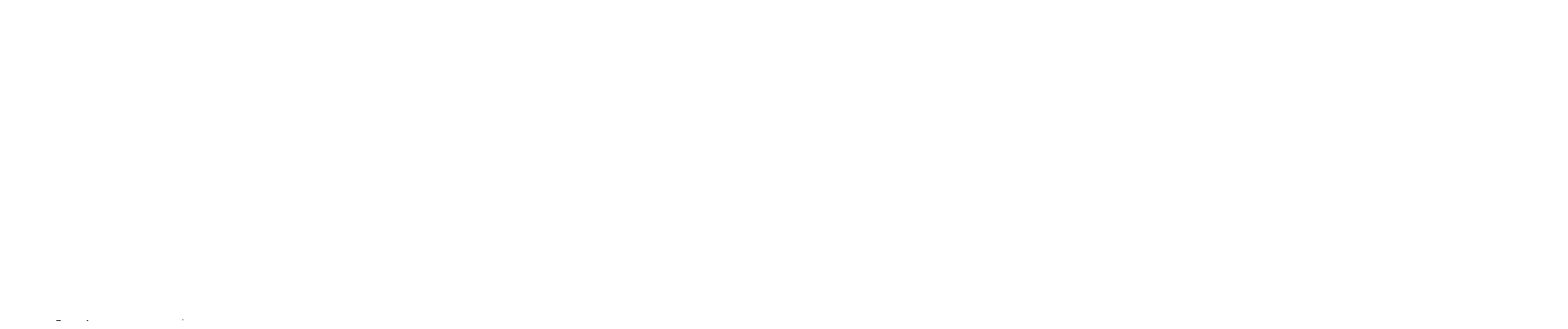

$C$ 


\section{NATURAL FIELD ELECTRICAL AND ELECTROMAGNETIC METHODS}

Subsurface electrical resistivity may be measured by means of surface observations of naturally occurring electrical and magnetic fields. The main advantage of natural field techniques is that no other electrical or electromagnetic field has to be generated, thus often leading to simpler field hardware than needed in controlledsource methods. The main disadvantage of the natural field techniques is the dependency on natural field activity, which may of ten be low and obscured by various noise sources over part of the spectrum of interest.

In this section we discuss natural field methods that have been used in geothermal exploration: a) self potential, b) tellurics, c) magnetotellurics/audio-frequency magnetotellurics. In addition, we shall also discuss briefly one method thus far not considered, AFMAG.

SELF-POTENTIAL

\section{Background}

The self-potential (SP) method has found application in geothermal exploration because anomalous self-potential readings--natural dc voltage variations of widely varying amplitude, polarity and spatial extent--have been reported from several geothermal areas. Examples of SP anomalies include the following:

1. A positive $1600 \mathrm{mV}$ anomaly, about $1 \mathrm{~km}$ in width, was measured on Kilauea volcano (Zablocki, 1976). 
2. A negative $200 \mathrm{mV}$ anomaly, about $1 \mathrm{~km}$ in width, was measured northwest of the Dunes geothermal area, California (Combs and Wilt, 1976).

3. A broad but steep-sided positive $30 \mathrm{mV}$ anomaly, $2 \mathrm{~km}$ in width, was measured over the Mud Volcano area of Yellowstone National Park, Wyoming (Zohdy et al., 1973).

Other SP anomalies described in the literature were found at Long Valley, California (Anderson and Johnson, 1976) and Raft River, Idaho (Williams et al., 1976), among other places. In one case, an SP anomaly led directly to a significant discovery at the Otake geothermal field, Japan (Onodera, 1974). Results of recent SP surveys in Nevada, Utah, and California will be discussed in a forthcoming paper by Corwin and Hoover (1977).

The causes of SP anomalies generated in geothermal areas are principally explained by (a) high temperature gradients (thermoelectric effect) which could produce source potentials of up to the range 200$300 \mathrm{mV}$ for a temperature difference of $100^{\circ}$ to $200^{\circ} \mathrm{C}$ in the earth, and (b) the flow of fluid (streaming potential) which produces an electric potential gradient from the interaction between the moving fluid and the Helmholtz double layer at the rock matrix-fluid interface (Corwin and Hoover, 1977). This mechanism can be explained theoretically by electrokinetic coupling. Both of the principal SP source mechanisms have been verified in laboratory measurements on various rocks or minerals in the field under semi-controlled situations, such as above a fire in a coal mine, around a flowing well, or in natural water seeps. 
Despite the apparent success of the SP method in certain geothermal areas and our general understanding of the two principal source mechanisms, the method does not always produce results that can be clearly interpreted. For reasons itemized below, the SP measurements may be plagued by high noise levels and poor reproducibility, problems that have cast doubt on the usefulness of the method. The geothermal SP anomaly often has a low amplitude and fairly broad wavelength, characteristics which are relatively easy to obscure by noise voltages from

(a) telluric current variations;

(b) electrode drift;

(c) geologic effects, such as lithologic changes, streaming of non-thermal subsurface water, and conductive minerals such as sulfides and graphite;

(d) stray currents from cultural activity; and

(e) various electrochemical phenomena related to variations in soil chemistry, temperature or moisture content.

Several of these noise effects can be minimized by means of careful field procedures. Telluric currents can be monitored and corrections applied to the SP data. Checks of electrode polarization and drift can be made and surveys should be run in closed loops to help eliminate the small errors which accumulate into large values in the course of a survey.

Procedural care improves the chance of obtaining reproducible data, but a reproducible anomaly is not necessarily indicative of geothermal activity. Other sources may have caused the SP anomaly, 
and therefore SP data must be interpreted in conjunction with other observations.

Of the more commonly used geophysical methods, SP requires relatively simple and inexpensive instrumentation, an accurate highimpedance portable voltmeter, wire, and electrodes, usually of the nonpolarizable porous pot variety. A survey can be carried out by one or two men, and therefore the method can be extremely cost-effective when applied by an experienced geophysicist.

In the following section we describe three research areas which cover specific topics dealing with the SP effect, its origin, relationship to geothermal systems, and the interpretation of field data. These research areas are listed below and shown graphically in the Research Matrix of Fig. 4:

- Self-Potential Data Base

- Origin of Self-Potential Anomalies

- Electrode Studies

\section{Research Areas}

\section{a. Area I: Self-Potential Data Base}

Problem Statement

Despite the low cost, simplicity, and many documented successes of the method, industry has been slow to accept SP for geothermal exploration. This, we feel, is due to a combination of many problems that have continued to plague the method since it was first applied, nearly 150 years ago, to mineral exploration. These problems are mainly related to the lack of a field and laboratory data base which 
RESEARCH AREAS

Research Category

2. Instrument Development

3. Data Processing

4. Data Interpretation

5. Field Tests
Laboratory studies of

electrokinetic and

thermoelectric

effects

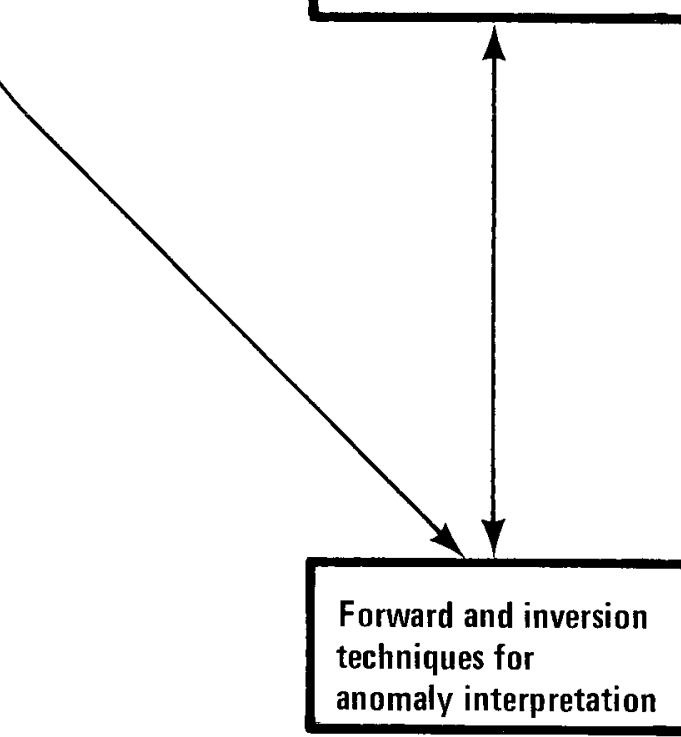

Supportive field

surveys
Electrode Studies

Laboratory and field

tests of electro-

chemical

"noise"

\section{$f$}

Design of a

stable electrode

Fig. 4. Research matrix for self-potential exploration. 
is needed to explain the origins of SP anomalies and to assist in the interpretation of field results.

\section{Solution}

A documented catalogue of SP anomalies, both geothermal and nongeothermal in origin, should be compiled from published and unpublished reports. This catalogue of field survey results should be supported with complementary geological and geophysical maps, sections, and profiles so that an understanding of characteristics of geothermal-related anomalies in their geological context can be developed. Data acquisition should also be supported by drilling and logging where these activities are needed to explain the cause of anomalies. In addition, the catalogue should be supported by new SP field surveys in selected areas where data may be missing, incomplete or of poor quality. These areas should not be restricted to known geothermal areas but should include sites where underground man-made thermal and streaming effects are present such as (a) coal mines fires, (b) steam or fire flooding of oil fields, and (c) underground coal gasification tests, and (d) controlled pumping or flow test of water or geothermal wells. SP surveys at coal gasification test sites (e.g., Hanna, Wyoming) are particularly well-suited to this study because the thermally affected region is monitored by means of temperature readings in drill holes.

\section{b. Area II: Origin Of Self-Potential Anomalies}

\section{Problem Statement}

There are many natural causes of self-potential anomalies. Of these, the movement of fluids through fractures and pores (electrokinetic 
effect) and large temperature gradients (thermoelectric effect) are considered to be the major causes of SP anomalies over geothermal areas. Presently, not enough is known about either phenomena in the natural state, and consequently there is not sufficient information on the characteristics of resulting anomalies to distinguish them from those due to nongeothermal sources.

\section{Solution}

Laboratory studies on rocks and cores from geothermal environments should be made to obtain quantitative information on the magnitudes of streaming and thermoelectric potentials. Measurements are needed over a range of confining pressures, temperatures and temperature gradients, fluid compositions, and fluid velocities.

Theoretical surface SP anomalies should be calculated from source magnitudes derived in laboratory tests and source dimensions derived from geological information, and compared to observed data. Also, observed SP anomalies should be treated by means of inversion techniques to obtain estimates of source magnitude and location. These estimates would then be compared to sets of forward calculated curves for different source geometries and to actual geologic information in order to determine whether inversion techniques can be applied to SP anomaly interpretation.

\section{c. Area III: Electrode Studies}

\section{Problem Statement}

The major instrumental weakness in the acquisition of SP data is that the voltage observations may not be reproducible when the identical stations are reoccupied at different times, whether hours, 
days or weeks apart. Part of this problem can be eliminated by means of telluric field corrections and various other survey precautions. However, these precautions cannot eliminate that part of the background noise that arises from electrochemical effects taking place between ground and electrode. Electrochemical effects may be due to change in soil chemistry, temperature, and moisture content as a function of time or station location. Effects may manifest themselves by electrode polarization in either a sudden jump in voltage, or a slow drift.

\section{Solution}

Careful laboratory and field tests must be conducted to quantify electrode effects as a function of soil type (chemistry), temperature changes at one or both electrodes, and soil moisture changes at one or both electrodes. These tests should be conducted with various types of electrodes so that comparisons can be made. From this we would hope to find which type of electrodes can be expected to be more stable under soil or climatic conditions. 


\section{References--Self-Potential}

Anderson, C. W., and Johnson, G. R., 1976, Application of the selfpotential method to geothermal exploration in Long Valley, California: J. Geophys. Res., v. 81, n. 8, 1527.

Combs, J., and Wilt, M., 1976, Telluric mapping, telluric profiling, and self-potential surveys of the Dunes geothermal anomaly, Imperial Valley, California: Proceedings, Second U.N. Symposium on the Development and Use of Geothermal Resources, San Francisco, Calif., v. 2, pp. 917-928.

Corwin, R. F. and Hoover, D. B., 1977, The self-potential method in geothermal exploration: Lawrence Berkeley Laboratory report, in preparation, $34 \mathrm{pp}$.

Onodera, S., 1974, Geoelectric indications at the Otake geothermal field in the western part of the Kyushu volcano group, Kyushu, Japan: Proceedings of a U.S.--Japan Cooperative Science Seminar, The Utilization of Volcano Energy, co-sponsored by the U.S. NSF, publ. by Sandia Laboratories, Albuquerque, N. M., pp. 50-106. Williams, P.L., et al., 1976, Geology and geophysics of the southern Raft River Valley geothermal area, Idaho, USA: Proceedings, Second U.N. Symposium on the Development and Use of Geothermal Resources, San Francisco, Calif., v. 2, pp. 1273-1282.

Zablocki, C.J., 1976, Mapping thermal anomalies on an active volcano by the self-potential method, Kilauea, Hawaii: Proceedings, Second U.N. Symposium on the Development and Use of Geothermal Resources, San Francisco, Calif., v. 2, pp. 1299-1309. 
Zohdy, A. A. R., Anderson, L. A., and Muffer, L. J. P., 1973, Resistivity, self-potential and induced polarization surveys of a vapor-dominated geothermal system: Geophysics, v. 38, No. 6, pp. 1130-1144. 
TELLURICS

\section{Exploration Techniques}

The measurement and analysis of natural electrical fields at frequencies below the range $10-20 \mathrm{~Hz}$ has been used as a reconnaissance tool in geophysical exploration for over 30 years (Yungul, 1977). The French and Russians who developed most of the fundamental theory have used the telluric (earth current) method for basin evaluation and petroleum exploration (Schlumberger, 1939; Berdichevskii, 1960). In the

U.S. the telluric method has historically been used to a lesser extent, but recent application to geothermal exploration has caused a renewed interest in it.

There are basically two techniques used in the telluric method; vector tellurics and profile tellurics. In each it is assumed that the incident natural electromagnetic field (source field) is spatially constant over the area of interest. In reality, the area of uniform field may only have a radius of up to $30 \mathrm{~km}$ (Berdichevskii, 1960). On the assumption of a spatially uniform source field, spatial variations in time-synchronous field recordings at measurement points are ascribed solely to the differences in geology between those points.

\section{a. Vector Tellurics}

In vector tellurics, signals are measured synchronously by means of orthogonal electrode arrays at a base station and at one or more remote stations. The data are then analyzed in terms of a two-bytwo tensor transfer function that relates the remote and base station time series to the electrical properties of the subsurface geology 
(Berdichevskii, 1960; Yungul, 1977). These transfer functions may be obtained from calculated tensor relationships (Thayer, 1975) or directly from field recordings (Yungul, 1968; Li, 1963; Berdichevskii, 1960) .

Instrumentation for vector tellurics has traditionally been very simple. A typical recording unit might consist of a two-channel system containing amplifiers, tunable band-pass filters, a dc buckout to suppress self-potential voltages, and a two-channel strip-chart or $x-y$ recorder. Telluric voltages are usually measured over orthogonal arrays $0.1-1.0 \mathrm{~km}$ on a side using nonpolarizing electrodes. For most reconnaissance surveys signals are recorded in the band 0.1-0.01 $\mathrm{Hz}$. Records are normally taken separately at base and remote sites although it is possible to use telemetry links so that all signals are registered at a common time base on a single tape recorder.

As a reconnaissance tool, the vector-telluric technique offers several advantages over controlled-source resistivity methods. In addition to simple instrumentation, tellurics provides deep penetration without the need for long, cumbersome wires and a two-man field crew is often sufficient.

Despite these advantages, vector tellurics has not been widely used for geothermal exploration. There is virtually no work of this type being done by commercial contractors at present. The lack of industry interest may be a combination of several factors: (a) the technique does not provide true or apparent resistivity, nor can it often provide detailed structural information (Combs and Wilt, 1975); (b) the cost-effectiveness is low because present systems require 
considerable amounts of manual data processing which can be expensive and inefficient; (c) it may also require long station recording times when field strengths are low and/or the survey is made in a conductive environment. For example, Combs and wilt (1975) reported that in the deep, conductive Imperial Valley, it was necessary to measure longperiod telluric signals to achieve the desired basement penetration. They could therefore manage approximately two remote station set-ups per day. The productivity could be doubled in a less conductive environment, or where the depth to resistive basement is shallow.

\section{b. Profile Tellurics}

Profile tellurics, first described by Neuenschwander and Metcalf (1942) and later by Yungul (1965) and also known as E-field ratio tellurics, utilizes an in-line array of adjacent dipoles to give a continuous one-dimensional view of resistivity variations along a survey line. Time synchronous telluric signals are measured at one or more selected frequencies between $10-0.01 \mathrm{~Hz}$ on adjacent dipoles to obtain the amplitude ratio which is related to the apparent resistivity ratio. Once the amplitude ratio is adequately determined the array is shifted one dipole length ahead to determine a second ratio, which may then be normalized to the first by multiplication. Further ratios are measured and normalized in the same manner until the profile is complete. The method is very sensitive to abrupt lateral variations in resistivity, such as at contacts or faults, and hence is a good tool for locating buried concealed geologic boundaries. 
Instrumentation used in telluric profiling differs from that used in vector tellurics in that narrow-band filters and an $x-y$ recorder are used. Instrumental complexity increases when, for the sake of speed, numerous dipole pairs are recorded simultaneously. In this case signals are telemetered to a multi-channel recording system at a central location (J. Pritchard, 1977, personal communication). Telluric profiles do not give apparent resistivity information but only the variation of this quantity. Depth discrimination is achieved through the use of several frequencies and the profiles are sometimes related to apparent resistivities by means of magnetotelluric calibration stations (A. Mazella, 1977, personal communication).

The method is most quantitatively useful when the profile is measured perpendicular to geologic strike or in the transverse magnetic (TM) mode (Beyer, 1977). In this mode results from profiles are repeatable and computer modeling can often be rewarding (Beyer, 1977). When geologic strike is unknown or the profile is measured oblique to strike, a TM type of profile may be obtained by selecting those amplitude ratios that lie at maximum deviation from unity (Yungul, 1977). This represents the greatest resistivity contrast or $\mathrm{TM}$ mode, but the requirement of manual selection eliminates use of signal averaging techniques (Beyer, 1977).

Telluric profiling has been used to help select areas for detailed electrical surveys, but there is little interest in the method currently. 


\section{Research Areas}

The future role of tellurics in geothermal exploration is very uncertain. If it is to continue as a qualitative or semi-quantitative tool for reconnaissance, the present technology is adequate. Tellurics will provide information which helps to identify conductivity anomalies due to thermal effects, as well as lithologic and structural changes. However, if the telluric method is to be improved, research is needed to understand the effects of regional geology on the fields, to develop better field instrumentation for data acquisition and to develop better methods for data interpretation. In this section we discuss the three research areas listed below and shown in the Research Matrix of Fig. 5 .

- The Separation of Local from Regional Effects

- Updating Vector Telluric Recording Systems

- Data Interpretation

\section{a. Area I: The Separation of Local from Regional Effects}

\section{Problem Statement}

Regional structure may induce undesirable nonuniformity to the telluric field and oftentimes obscure the effects of local geology, and hence the targets sought.

Background

Regional and sometimes distant structures may induce an undesirable nonuniformity to the measured field and obscure the local geological effects sought. These regional effects may also vary with time as the direction of the source field changes, and therefore cause scatter and error in the calculation of telluric field parameters. For example, 


\section{RESEARCH AREAS}

Local and Regional

Effects
Data Acquisition

and In-Field Processing
Data

Interpretation

1. Fundamental Studies

2. Instrument Development

Design and build

microprocessor-

controlled acquisition

and processing system

3. Data Processing

4. Data Interpretation

5. Verification Studies

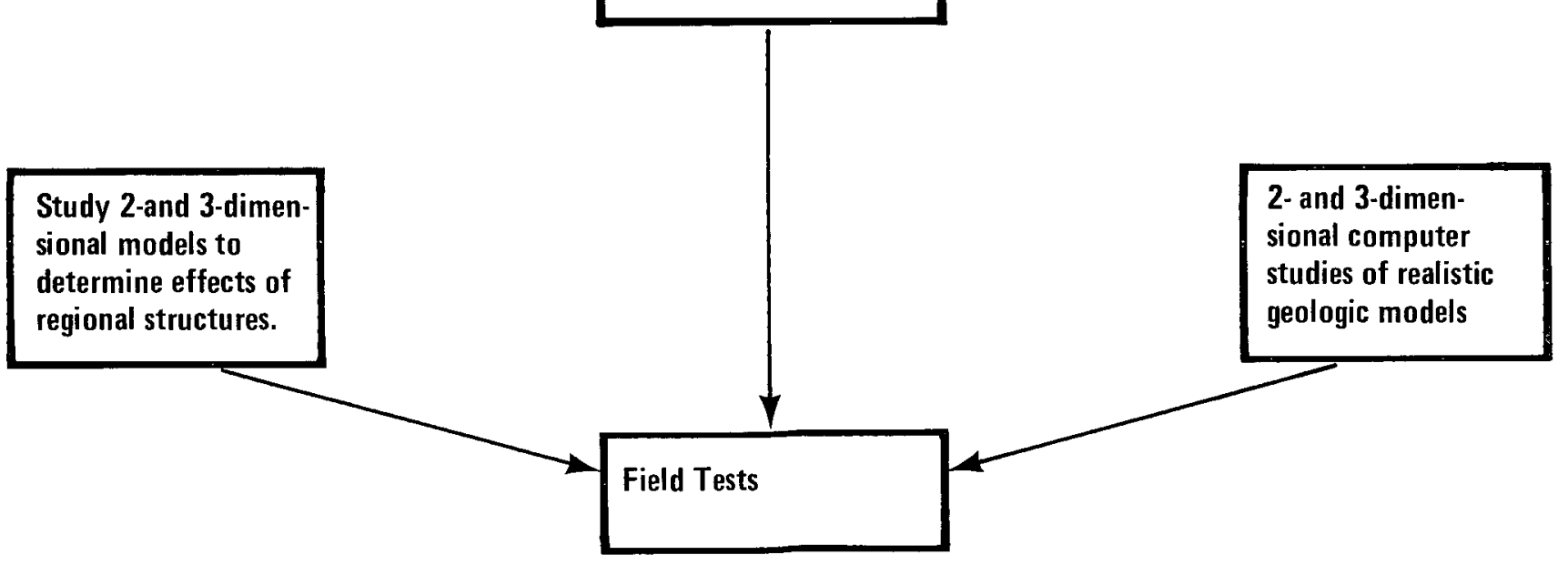

Fig. 5. Research matrix for telluric exploration. 
a common regional disturbance is that associated with the margin of a sedimentary basin. This boundary causes the observed field to be strongly and linearly polarized in the direction of basin alignment, resulting in such strong field distortion that it is often not possible to the calculate telluric parameters in the vicinity of basin margins (Yungul, 1968; Wilt, 1975).

\section{Solution}

The problem has been recognized and studied to some extent by French and Russian scientists (S. Yungul, 1977, personal communication), but there is no easy way out of this difficulty other than to study the problems by means of forward model calculations for two- and threedimensional structures (see Area III: Data Interpretation).

\section{b. Area II: Updating Vector Telluric Recording Systems}

\section{Problem Statement}

Vector tellurics, widely used in Europe and Russia with good results, has been used to a much lesser extent in the U.S. As usually applied in America, it tends to be slow and cumbersome due to the reliance on primitive equipment and the need for a great deal of post-field processing. As a result the cost of surveys is high and the use of vector tellurics is largely restricted to universities and research laboratories. 


\section{Solution}

Recent advances in technology make it possible to design and build field instrumentation with automatic data reduction capabilities. The system might also provide more efficient extraction of data from records, more reliable estimates of parameters and errors, and calculation of more quantitatively useful parameters. For example, if a telluric transfer tensor is first calculated from recorded time series, rather than the more common "relative ellipse area" parameter, then at any time in the future an appropriately placed magnetotelluric station could convert telluric data to apparent resistivity data (Thayer, 1975). Several approaches are possible in updating the vector telluric method, and some of these are summarized below.

\section{i. In-Field Processing}

New digital minicomputers can be used to perform all of the data processing tasks for vector telluric surveys in the field. Such systems using large memories could calculate the telluric transfer tensor in real time, allowing the operator to evaluate data quality as well as resistivity structure as the survey progresses. Simpler systems, based around smaller microprocessors, can be used to obtain the transfer tensor elements in narrow bands around several discrete center frequencies. These systems, similar to the multi-channel digital synchronous detector (Snyder, 1976; Jain and Morrison, 1976), can provide the average Fourier complex coefficients for selected frequency bands for four electric field components. Repeated measurements over 
many time intervals can then be combined for averages of autoand cross-power spectra required in a least-squares estimate of the tensor elements. The latter operation can now be performed with a hand-held programmable calculator. One possible recording scheme could involve telemetry communication and real-time processing of incoming data at a base station. This would allow immediate data quality evaluation and efficient survey planning. A slightly different approach could involve remote recording of field station data on portable analog or digital tape recording systems equipped with a clock or a WWV receiver. Data could then be reduced on a four-channel microprocessor in the field. This approach allows for simultaneous recording at a large number of stations. Both systems would reduce cost and time of surveys and allow for in-field processing of data.

\section{ii. Digital Recording for Post-Field Processing}

With the advent of digital cassette recorders, it is possible to assemble a highly portable, low power, digital telluric recording system. Although in-field processing is not done, much of the post-field processing would be handled more efficiently by direct computer analysis of tapes. The system would be low cost, low maintenance, and it could accept data from a large number of stations. The hardware would also be directly applicable to other passive geophysical systems, e.g., microearthquake, seismic noise, and remote telluric-magnetotelluric systems. 
c. Area III: Data Interpretation

\section{Problem Statement}

Most telluric surveys are analyzed semi-quantitatively, based on techniques developed for exploration in sedimentary basins. In one vector technique, for example, a simple ratio of telluric field ellipse areas at two stations is used to calculate the corresponding conductance ratio of rocks above basement. This analysis assumes the presence of a resistive basement and ignores lateral resistivity inhomogeneities, which can greatly modify the field polarization. The interpretation is suited to basin environments, where lateral variations are slow. Interpretation of data from geologically complex areas requires numerical solutions to the forward problem--the electromagnetic response of inhomogeneous half-spaces.

\section{Solution}

Theoretical computer-assisted studies of telluric transfer function over a wide range of geologic models should be performed. Computer programs capable of these functions already exist and are used extensively for magnetotelluric interpretation, but little has been published on the subject (H. F. Morrison, 1977, personal communication). Joint inversion of telluric and resistivity data could provide more unique modeling, but this analysis is not widely used (Beyer, 1977). Analog models have also been of great help for complex structures (Yungul, 1977), and these are often used in Europe but seldom in the United

States. The European literature may be very helpful in this area. 


\section{References--Tellurics}

Berdichevskii, M. N., 1960, Electrical surveying by means of telluric currents: Moscow Gostophekhizpat; English translation, G. V. Keller, 1965, Quarterly of the Colorado School of Mines, v. 60, no. 1, 215 pp.

Beyer, J. H., 1977, Telluric and dc resistivity techniques applied to the geophysical investigation of Basin and Range geothermal systems (Part I: The E-field ratio telluric method): Ph. D. thesis, University of California, Berkeley.

Combs, J., and Wilt, M. J., 1975, Telluric mapoing, telluric profiling and self-potential surveys of the Dunes geothermal anomaly, Imperial Valley, California: Proceedings, Second U. N. Symoosium on the Development and Use of Geothermal Resources, v. 2, pp. 917-928. Jain, B. and Morrison, H. F., 1976, Inductive resistivity survey in Grass Valley, Nevada: Progress Report, Lawrence Berkeley Laboratory, $46 \mathrm{pp}$.

Li, Y-Shu, 1963, Calculating the parameters used in telluric current prospecting: Geophysics, v. 28, pp. 482-485.

Maas, J. P., 1976, Telluric mapping of the Mesa geothermal anomaly:

Ph. D. thesis, University of California, Riverside.

Mazella, A., 1977, personal communication.

Morrison, H. F., 1977, personal communication.

Neuenschwander, E. F., and Metcalf, D. F., 1942, A study of electrical earth noise: Geophysics, v. 7, no. 1, pp. 69-77.

Pritchard, J., 1977, personal communication.

Schlumberger, M., 1939, The application of telluric currents to surface prospecting: Trans. AGU, pp. 271-277. 
Snyder, D. D., 1976, Field tests of a microprocessor-controlled electrical receiver: Abs., 45th Annual International Meeting, SEG, Denver, Colorado.

Thayer, R. E., 1975, Telluric and magnetotelluric investigations of regional geothermal processes in Iceland: Ph. D. thesis, Brown University, Providence, Rhode Island.

Wilt, M. J., 1975, An electrical survey of the Dunes geothermal anomaly and surrounding region, Imperial Valley, California: M. S. thesis, University of California, Riverside.

Yungul, S., 1965, Telluric current method of determining ellipse area by simultaneously measuring two voltages with a collinear threeelectrode array: U. S. Patent office, no. $3,188,557$.

Yungul, S., 1968, Measurement of telluric "relative ellipse area" by means of "vectogram:" Geophysics, v. 33, pp. 127-131. Yungul, S., 1977, The telluric methods in the study of sedimentary structures--a survey: Geoexploration, v. 15, pp. 207-238.

Yungul, S., 1977, personal communication. 
MAGNETOTELLURICS/AUDIO-FREQUENCY MAGNETOTELLURICS

\section{Exploration Techniques}

In the magnetotelluric (MT) method the natural electrical and magnetic fields at frequencies between dc and $100 \mathrm{~Hz}$ are measured and analyzed to obtain an estimate of the vertical resistivity distribution in the earth. The MT "sounding" may be compared to a "smoothed" resistivity well $\mathrm{log}$. In an area of relatively uniform geology, analysis of lateral earth variations is made by correlating soundings as one would correlate well logs. In areas of more complex geology, MT provides information on geologic strike, earth anisotropy and structural discontinuities. In these cases, MT resistivity data must be interpreted with two- and three-dimensional models.

Audio-frequency magnetotellurics (AMT) is an extension of the magnetotelluric method into the audio-frequency range $(1-20,000 \mathrm{~Hz})$ and the two are often discussed together. AMT has developed as a separate exploration technique because the higher frequency range permits measurements to be made faster and with lighter, more portable equipment. The higher frequencies, however, restrict depth of exploration to 1 or $2 \mathrm{~km}$. It is possible to use both methods at a single site, thereby extending the frequency range of measurements and allowing for resistivity analysis of very shallow to very deep earth structures. Scientists at University of Texas, Austin have performed several simultaneous MT-AMT surveys with good effect (F. X. Bostick, 1977, personal communication; Stanley et al., 1977). 
Electrical fields are measured between pairs of non-polarizing electrodes, 0.1 to $1.0 \mathrm{~km}$ apart. Magnetic fields are detected with sensitive component magnetometers. Induction coil, fluxgate, or Josephson effect (SQUID) magnetometers are most commonly used. Electric and magnetic field signals are amplified, bandpass-filtered and recorded in analog or digital form. Signals are normally monitored on strip chart recorders for subsequent editing of tapes. Computer analysis of field tapes yields statistical estimates of impedance vs. frequency from which a vertical distribution of resistivity may be inferred. The need for data averaging to reduce error results in long recording times, particularly in the low frequency bands where periods ranging from 100 to 10,000 seconds may be of interest. Depending on the average resistivity of the area, the depth of penetration desired, the level of natural field activity, and the presence of local man-made noise, the recording duration per station varies from only 30 minutes for AMT up to between six hours and several days for MT.

Initial, as well as some recent applications of MT, were to determine the large scale conductivity structure of the crust and upper mantle and for mapping regional geothermal anomalies. For example, Hermance and Pederson (1976) reported on the results of an MT, telluric and magnetic variation study across the southwestern U.S., and they showed that the Basin and Range province is underlain by an anomalous conductor at the base of the crust. This work also identified a highly conducting structure at a depth of $5-10 \mathrm{~km}$ beneath the Southern Rio Grande Rift, which they believe could be a derivative of a major geothermal phenomenon, possibly a major fracture zone along which hydrothermal 
fluids are circulating, or a magmatic intrusion. Farther north, near Socorro, New Mexico, the University of New Mexico, JPL and Cal Tech have performed a regional Mr survey to verify, among other things, the existence of a magma body suggested from a study of deep seismic reflections (Jiracek et al., 1977). Based on a preliminary onedimensional inversion of the data, they, too, find evidence for a conductive zone in the shallow crust, which might be due to a partial melt at a depth of $5 \mathrm{~km}$. Stanley et al. (1977) conducted MT soundings northeastward from the Raft River geothermal area, Idaho, to Yellowstone National Park, Wyoming. A one-dimensional interpretation of the data reveals an anomalous crustal structure involving a conductive zone ranging in depth from $18 \mathrm{~km}$ in the central part of the Snake River Plain to $7 \mathrm{~km}$ at the Raft River geothermal area and only $5 \mathrm{~km}$ in Yellowstone. The elevated conductive zones at the Raft River thermal area and at Yellowstone are explained by an abnormally hot crust. The depths to the shallow conductive zone in Yellowstone corresponds to Curie point depths and to maximum depths of earthquake foci, and therefore the MT soundings are believed to show the depth to intense hydrothermal alteration and partial melting beneath part of the caldera system.

The AMT method was developed in the U.S. with intended application to the mining industry; the first commercial system was designed and built by Kennecott Exploration, Inc. in 1963 (Strangway et al., 1973; Slankis et al., 1972). The speed and relative ease in which measurements could be made and the sensitivity of the method to shallow and intermediate structures made it a promising tool for mining applications. The 
interest in AMT for mining applications has waned, however, because the method was found to be relatively insensitive to steeply dipping laterally discontinuous conductors, typical of orebody geometries (G. Hohmann, 1977, personal communication). The first widespread application of AMT to geothermal prospecting was conducted by the U.S. Geological Survey (USGS) in a program begun in 1972 (Hoover and Long, 1975). For this project the USGS designed and built a scalar AMT system and later used it to conduct reconnaissance surveys at KGRA's throughout the western United States (Hoover and Long, 1975; Hoover et al., 1974). The purpose of this program was to allow a preliminary evaluation of geothermal properties for the purposes of land acquisition and detailed exploration. The USGS experience showed that AMT had application in reconnaissance exploration for shallowto intermediate-depth geothermal systems and is most effective when combined with telluric, MI or galvanic resistivity data over the same area (Hoover and Long, 1975). AMT has been little used for geothermal exploration outside the U.S. It was tested over the Broadlands Geothermal Field, New zealand and found to accurately outline the known geothermal field (Whiteford, 1975).

Many MT surveys performed recently for industry are conducted for structural and conductivity information at depths of one to several kilometers in particular prospect areas where this information is unattainable from dc resistivity surveys. In areas of complex geology, the station density has to be far greater than in regional work, with stations sometimes only $1 \mathrm{~km}$ apart. These applications have brought to light a number of problems in data accuracy and interpretation 
that were of less concern to researchers performing the larger-scale studies. Crustal investigators might have taken data for weeks or even months at a single station. Exploration economics require many stations be occupied in the shortest possible period of time, and yet the data must be accurate enough to allow a fairly sophisticated interpretation in terms of two- or even three-dimensional subsurface models. These requirements have not always been met in commercial MT surveys.

The potential advantages of MT/AMT over other electrical methods provide a powerful impetus to resolve the above difficulties. In particular: (i) MT/AMT provides the only source-free method of determining subsurface resistivities; (ii) in many U.S. geothermal regions, targets, or heat sources for shallower reservoirs, lie 1-5 km beneath the surface and are thus beyond the practical reach of most other methods currently in use; (iii) MT/AMT is inherently sensitive to conductive bodies; (iv) MT/AMT is insensitive to surficial resistive rocks which are difficult to probe with dc resistivity techniques; and (v) it has been noted that the deep crustal conductor appears to become shallower under geothermal areas and mapping its depth with MT could be a powerful reconnaissance exploration tool.

Three versions of the MT method have been used commercially in geothermal exploration. These are scalar MT, tensor MT, and remote telluric MT. (A fourth method, called dual station MT, is under study at LBL and other research groups may have methods under development.) The theoretical differences between these methods are based on the 
earth model assumed. The practical differences are based on the validity of these assumptions for geothermal areas.

\section{a. Scalar MT/AMT}

With the scalar MT method, it is assumed that the earth is horizontally layered and isotropic (Cagniard, 1953). In this case, the impedance at any frequency is simply the ratio of electrical and magnetic fields, and is independent of the direction of measurement so long as the fields are measured perpendicular to each other. With a complete frequency determination of the impedance an electrical sounding can be made; the layered section is interpreted by means of an automatic one-dimensional inversion or curve-matching. The scalar method is best suited to areas where the geology is smoothly varying and reasonably isotropic, and this eliminates geothermal areas. Nevertheless, scalar MT has been used in geothermal exploration as a reconnaissance technique to locate conductivity anomalies, and in conjunction with telluric surveys for converting telluric field parameters to apparent resistivity. Analysis is quantitatively useful, however, only if the subsurface is approximately horizontally layered or if the electric dipole is aligned parallel or perpendicular to a well defined two-dimensional strike. If these conditions are not met, then analysis is not representative of the subsurface and interpretations can be misleađing (Vozoff, 1972). 


\section{b. Tensor MT/AMT}

With tensor MT/AMT impedance is defined through a 2 × 2 complex tensor for which, in general, all. four impedance terms are nonzero and unequal. If measurement axes are parallel and perpendicular to geologic strike, however, the diagonal terms of the impedance tensor vanish and parallel (TE mode) and perpendicular (TM mode) to strike apparent resistivity vs frequency functions are obtained (Vozoff, 1972). For the general case of unknown geologic strike the impedance tensor is rotated analytically to minimize diagonal terms; the direction where these terms are minimum will best approximate alignment in directions parallel and perpendicular to strike. A complete determination of the impedance with frequency can, therefore, result in two complete apparent resistivity curves, often referred to as the $\mathrm{TE}$ and TM curves. For most two-dimensional cases the TM curve is very sensitive to crossing structure while the TE curve is much less affected. It is, therefore, normal practice to obtain a one-dimensional vertical resistivity model from the TE curve, and use the TM curve as a measure of earth anisotropy and lateral inhomogeneity.

In most MT surveys, a fifth component, the vertical magnetic field, is also measured. This measurement allows for an estimate of geologic strike independent of the impedance, and gives some measure of earth inhomogeneity. Vertical magnetic field measurements offer a means of identifying $\mathrm{TE}$ and $\mathrm{TM}$ apparent resistivity curves, and are also useful in two-dimensional modeling.

Tensor MT/AMT is a powerful technique, particularly where the earth's structure is strongly two-dimensional such that TE and TM 
resistivities can be clearly identified and interpreted with twodimensional models. However, in geothermal areas sufficient threedimensionality exists to make interpretation extremely difficult.

Tensor MT surveys are considerably more complex than scalar surveys; they require fairly sophisticated data acquisition systems followed by computer analysis. Computer analysis is needed because the tensor impedance $\mathrm{z}$ contains four unknowns that are involved in only two equations, i.e.,

$$
E_{x}=z_{11} H_{x}+z_{12}{ }_{y}
$$

and

$$
E_{y}=Z_{21} H_{x}+Z_{22}{ }_{y}
$$

From a single data record a single set of $\mathrm{E}$ and $\mathrm{H}$ values over the desired frequency band can be obtained but, except in the trivial case of layered medium where $z_{11}=z_{22}=0$ and $z_{21}=-z_{12}$, there is not enough data to determine all the $\mathrm{z}$ 's. Thus, multiple data sets are required and some least-squares process must be used to determine the impedances.

Acquisition systems vary in complexity from five-channel analog systems to multichannel digital systems with on-board computers. Tensor systems normally use SQUID magnetometers or induction coils for magnetic measurements; fluxgate magnetometers have been used at low frequencies but may not be sufficiently sensitive to gather data in the higher frequencies where magnetic signals are weakest $(0.1$ to $10 \mathrm{~Hz})$. 
Some newer AMT/MT systems have on-site computers which allow real-time or same-day processing of field data. This advance is of particular significance in magnetotellurics because operators have a verification of data quality, besides visual analysis of chart records, and know when sufficient data have been collected. Initial results from systems in use have shown an overall improvement in data quality and efficiency of field operations (F. X. Bostick, 1977, personal communication) .

The several on-site computer systems in use are based on different approaches to the problem. The University of Texas, Austin's MT-AMT system utilizes an off-the-shelf programmable calculator and sets of cascading filters for real-time processing of narrow-band data at frequencies below $1 \mathrm{~Hz}$. For higher frequencies, a tensor AMT receiver is used (F. X. Bostick, 1977, personal communication). The system is capable of gathering data from $10^{-3}-10^{3} \mathrm{~Hz}$ at the rate of 1-2 stations per day (Stanley et al., 1977; F. X. Bostick, 1977, personal communication). The soon-to-be-activated USGS system utilizes an on-board minicomputer for real time analysis of wide-band data (D. Stanley, 1977, personal communication). The system is designed to perform all the standard data analysis (Vozoff, 1972) and compute a one-dimensional inversion on-site. Other approaches to in-field computer analysis of MT data include the use of a trailer-mounted minicomputer (K. Vozoff, 1977, personal communication) and the use of a minicomputer at the field site office for same-day (but not on-site) data analysis (J. Hermance, 1977, personal communication) . 
One AMT tensor system under development utilizes a microprocessor for impedance calculations and tensor rotations (D. B. O'Brien, 1977, personal communication). In another system under development tensor calculations are performed in a programmable calculator (D. B. Hoover, 1977, personal communication). AMT phase information may be obtained directly from a phase-lock loop detector or by subsequent computer analysis of field tape recordings (D. B. Hoover, 1977, personal communication) .

Although considerably more complex than scalar MT, tensor MT measurements are more quantitatively useful because the assumed model closer approximates true earth conditions. Tensor parameters are theoretically time invariant and therefore some analysis of twodimensional structure is possible. No other electrical method provides as much information about the subsurface from measurements at a single site as MT/AMT. Disadvantages include the high cost of performing tensor MT surveys (as much as three to four times the cost of scalar surveys), and the difficulty of data interpretation in complex geological situations.

Compared to tensor MT, AMT operations are rapid and simple; a one- or two-man crew is usually sufficient for most AMT surveys. Because complete AMT soundings may be made in 30 minutes or less and require equipment that is better suited to remote or off-road terrain, AMT is the preferred method over MT whenever shallow exploration suffices. AMT systems have also been used in conjunction with a controlled source. Using a grounded dipole Goldstein and Strangway (1975) found that a source to observation-point distance of three skin depths (relative 
to the maximum resistivity in the section) was adequate. At this distance (usually less than $5 \mathrm{~km}$ ) the fields are approximately plane waves, and conventional interpretations can be applied. This method offers the advantage of a known source field and is quite attractive in areas of low natural signals or high noise. Several such EM-AMT systems are commercially available (D. O'Brien, 1977 personal communication). c. Remote Telluric-Magnetotellurics

The remote telluric-magnetotelluric (T-MT) method combines telluric measurements at several stations with a magnetotelluric sounding at one station. All measurements may either be done simultaneously (Hermance et al., 1975) or a telluric base station may be later established over a previous MT station and recordings made simultaneously at the base and several remote telluric stations (Hermance and Thayer, 1976; Yungul, 1966). In either case, magnetotelluric depth soundings are obtained at each station from magnetic records at the one station.

The potential advantages of T-MT over conventional MT are:

(a) a lower cost per station due to reduced data acquisition time, and (b) suitability for remote terrain at sites where it is difficult to install full MT stations. Among the disadvantages are the complex logistics involved in operating a multi-station system, particularly as remote stations become farther from the central recording station. However, the most critical feature of the T-MT method is that the magnetic field must be uniform over the area of the stations to produce valid MT results. Although the incident magnetic field may not always be uniform, experiments indicate that the incident field is probably uniform over distances of at least $30 \mathrm{~km}$ and sometimes up to $150 \mathrm{~km}$. 
Local inhomogeneities distort the incident field, a condition recognized by the presence of a vertical magnetic component. Therefore, the T-MT method is best applied where the earth approaches homogeneous, layered situations, and for this reason the technique has been successfully applied in petroleum exploration (Thayer, 1975). Whether the technique will have application in geothermal exploration will depend on the specific geologic setting and economics. If it can be shown T-MT can significantly reduce the per station cost, MT could become a more widely used technique despite the possible bias of results from a non-uniform field.

T-MT instrumentation tends to be complex, involving sophisticated multi-channel digital systems with radio telemetry (A. Mazella, and T. Meidav, 1977, personal communications) in which all telluric and magnetotelluric data are simultaneously recorded on a single magnetic tape. WWV radios or synchronized digital clocks are also being used at remote stations to replace radio telemetry (W. Czimer, 1977, personal communication) .

\section{d. Dual Station Magnetotellurics}

Recently Gamble et al. (1978) reported on a two-station method in which two tensor-MT stations operate simultaneously, the data from one telemetered to the other, the recording station, where all channels of data are recorded on a single magnetic tape. The data obtained at each site are analyzed using the horizontal magnetic field components at the other site as reference. That is, the impedance elements are calculated using only cross products involving the magnetic reference. 
As a result, the impedance tensor estimates are unbiased by noise, provided there is no correlated magnetic noise at the two stations. Field experiments show that valid apparent resistivities can be obtained at periods where the E-E predicted coherencies were as low as 0.1 . The advantages of the dual station technique are that it enables one to make MT measurements in an area contaminated by cultural noise, provided the two magnetometers are far enough apart, and it provides a faster, more efficient operation, in general, because more of the data collected will give reliable estimates of apparent resistivity.

\section{Research Areas}

Although the MT/AMT method has achieved some success in geothermal exploration, users of the method have experienced problems in data collection, data analysis, and interpretation. The major areas of concern include (a) difficulty in obtaining noise-free signals at all frequencies of interest, (b) scatter and apparent non-repeatability of some "good" data, and (c) difficulty in interpreting MT data obtained in complex geologic situations. In addition, the cost of performing MT surveys is sufficiently high as to sometimes prohibit the use of optimum station densities, or to collect data over long enough sampling times.

Each of these problem areas has received considerable attention by workers in government and private industry, and research is continuing. In the sections below, several areas of pertinent research are listed. A discussion is given at some length to past and present efforts in 
the area. In addition, an assessment is given on future research needs and the goals of future efforts.

The research areas discussed include the following (also see Fig. 6):

- Effects of Geologic and Man-Made Noise

- Data Processing and Noise Reduction

- Remote Telluric-Magnetotellurics

- Modeling and Interpretation

- Tipper Reconnaissance

- Improvement of AMT Field Systems

\section{a. Area I: Effects of Geologic and Man-Made Noise}

\section{Problem Statement}

Regional and sometimes distant structures may affect magnetotelluric measurements by distorting the impedance estimates. In addition, nonplanar signal sources, natural and man-made, produce scatter and error and are often very difficult to separate from planar signals. Finally, local inhomogeneities can strongly distort the apparent resistivity calculations and these effects are dependent on the length of electric dipole used.

\section{Background}

The geometry of certain large scale earth structures may strongly influence magnetotelluric data even at distant points. For example, an elongate but closed Basin and Range valley may cause an appreciable loss of current density at points interior because of the closed or tapered ends; observed apparent resistivities may, therefore, appear low (H. F. Morrison, 1977, personal communication). A fault involving 


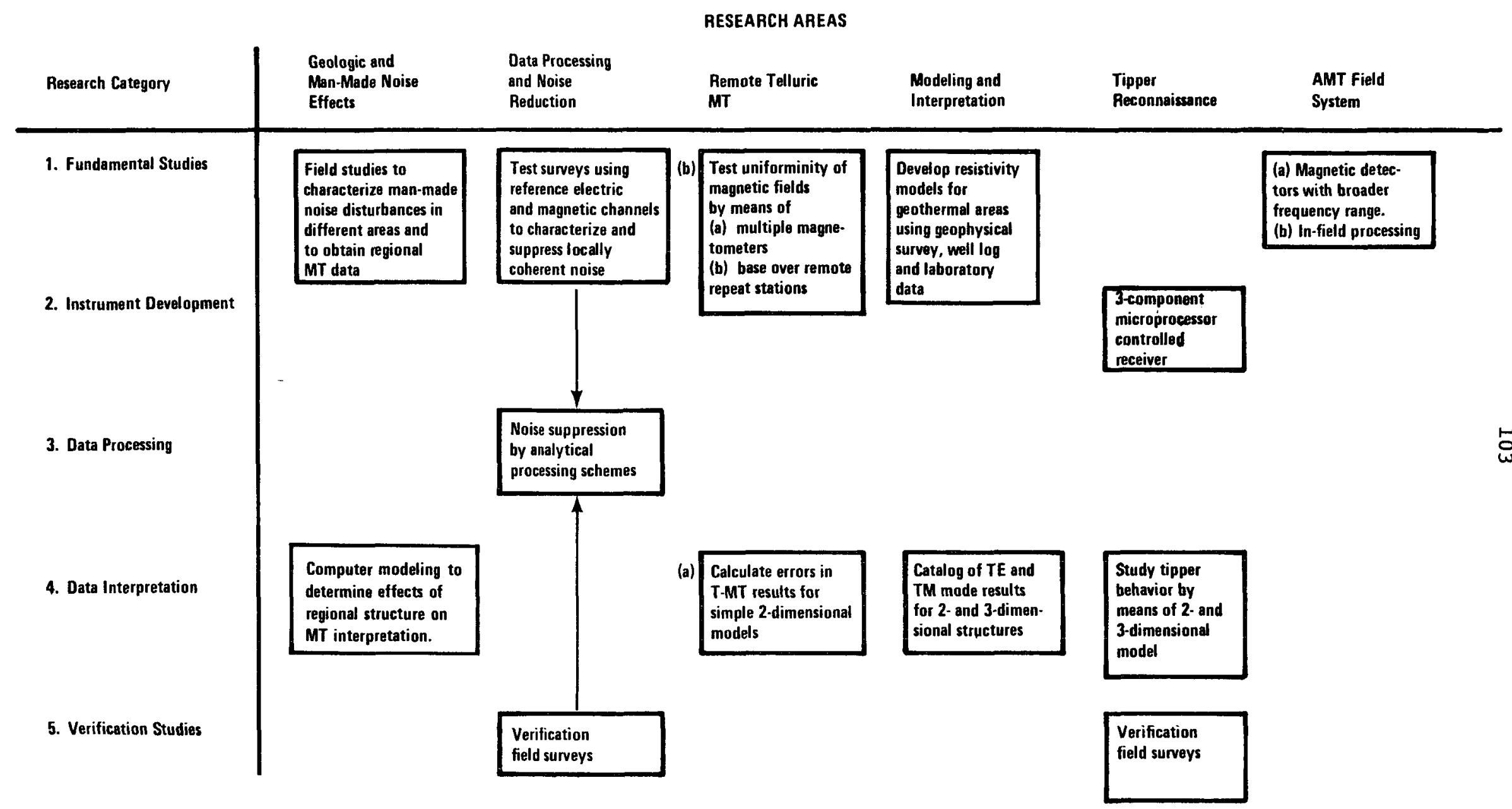

Fig. 6. Research matrix for magnetotelluric and audio-frequency magnetotelluric exploration. 
a significant resistivity contrast will also result in field distortion for appreciable distances on the resistive side of contact. This may lead to misinterpretation if effects of the structure are not included (Vozoff, 1972). A variety of other structures, such as mountain ranges and coastal margins, may also significantly distort magnetotelluric data some distance away.

Nonplanar signals may originate from natural sources such as atmospheric phenomena or man-made sources such as grounded power networks, rail lines, or electric machinery. Signals from nonplanar sources may degrade data quality or impart a significant bias to the measurements.

Solution

Only the most fundamental type of research has been done in the United States in this area (Srivastava et al., 1963), although the problem has been identified by several workers (F. X. Bostick and I. K. Reddy, 1977, personal communications). Research efforts have been especially slow since the problem is particularly difficult and the research is expensive; studies are under way, however, at the University of California and the USGS. At the University of California research is progressing by means of two-dimensional modeling and field experiments to determine errors caused by edge effects and narrow boundaries of Basin and Range valleys on MT data (H. F. Morrison, 1977, personal communication). At the USGS problems associated with power line harmonics are being examined (D. B. Hoover, 1977, personal 
communication). Additional and/or continued effort is needed in the following areas:

1) Analog and mathematical models for representative regional geologic structures are needed to determine the effects on MT soundings at varying ranges.

2) Regional MT data should be gathered at a wide station spacing in areas of geothermal interest. Regional structures detected and supported by model studies will lead to improved interpretations of "local" anomalies.

3) A study of the effects of various types of local power distribution networks on MT data could greatly improve overall data quality by superior survey planning. It is known, for example, that certain types of grounded power networks have devastating effect on MT measurements but some high voltage types do not. In many cases the effects of power line noise contamination are not evident until data analysis is performed and the field crew has left the area. Quantitative information on the noise characteristics of various power networks should be gathered and published. The affected areas should then be avoided or some provisions made for removing noise.

4) The effect of electric dipole length on apparent resistivity estimates needs to be studied in greater detail and clarified for geothermal exploration MT applications. Local inhomogeneities can distort the apparent resistivity estimates unless time and care are taken to make the dipoles long, thereby achieving a spatial averaging effect. 
In actual exploration surveys this approach may be impractical because of terrain and other factors, and the result is biased resistivity estimates. The effect of local inhomogeneities should be studied by means of combined mathematical models and field experiments.

b. Area II: Data Processing and Noise Reduction

Problem Statement

Standard techniques for calculating impedance and other MT parameters produce estimates that are biased and scattered because of electromagnetic noise. The problem is not only to devise data acquisition and processing techniques to help eliminate noise, but also to understand the nature of the noise, some of which may have geological significance.

\section{Background}

Because of man-made electromagnetic noise and the low naturalsignal-strength in certain frequency bands, resulting impedance estimates show some scatter or are otherwise biased and inaccurate. This leads to erroneous, misleading or incomplete interpretations. To solve this problem one could record for unlimited durations, processing only data segments from times of peak signal strength. However, this is often impractical and always expensive. Reliable MT results must be obtained without the need for long recording sessions if MT is to become a cost-effective exploration method. 
Solution

Recently, researchers have proposed several methods for noise rejection. These methods have included improved techniques for calculating impedance (Kao and Rankin, 1977; Gamble et al., 1977) and the use of additional electrical or magnetic field measurements as reference channels for noise reduction analysis (Goubau et al., 1977). In addition, new methods for calculating power spectra from time series have been proposed (Hernandez, 1976). These methods give the promise of more accurate determination of impedance quantities from more accurate frequency determination of time series.

\section{i. Improved Impedance Calculations}

The impedance tensor may be calculated from power spectra by at least six different mathematical formulae (Goubau et al., 1977; Swift, 1967). These are equivalent in the absence of electromagnetic noise, but yield different results depending on the presence of electric and/or magnetic noise. In a recent paper (Kao and Rankin, 1977) it was demonstrated that uncorrelated noise on any channel may be eliminated by the use of cross-spectral terms only in impedance calculations, since the uncorrelated signals in these terms average to zero. The paper gave an iterative scheme that converges to the actual value of the impedance if uncorrelated noise only is present; if correlated noise is present, the technique is less effective. An analytical solution to this cross power impedance expression has also been published (Goubau et al., 1977). 
Other expressions for impedance calculation that are less biased in the presence of correlated noise have been published; these include the weighted averages and double averages methods of calculation (Goubau et al,, 1977). Application of these techniques to noisy data sets in Grass Valley, Nevada have demonstrated significant improvement (Gamble et al., 1977) . Clearly more experience is needed with these new methods of impedance calculations to discover the limits of applicability.

\section{ii. The Use of Reference Channels in Impedance Calculations}

When noise is correlated on two or more channels the problem of noise elimination becomes more difficult since the noise component of cross spectral terms does not average to zero. In this case a portion of the correlated noise may be eliminated by multiplying impedance expressions by a reference channel which contains identical signal but different (or uncorrelated) noise. Gamble et al. (1977) attempted this scheme using a third electric field dipole, but local correlated noise sources also contaminated this channel, and results were not significantly improved. Greater success in noise elimination was later achieved by using a remote magnetometer because the magnetic field noise was more random (T. Gamble., 1977, personal communication). Later tests with the reference magnetometer have evolved into the dual station MT technique discussed earlier (Gamble et al., 1978). 


\section{iii. Maximum Entropy Method}

The so-called maximum entropy method forms a separate technique in calculating power spectra for MT data and may offer a more accurate method of time series analysis (Hernandez, 1975; LaCoss, 1971). It has proved especially effective when the signals are discrete or impulsive or when short data segments are analyzed. The method is actually an exercise in inverse filter theory. That is, it seeks to find a filter that would yield a white noise (or maximum entropy) spectrum when acting upon time series. The inverse of this filter is, therefore, the true power spectra at the time series.

Critics of the method assert that absolute power spectral calculations are not crucial to determining impedance, but only the proper ratios of spectra. Thus, if all spectra were biased in the same manner, the final impedance calculations would be unaffected. In addition, evidence for significant improvement of actual field data with this technique is lacking in the literature and many workers will remain unconvinced until such evidence is presented. Research on this subject is being undertaken by the USGS.

\section{iv. Noise Studies}

There is limited evidence that suggests that the noise may have geological significance in certain areas. Gamble et al. (1977) found at Leach Hot Springs, and Grass Valley, Nevada, electric field noise spatially coherent over a distance of $1 \mathrm{~km}$ 
near the springs. These voltages may be caused by varying streaming potentials. Potentials from electrokinetic effects were inferred from detailed SP surveys in the same area (Corwin and Hoover, 1977). If this is the case, a totally new aspect of MT interpretation may be at hand, involving the use of electric reference dipoles to determine simultaneously whether locally coherent electric noise is present. An effort must also be made to better understand the source of the noise and how the noise may be exploited for geothermal exploration purposes.

\section{c. Area III: Remote Telluric-Magnetotellur ics}

Problem Statement 1

The quantitative value of the remote telluric-MT technique is open to question because the uniform magnetic field assumption is not safe at all frequencies in areas with complex geology. Unless there is a way of estimating corrections to apparent resistivities for non-uniformity, the technique will have application mainly in areas of homogeneous, layered structures.

\section{Solution}

Experiments to study the applicability of remote telluric MT are being done at LBL and at the University of Texas, Austin. At LBL experiments are combined with a geothermal assessment survey at Mt. Hood, Oregon. Uniformity is being checked by means of two separated magnetometers and the T-MT results are being quantitatively checked by means of systematic reoccupation of selected remote telluric stations by a magnetotelluric station. Researchers at U. T. Austin used two 
sets of induction coils in a recent survey at the Snake River Plain (Stanley et al., 1977). Coil sets were located considerable distances apart and results on field uniformity will be reported in the literature at a future time.

Where original inhomogeneities cause non-uniformity a first order correction to T-MT apparent resistivities might be obtained by (a) using conventional MT results to find an approximate regional model, and (b) comparing calculated MT results for the model observed results at remote telluric stations to improve and refine the interpretation.

Problem Statement 2

The need for on-site processing and noise reduction techniques is particularly acute with remote telluric MT. Since many soundings are obtained with one set-up of detectors, it is important to evaluate data quality in the field and be able to eliminate noise.

\section{Solution}

As more remote telluric MT surveys are being performed, the vulnerability of the method to noise and low magnetic signal is becoming more apparent (I. K. Reddy, 1977, personal communication). Techniques for multi-channel on-site computer processing need to be developed; much technology could be borrowed from seismic reflection. The use of reference channels for noise reduction may also become an integral part of remote-telluric MT surveys (T. Gamble, 1977, personal communication); if the use of many channel systems becomes common, the addition of two extra channels for noise reduction will have small 
significance. Some research groups, for example, are now planning to modify idle 96-channel seismic systems for remote telluric MT surveying (R. Thayer and F. X. Bostick, 1977, personal communications). The use of these systems could have an enormous impact on geothermal exploration and the need for on-site data analysis with such systems is clear.

\section{d. Area IV: Modeling and Interpretation}

\section{Problem Statement 1}

Use of one-dimensional models may often lead to erroneous MT/AMT interpretations. There is a strong need for efficient two- and three-dimensional modeling programs for the forward problem and a two-dimensional inversion program.

\section{Background}

It is normal practice to make a one-dimensional inversion of the apparent resistivity curve identified to correspond to the $\mathrm{TE}$ mode following tensor rotation. The TM mode apparent resistivity curve is generally ignored for the quantitative interpretation. This procedure will lead to erroneous interpretations except where the subsurface is one-dimensional or smoothly varying. For regions of distorted geology, one-dimensional interpretations will be in gross error, especially near vertical or steeply dipping resistivity boundaries. A TE mode inversion of a sounding performed near the edge of a Basin and Range valley, for example, consistently underestimates depths to subsurface layers. These errors are viewed as the result of current channeling in a direction parallel to the axis of the valley and amount 
to a 40 percent discrepancy in the depth estimate of subsurface layers

(H. F. Morrison, 1977, personal communication).

Existing two- and three-dimensional modeling programs are expensive, do not always give identical results for the same structure, and are not widely distributed (Hohmann, 1977). Most of these programs are capable only of modeling variations in the TE mode curves and hence results can be misleading.

\section{Solution}

To accurately model a two-dimensional earth both TE and TM mode sounding curves need be considered. It is now possible to perform dual-curve MT/AMT modeling over simple two-dimensional geometries with forward modeling computer programs (Reddy et al., 1977; H. F. Morrison, 1977, personal communication). These programs give accurate results in certain cases where one-dimensional programs fail but they are presently difficult and expensive to use (K. Lee, 1977, personal communication). A catalogue of dual curve forward models will be published by the University of California (Morrison et al., 1977). Continuation of this line of research is needed to develop efficient two- and three-dimensional-model programs for the forward calculation and to ultimately develop a two-dimensional inversion process.

An alternate scheme for improved resolution in MT interpretation is the use of joint inversions. Results from joint inversion computer programs involving MT and dc resistivity have been published (Oldenburg, 1977; Vozoff and Jupp, 1977) and these indicate that the joint model is significantly more accurate than either of the separate models. 
The MT and dc methods seem to form complementary data sets but joint inversions involving MT and seismics or gravity may also be useful; these should be evaluated. The distribution and testing of joint modeling programs should proceed with dispatch as these offer a more unique and more accurate earth model in most cases.

Three-dimensional forward computer modeling programs have been developed to aid MT interpretation, but these apply to simple geometries and are expensive to use (Stanley, 1977). A possible application of such models is to calculate the effect of large scale regional structure on local MT data (see Research Area I).

\section{Problem Statement 2}

The intrinsic resistivity of rocks within and encompassing geothermal reservoirs is not well documented or understood, and therefore MT/AMT interpretations are somewhat handicapped by lack of resistivity models for the targets sought.

\section{Solution}

Resistivity models for known geothermal reservoirs and the surrounding regions should be compiled from various data sources. For the near surface environment the data could be supplied by interpreted surface survey results supported by electrical logs from drill holes and laboratory measurements of cores. For the deeper environments, the data would have to be obtained from careful laboratory studies in which resistivities are measured under temperature, pressure and pore fluid conditions known or inferred to exist. The laboratory studies should also include a study of frequency dependent resistivity, which is important for 
evaluating the induced polarization as well as helping to determine the frequency-dependent effects on AMT results.

\section{e. Area V: Tipper Reconnaissance}

\section{Problem Statement}

It is not always easy to plan and later analyze the results of an MT survey made in a geologically complex area. It may be possible to overcome both difficulties if a simple and rapid technique involving the magnetic field only is carried out prior to a standard MT survey. Background

When measured at several stations the magnetic field provides useful information on geologic strike and proximity to lateral inhomogeneities. Similar to the higher frequency AFMAG method, discussed in a later section, the magnetic components of the MT fields may be processed to yield this information based on tipper analysis (Oppliger, 1977). The tipper (Vozoff, 1972) is the ratio of the vertical magnetic field to the horizontal field perpendicular to strike and has a number of properties that have been studied by means of twodimensional model calculations. Among these properties are:

(a) the tipper has a maximum value close to, but displaced from, the vertical discontinuity between two regions of different resistivity, e.g., a fault with vertical displacement;

(b) the tipper vector, determined by processing the three magnetic field components in a manner similar to the complex impedance tensor 
method used in conventional MT, points toward the region of higher resistivity;

(c) the tipper directions as a function of frequency tell whether three-dimensional structure is present.

\section{Solution}

Tipper reconnaissance can be conducted using a three-component magnetometer connected to a three-component synchronous detector/ microprocessor. Differing from conventional MT, this technique requires no electric dipoles nor does it require long recording times for complete information over a wide range of frequencies. Similar to E-field ratio tellurics, the signal may be narrow-band filtered at selected frequencies where magnetic field activity is usually high. The only nonstandard component for the technique is in the programming for the microprocessor which is needed to calculate and display the strike of a conductivity inhomogeneity, tipper amplitude and direction.

\section{f. Area VI: Improvement of AMT Field Systems}

\section{Problem Statement}

Present field systems have limited capabilities. For example, they are unable to provide a reliable evaluation of data quality and they are unable to calculate either impedance phase or apparent resistivity below $5 \mathrm{~Hz}$. 


\section{Background}

AMT data quality is evaluated from the statistical scatter of impedance estimates (Hoover et al., 1974). If a noise source is coherent or continuous during time recording, it may not produce statistical scatter and the bias error in impedance estimates may go unnoticed. Therefore, effort is needed to design a better means for evaluating data quality in the field. Tape recording data for post-field processing might be considered.

The majority of AMT systems in use do not calculate impedance phase. The reasons for this are: (a) phase has not been considered significant for reconnaissance purposes, (b) phase calculation requires more instrumental sophistication and hence is more costly, and c) some attempts at calculating phase with phase-lock-loop detectors have yielded wildly scattered results (D. B. Hoover, 1977, personal communcation). Phase calculations are very useful and desirable if data are to be quantitatively evaluated or used in conjunction with MT data.

The coils in AMT systems prohibit the measurement of apparent resistivity below $5 \mathrm{~Hz}$. The extension of the frequency range to $1 \mathrm{~Hz}$, for example, would double the depth of penetration and allow for more effective exploration in conductive environments. The design problem is to extend the frequency response of coils but still allow for portability. 


\section{Solution}

The use of microprocessors in field systems to calculate predicted coherencies, skew and other parameters useful in data evaluation would allow operators to recognize poor quality data (Vozoff, 1972). Because this approach could add considerable complexity and expense to the field system, an alternative is to record data on magnetic cassettes for later analysis. Analysis could be performed on a minicomputer or even a programmable calculator since it would not involve timeconsuming Fourier transformations.

Although some success with impedance phase measurements has been achieved (F. X. Bostick, 1977, personal communication), the problem is far from solved. Phase errors and scatter may be due to the erratic behavior of natural fields at high frequencies or due to noisy data to which phase calculations are very sensitive. The cause of high frequency phase errors should be carefully investigated to determine if the errors are due to the natural fields, the inhomogeneous earth or the instruments used in measurement. Better phase detectors could then be designed if the problem lies with measurement.

Improvements in magnetic detectors are needed to extend coverage to lower frequencies, thereby increasing the depth of penetration and making AMT more effective in conductive environments. Present coils are most effective between $5 \mathrm{~Hz}$ and tens of $\mathrm{Hz}$; fluxgate magnetometers have a broader frequency range but are ineffective above $1,000 \mathrm{~Hz}$. 
Experimentation in design of cores, windings, and geometrics of induction coils should be encouraged. Fluxgate magnetometers should also be improved. 
3. References--Magnetotellurics/Audio-Frequency Magnetotellurics Bostick, F. X., 1977, personal communication.

Cagniard, L., 1953, Basic theory of the magnetotelluric method of geophysical prospecting: Geophysics, v. 8, p. 605.

Corwin, R. F. and Hoover, D. B., 1977, The self-potential method in geothermal exploration: Lawrence Berkeley Laboratory report, in preparation, $34 \mathrm{pp}$.

Czimer, w., 1977, personal communication.

Gamble, T., 1977, personal communication.

Gamble, T., Goubau, W., and Clarke, J., 1977, Magnetotelluric data analysis: tests of methods using data obtained at Grass Valley, Nevada: Lawrence Berkeley Laboratory report, LBL-6648.

Gamble, T., Goubau, W., and Clarke, J., 1978, Magnetotellurics with a remote magnetic reference: Lawrence Berkeley Laboratory report, LBL-7032.

Goldstein, M. A., and Strangway, D. W., 1975, Audio-frequency magnetotellurics with a ground electric dipole source: Geophysics, v. 40 , pp. $669-683$.

Goubau, W., Gamble, T., and Clarke, J., 1977, Magnetotelluric data analysis: removal of bias: Lawrence Berkeley Laboratory report, LBL-6634.

Hermance, J., 1977, personal communication. Hermance, J. F., Thayer, R., and Bjornsson, A., 1975, The telluricmagnetotelluric method in the regional assessment of geothermal potential: Proceedings, Second U. N. Symposium on the Development and Use of Geothermal Resources, v. 2, pp. 1037-1047. 
Hermance, J. F. and Pedersen, J., 1976, Assessing the geothermal resource base of the southwestern United States: Status Report of a Regional Geomagnetic Traverse (Abs.), 46th Annual International Meeting, SEG, Houston, Texas.

Hermance, J. F., and Thayer, R. E., 1976, The telluric-magnetotelluric method: Geophysics, v. 40, pp. 664-668.

Hernandez, W., 1976, Magnetotelluric signal processing: Interim Technical Report \#1, ENSCO Contract \#14-08-001-15322.

Hohmann, G., 1977, personal communication.

Hohmann, G., 1977, Modeling team report: Workshop on Electrical Methods in Geothermal Exploration, University of Utah, Salt Lake City, Utah.

Hoover, D. B., 1977, personal communication.

Hoover, D. B., and Long, C. D., 1975, Audio-magnetotelluric methods in reconnaissance geothermal exploration: Proceedings, Second U.N. Symposium on the Development and Use of Geothermal Resources, vol. 2, pp. 1059-1064.

Hoover, D. B., Frischknecht, F. C., and Tippens, C. H., 1974, Evaluation of audio-magnetotelluric techniques as a reconnaissance exploration tool in Long Valley, Mono and Inyo Counties, California: U.S. Geological Survey Open-File Report.

Jiracek, G. R., Reddy, I. K., Phillips, R. J. and Whitcomb, J. H., 1977, Magnetotelluric soundings of the Rio Grande Rift, COCORP seismic profile in New Mexico: Abs., 47th SEG Conference, Calgary, Alberta, Canada. 
Kao, D. W., and Rankin, D., 1977, Enhancement of signal to noise ratio in magnetotelluric data: Geophysics, v. 42, pp. 103-110. LaCoss, R. T., 1971, Data adaptive spectral analysis methods: Geophysics, v. 36, pp. 661-675.

Lee, K., 1977, personal communication.

Mazzella, A., 1977, personal communication.

Meidav, T., 1977, personal communication.

Morrison, H. F., 1977, personal communication.

Morrison, H. F., Lee, K. H., Oppliger, G., and Dey, A., 1977, Interpretation of MT data from Grass Valley, Nevada: Lawrence Berkeley Laboratory report, in preparation.

O'Brien, D. P., 1977, personal communication.

Oldenburg, D. W., 1977, The joint inversion of magnetotelluric and direct current resistivity measurements: Abs., 47th SEG Conference, Calgary, Alberta, Canada.

Oppliger, G., 1977, Tippers as earth structure dimensionality indicators for magnetotelluric investigations: Engineering Geosciences, University of California, Berkeley, unpublished report. Reddy, I. K., 1977, personal communication. Reddy, I. K., Phillips, R. J., Whitcomb, J. H., and Rankin, D., 1977, Electrical structure in a region of the transverse ranges, Southern California: Earth and Plan. Sci. Letters, v. 34, pp. 313-320. Slankis, J. A., Telford, W. M., and Becker, A., 1972, $8 \mathrm{~Hz}$ telluric and magnetotelluric prospecting: Geophysics, v. 37, no. 5 . 
Srivastava, S. P., Douglas, J. L., and Ward, S. H., 1963, The application of the magnetotelluric and telluric methods in central Alberta: Geophysics, v. 28 , no. 3 .

Stanley, w. D., 1977, Applications, limitation and instrumentation: telluric and MT/AMT team report: Workshop on Electrical Methods in Geothermal Exploration, University of Utah, Salt Lake City, Utah. Stanley, W. D., 1977, personal communication. Stanley, W. D., Buehl, J. E., Bostick, F. X., and Smith, H. W., 1977, Geothermal significance of magnetotelluric sounding in the eastern Snake River Plain--Yellowstone region: J. Geoph. Res., v. 82, no. 2, pp. 2501-2514.

Strangway, P. W., Swift, C. M., Jr., and Holmes, R. C., 1973, The applications of audio-magnetotellurics (AMT) to mineral exploration: Geophysics, v. 38 , no. 6, pp. 1059-1075.

Swift, C. M., Jr., 1967, A magnetotelluric investigation of an electrical conductivity anomaly in the southwestern United States: Ph. D. thesis, Massachusetts Institute of Technology, Cambridge. Thayer, R. E., 1975, Telluric-magnetotelluric investigations of regional geothermal processes in Ireland: Ph. D. thesis, Brown University, Providence, Rhode Island.

Thayer, R. E., 1977, personal communication. Vozoff, K., 1972, The magnetotelluric method in the exploration of sedimentary basins: Geophysics, v. 37, no. 1, pp. 98-141. Vozoff, K., 1977, personal communication. 
Vozoff, K., and Jupp, D. L. B., 1977, Effective search for a buried layer: an approach to experimental design in geophysics: Bull. Aust. Soc. Explor. Geophys., v. 8, no. 1 .

Whiteford, P., 1975, Assessment of the audio-magnetotelluric methods for geothermal resistivity surveying: Proceedings, Second U.N. Symposium on the Development and Use of Geothermal Resources, v. 2, pp. $1255-1261$.

Yungul, S., 1966, Telluric sounding--a magnetotelluric method without magnetic measurements: Geophysics, v. 31, pp. 185-191. 


\section{AUDIO-FREQUENCY MAGNETICS (AFMAG)}

\section{Background}

In the audio-frequency magnetic method (AFMAG) natural magnetic fields, usually below $500 \mathrm{~Hz}$, are used to map near-surface conductivity anomalies. In the late $1950^{\prime}$ s, a dual-coil, portable system was developed to measure the principal horizontal magnetic field direction and the total field inclination (dip angle) at two frequencies. The method was originally developed for mining applications (Ward, 1967), and both ground and airborne systems have been used for massive sulfide exploration. To the knowledge of the authors, this method has not been used in geothermal exploration, and there has been relatively little interest in AFMAG since the mid-1960's.

Commercially available AFMAG instrumentation consists of two orthogonal, tuned induction coils, electronic amplifiers and filters, a phase-sensitive detector for ground systems or a comparator for airborne systems, and galvanometer or chart recorder. The ground system uses a phase-sensitive detector to compare in-phase signals from the "reference" coil to the "signal" coil. By this means the eccentricity of elliptically polarized signals is exaggerated, and the direction of greatest polarization is easy to detect. The coils are first rotated in a horizontal plane to determine the direction of maximum field strength and then rotated in a vertical plane to determine the tilt angle of the total field vector. Frequencies of 150 and $510 \mathrm{~Hz}$ are used in the commercial system; the frequencies are chosen to minimize noise interference from power-line harmonics and yet achieve adequate depth of penetration (Ward, 1959). 
As in the AMT method, the predominant signal source is distant thunderstorms, which produce essentially plane waves. Over a uniform or layered earth, the magnetic field component is horizontal, but it varies in direction as source azimuth fluctuates. Near a conductor, eddy currents tilt the magnetic field and tend to reduce the field's azimuthal variability. In the northern hemisphere, natural signal strength is highest during summer afternoons and evenings and lowest during winter days. During periods of low signal, measurements are sometimes not possible because signal levels fall below the instrument noise level.

AFMAG data can be plotted as tilt angle profiles or as field vector planimetric presentations, with the length of the vector proportional to the tilt angle and its direction in the direction of maximum magnetic field. Conductors are indicated where tilt angles are large and the polarities reverse over a short distance. Quantitative information on depth to conductors and relative conductivity contrast is possible by comparing amplitudes of anomalies measured at different frequencies; however, these calculations give only a crude estimate of the cause of the anomaly.

The AFMAG method should have potential applications in geothermal exploration. Instrumentation is relatively inexpensive, measurements may be done quickly by one man, and the technique is not badly hindered by terrain and access. Disadvantages are limited depth penetration in conductive areas $(\sim 100 \mathrm{~m})$ and a source field that is sometimes unreliable in strength and too highly variable in direction when local sources are present. For example, even when no conductor is present, 
dip angles may be appreciable from a local source (Reller and Frischknecht, 1966).

The future use of AFMAG in exploration does not seem assured for the reasons given above. Moreover, the development of a tensor AMT system with in-field processing may eventually supplant whatever applications exist for AFMAG. For the sake of scientific inquiry, it would be interesting, however, to map selected geothermal reservoirs with AFMAG to determine and demonstrate its applicability. 


\section{References--Audio-Frequency Magnetics}

Keller, G. V., and Frischknecht, F.C., 1966, Electrical methods

in geophysical prospecting: Pergamon Press, New York, pp. 376-380.

Ward, S.H., 1959, AFMAG, airborne and ground: Geophysics, v. 24, no. 4 , pp. $761-789$.

Ward, S.H., 1967, The electromagnetic method, Part C: Mining Geophysicists, Tulsa, pp. 249-276. 
VI. CONTROLLED SOURCE ELECTRICAL AND ELECTROMAGNETIC METHODS This class of methods includes the various field techniques used to obtain the subsurface electrical resistivity variations from surface measurements involving either current impressed directly into the ground or currents inductively generated by means of an oscillating magnetic field. In all techniques an artificial or man-made source of excitation is used, hence the name "controlled source."

The advantages of controlled source methods over natural field methods for resistivity measurements are an energy source whose geometry is known and whose frequency and intensity can be controlled; these functions ultimately result in simpler and sometimes more diagnostic data interpretation. The main disadvantage of controlled source methods is the need to field a large and expensive motor generator, switching bridges and other electronics capable of producing and controlling the usually large currents employed in geothermal exploration.

In this section we discuss three controlled source methods that are used in geothermal exploration: 1) galvanic electrical resistivity, 2) magnetometric resistivity, 3) induced polarization and 4) electromagnetic induction.

\section{GALVANIC ELECTRICAL RESISTIVITY}

\section{Background}

Among the geophysical methods first to be used in geothermal exploration, and perhaps the most widely used method for this purpose, is galvanic electrical resistivity, sometimes abbreviated ER. Interest in ER techniques and dollars spent to acquire ER data peaked in the 
period between 1968-1975, and are now greatly depressed from previous levels for reasons described in the following pages. However, despite industry's disenchantment with ER, the method continues to be an exploration staple in some parts of the world, and significant recent improvements in instrumentation and data interpretation have made it more effective.

Attention was first called to ER when it was demonstrated that a number of known geothermal areas (e.g., Larderello, Italy and the Taupo volcanic zone, New Zealand) exhibited lower resistivities than their surroundings. This was attributed to various factors: more intense hydrothermal alteration, higher porosity and higher conductivity of the pore fluids because of increased ionic concentrations and temperature. However, the search for new resistivity lows in prospective areas led to a number of problematic discoveries about ER as an exploration tool: a) resistivity lows occur for several reasons other than the presence of a geothermal resource, b) some known geothermal areas produce no resistivity anomaly because of the high background conductivity caused by saline-water saturated sediments at surface, c) steam-saturated reservoirs produce resistivity highs, and finally, d) resistivity data can be expensive to acquire and difficult to interpret.

ER surveys are performed using a variety of techniques, but all involve impressing a current into the ground through two separate "current electrodes" and measuring the resulting voltage drop some distance away by means of a sensitive voltmeter connected to two grounded "potential electrodes." Knowing the current delivered, the 
voltage observed and the geometry of the four electrodes, the geophysicist can calculate an "apparent resistivity," a volumetric average resistivity in the vicinity of the electrodes and averaged over a depth which is some fraction of the distance between the two most widely separated electrodes.

Field operations are conducted using a low-frequency, square-wave, constant-current source. Currents employed range from less than one ampere, delivered by a battery-operated source $(50-200 \mathrm{~W})$ to hundreds of amperes delivered by large four-cycle gasoline- or diesel-driven motor generators $(>20 \mathrm{~kW})$. In most geothermal surveys, motor-driven generators are used, typically 3-phase, $400 \mathrm{~Hz}$ generators to reduce ripple and transformer weight. The ac voltage from the generator is transformed to a higher voltage and then rectified. This is chopped and reversed by means of an SCR-controlled switch before the current is applied to the ground.

The voltage between potential electrodes is measured by means of a variety of available instruments. These range from simple, portable, high-impedance voltmeters which give only a meter deflection, to the newer, commercially available detectors which use clock-synchronized signal averaging, such as the Bison model 2390 signal-enhancement resistivity system (Morrison, 1975). More versatile, but more expensive, microprocessor controlled synchronous detectors are also available, e.g., Edcon's GeoPhase receiver. The newer detectors can detect very small voltages, making it possible to use smaller, lighter generators and/or to increase exploration depth by permitting operation with 
larger electrode separations. These signal averagers also make it easier to conduct surveys in the presence of man-made noise.

Field operations are conducted in various ways depending on the type of information desired. The techniques that have been used may be grouped as follows: a) reconnaissance mapping or profiling,

b) vertical electrical soundings, and c) electrical sections.

\section{Exploration Techniques}

\section{a. Reconnaissance Mapping or Profiling}

For a number of years, resistivity reconnaissance in geothermal exploration was conducted using the bipole-dipole technique--a mapping technique designed to quickly identify areas of anomalously low resistivity (Keller et al., 1975). The earth is energized by means of a fixed transmitting bipole, two to five kilometers in length. Potential differences are measured by short receiver dipoles, often orthogonally paired, which are moved from point to point on the surface in the vicinity of the bipole. By convention, the calculated apparent resistivities are plotted at the receiver locations, and a contoured map is made and interpreted in terms of resistivity changes between stations (Keller et al., 1975). Several bipoles at different locations and orientations, together with a high density of receiver stations, are necessary to define a change in subsurface resistivity (Beyer et al., 1976; Dey and Morrison, 1977). This has detracted from the rapidity and relative simplicity of the initial concept, and has 
resulted in the use of more complex field and data processing procedures, such as rotating bipole sources at multiple locations (Furgerson and Keller, 1974; Hall and Davis, 1977).

Recently, Dey and Morrison (1977) evaluated the effectiveness of bipole-dipole by calculating apparent resistivities over two-dimensional structures. Their principal findings agree with the conclusions from field surveys: namely, the results can be ambiguous, highly dependent on bipole locations and orientation, and the resolution is poor unless many sources and receiver locations are used or unless the resistivity structure comes to surface. Thus, even though (bipole-dipole) reconnaissance can provide useful information, as confirmed by (dipole-dipole) follow-up surveys, industry exploration groups have become aware of its problems and little (bipole-dipole) work is being done currently (A. Ramo and R. Bowers, 1977, personal communications). Providing less ambiguous information, the Schlumberger array has been used for reconnaissance profiling. A symmetric collinear array of electrodes is employed, with the short receiver dipole at the center of the transmitter dipole. Constant dipole lengths are maintained as the array is advanced along an expected or known geologic strike. This technique was applied over much of the northern Mexicali valley, and delineated a resistivity low which correlates with the Cerro Prieto field (Garcia, 1975). As a reconnaissance method, this approach tends to be expensive because of the need to move wires and electrodes frequently.

A similar but simpler reconnaissance technique which can be used in place of Schlumberger profiling is the "gradient array." Although 
often used for mineral surveys, this technique is not reported to have been used yet in geothermal exploration. Current is impressed between two fixed electrodes, kilometers or tens of kilometers apart, and the potential differences are measured by means of a short dipole which is advanced along lines parallel to the current dipole. The apparent resistivity calculations and interpretations are based on the assumption of horizontal current flow. In this respect, the gradient array can be thought of as the controlled-source counterpart of E-fieldratio tellurics. However, the depth of exploration for the gradient array may be less than that obtained using the natural field technique. The gradient array is a rapid means for obtaining a resistivity profile or map over a fairly small area (up to tens of square kilometers), and the technique may have potential application in certain geothermal problems.

A variation of the gradient array is the "three-array" profile. Again, an extremely long fixed transmitting dipole is used with one electrode assumed at infinity. A short potential dipole is advanced collinear to, but outside the transmitter dipole.

\section{b. Vertical Electrical Soundings}

To determine how resistivity changes as a function of depth below a station, an expanding array of the Schlumberger type is commonly used. This is a symmetric collinear array with the receiver dipole located at the center of the transmitter dipole whose length is increased to achieve progressively greater depth penetration. Interpretation is accomplished by means of a one-dimensional (horizontally layered 
earth) inversion. This approach is subject to errors introduced if an electrode crosses a lateral conductivity inhomogeneity.

Vertical electrical soundings (VES) are used in various situations, e.g., to supplement MT observations or to help calibrate telluric field results. However, VES surveys are seldom made at isolated or widely spaced locations; it is more usual to conduct soundings at closely spaced locations along a line and derive a two-dimensional resistivity picture (Zohdy et al., 1973). This application is discussed next.

\section{c. Electrical Sections}

Because of the geologic complexity in geothermal environments, it is often necessary to obtain a detailed two-dimensional resistivity section which can be interpreted in terms of both vertical and lateral variations in resistivity. For this purpose, Schlumberger soundings can be made at regular intervals, but it is more common to use the axial dipole-dipole array. The latter consists of collinear transmitter and receiver dipoles of equal length, $\underline{a}$, separated from each other by distances equal to integer multiples, $\underline{N}$, of the dipole length. For large depth penetrations both $\underline{a}$ and $\underline{N}$ must likewise be large. It is typical to employ an a of $500 \mathrm{~m}$ to $1000 \mathrm{~m}$ and to take readings with $\underline{N}$ in steps of $1,2,3,4,5,6,7$. . etc. Interpretation of the electrical sections is made by fitting calculated values, based on two-dimensional models, to the observed results plotted in pseudosection form. The difficulty with this procedure is that interpretation is expensive and difficult, and few industry groups have the resources 
and capabilities to interpret Schlumberger or dipole-dipole pseudo-sections as they should be interpreted for a proper evaluation of the data. Computer programs for this purpose, utilizing finite difference, finite element or transmission line analogy, are available (Dey and Morrison, 1976, for example). However, Beyer (1977b), who spent considerable time modeling and interpreting dipole-dipole data, found the task to be both difficult, time consuming, and in the final analysis found the solutions to be non-unique. Consequently, we suspect that much of the data in industry files has received only qualitative interpretation.

The question of whether Schlumberger or dipole-dipole offers advantages in terms of resolution, rejection of surface (geologic) noise due to local inhomogeneities, and ease of interpretation was investigated by Beyer (1977a). He concludes that the choice would depend on the target sought. For locating an extensive, flat-lying geothermal reservoir, such as at Ahuachapan, El Salvador, the Schlumberger technique is most useful because soundings can be carried out with a low station density. However, in the Basin and Range where narrow, near-vertical structures are sought, dipole-dipole may be more diagnostic.

Because the depth of exploration is limited by a conductive overburden, fewer dipole-dipole surveys are being done now by industry (R. Edminston and w. Smith, 1977, personal communications). Instead, the current exploration trend is toward magnetotelluric surveys for deep information in conductive areas. 


\section{MAGNETOMETRIC RESISTIVITY}

The magnetometric resistivity (MMR) method is based on the measurement of the magnetic fields associated with noninductive current flow in the earth between two electrodes. Although various field techniques are possible, the present approach (Edwards, 1974; Edwards and Howell, 1976) is to use a technique similar to that described by Jakosky (1933; 1950). A constant-current, fixed-frequency transmitter, such as used in IP work, energizes the earth through two widely separated electrodes. The resulting horizontal magnetic field, at right angles to the line between electrodes, is detected by means of a sensitive component magnetometer, such as a fluxgate device, connected to a narrow-band tuned voltmeter.

The MMR anomaly is defined as the difference between the measured values of the horizontal component and the "normal values", those expected over a uniform earth. In practice, electromagnetic induction effects are ignored, a safe assumption so long as galvanic currents are much larger than induced currents. For this reason, low-frequency excitation ( 1 to $5 \mathrm{~Hz}$ ) is used. It is not certain whether these frequencies are low enough to avoid inductive coupling but low operating frequencies run into the problem of higher natural field noise. As a further precaution against unwanted fields, the current-carrying wires must be long, kept well away from the area of measurement and laid out as close to horizontal as possible.

There are no known reports of MMR prospecting applied to geothermal exploration, but the technique has certain advantages over conventional galvanic resistivity. For example, in some areas it may be faster and 
easier to measure magnetic field than to measure an electric potential difference. More important, MMR is theoretically more sensitive than gradient-array galvanic resistivity to conductive inhomogeneities beneath overburden, and is less affected than conventional resistivity by noise from conductive overburden thickness variations and local surficial conductivity inhomogeneities.

\section{INDUCED POLARIZATION}

Induced polarization (IP) is the name given to an energy storage phenomenon observed in many types of rocks. It is caused by an ionic charge build-up at the boundaries between volumes of different ionic mobility when current is passed through the rock. In the field, the phenomenon is manifested by a voltage decay observed across potential electrodes when the energizing current is terminated. It is also manifested by the development of a complex frequency-dependent apparent resistivity when the current is sinusoidal. Because the method is sensitive to small concentrations of disseminated sulfides, as well as more massive sulfide concentrations, it is one of the principal methods used in mineral exploration.

Procedurally, IP surveys are conducted most often with the dipole-dipole array, in a manner similar to ER surveys. Apparent resistivity is obtained at the same time the IP effect is being measured. However, a compatible IP transmitter and receiver must be used, and a variety of suitable instruments are commercially available. The IP receiver is a more sensitive and precise voltmeter than one used for resistivity only. (There are many competent geophysical contractors 
in North America and elsewhere in the world who conduct these surveys, mainly for mineral exploration.)

IP measurements may be made in the "time-domain" by means of a receiver that integrates and averages the voltage decay after a constant-current source is interrupted. The IP effect, called the chargeability, $M$, is the integrated voltage below a portion of the decay curve normalized by the voltage prior to current interruption. Another standard way of obtaining the IP effect is in the frequency domain. Voltages of two or more frequencies, usually $1 \mathrm{~Hz}$ and lower, are measured separately from the current-controlled full-wave transmitter. The percent difference in the measured voltages, or percent frequency effect (PFE), is obtained. Using a current waveform composed of two frequency components, MaPhar Geophysics, Toronto developed a transmitter-receiver to obtain PFE directly.

Newer frequency domain receivers also give the phase angle between transmitted and received signal at each frequency (Zorge et al., 1972). For this purpose a phase-lock or phase-referencing system is needed, e.g., crystal-controlled clocks, telemetry link, or hardwire link. (The phase angle, in milliradians, is also a measure of the IP effect.) In recent years receiver designers have been going more to the phase reference or coherent method of detection, because it offers a means for suppressing noise. There are receivers available using minicomputer and microprocessor-controlled circuits that can be used for time, frequency or phase measurements (Zonge, 1975; Muller et al., 1975; Synder, 1976). For a more complete discussion of IP principles and instrumentation, the reader is referred to Sumner (1976). 
For the application of IP in geothermal exploration, the source of polarization can be envisioned as a halo or zone of disseminated sulfides or perhaps a clay-rich zone of hydrothermal alteration. Limited field survey evidence at the mud volcano area of Yellowstone National Park (Zohdy et al., 1973) showed an enhanced polarization at shallow depth near the field boundary, and Risk (1975) suspects that his resistivity measurements at the Broadlands field, New zealand also showed a polarization effect near the field boundary. In both instances, the cause of the polarization effect was attributed to pyrite. Based on chemical stability studies for geothermal systems (Ellis, 1969) and mass transport calculations for hypothetical connective systems (Cathles, 1977) it is reasonable to expect that pyrite, pyrrhotite, and other metallic-luster minerals can be deposited because of pH-salinity changes due to mixing of hydrothermal and meteoric waters or because of a gas-phase separation. Ellis (1969) studied the occurrence of pyrite or pyrrhotite in hydrothermally altered rocks and found that sulfide mineral precipitation depends on the $\log \left(\mathrm{P}_{\mathrm{H}_{2} \mathrm{~S}} / \mathrm{P}_{\mathrm{H}_{2}}\right)$ in the environment. As hydrogen is less soluble in water than hydrogen sulfide, geothermal water which has lost $\mathrm{H}_{2}$ to a steam phase would be more likely to form pyrite in its reaction with the country rock. On the other hand, rock exposed to a separated steam phase may produce pyrrhotite because of the lower $\mathrm{P}_{\mathrm{H}_{2} \mathrm{~S}} / \mathrm{P}_{\mathrm{H}_{2}}$ ratio in the steam. In a two-phase system, where flashing occurs within the reservoir, pyrrhotite should grade with depth into pyrite. A suggestion of this behavior is noted in drill cuttings from wells at the Cerro Prieto field, Baja California (Wilfred Elders, personal communication). 
Highly saline geothermal water, such as in the Salton Sea area, is capable of holding high concentrations of $\mathrm{Fe}, \mathrm{Mn}, \mathrm{Cu}, \mathrm{Zn}, \mathrm{Pb}$ and Ag in solution. These metals precipitate as temperature and/or salinity decrease, as in the case where the fluids discharge at the surface. However, even dilute metal concentrations can produce extensive mineralization within present-day geothermal fields, if a large volume of water moves through the rocks. For example, drill holes at depths of 2500 to $5000 \mathrm{ft}$ at Broadlands, New Zealand have intersected mineralized bands deposited from solutions carrying metals in the ppb range. Ore-grade amounts of gold and silver are being deposited at surface, whereas erratically distributed amounts of pyrite, galena, chalcopyrite and sphalerite are forming at depth (Ewers and Reays, 1977) .

Despite these indications that IP could play a role in geothermal exploration, the method has been little used. The "Geophysical Activity Report" for 1976 (Espey, 1977) shows no geothermal IP work anywhere in the world. The lack of interest in the method, confirmed by geophysical contractors (Bruce Bell and Tsvi Meidav, 1977, personal communications) and industry (William Dolan, 1977, personal communication) may be due to several factors, e.g., unsuccessful early survey attempts discouraged further tests, and a relatively low interest in controlled-source electrical methods presently. In addition, there are certain practical limitations that should be considered. The cost of IP surveys is higher than ER because of more costly equipment, longer average time per site to make a field measurement, and longer time needed to process and interpret the data. Based on mineral survey 
statistics, Espey (1977) shows the average cost of IP is four times greater per line mile than ER. (This difference seems too high; costs were compiled without proper allowances for the actual field techniques involved) .

Another limitation is that a sulfide zone related to a concealed geothermal system may be too small relative to its depth to produce a diagnostic IP response. This would be particularly true wherever the surface layer is more conductive than the basement rock containing the IP source. The conductive layer and the large source depth would combine to reduce the expected response, and at the same time the large electrode separations needed might introduce a noise component due to inductive coupling between transmitter and receiver wires which cannot be removed to the desired accuracy (Sumner, 1976). This latter problem is the major obstacle to the use of IP as a reconnaissance or detail survey tool in areas of conductive surface rocks, such as the Imperial Valley and the intermontane valleys of Nevada and Utah. This problem could be somewhat academic in geothermal systems involving hot water circulation along deep fracture zones, such as occur in the Basin and Range province. This geological environment may not be right for the precipitation of significantly large volumes of metallicluster sulfides (C. M. Swift, 1977, personal communication). In more resistive areas, such as young volcanic terrains, IP is yet a largely untested reconnaissance technique.

Lastly, another limitation is that IP anomalies can occur for a variety of mineralogies unrelated to present-day hydrothermal activity. These include pyritic or carbonaceous sediments, pyritic volcanics, 
zeolitic basalts, thick clay sequences, and certain metamorphic rocks, such as tremolitic limestone, schists and serpentinized basic and ultrabasic rocks. There have been investigations of the complex resistivity spectra for many rocks as a means for identifying the source of an IP anomaly. W. Pelton (1977, personal communication) has results showing that clay-rocks can be recognized by their spectra, and because they exhibit a high frequency response are easy to identify.

\section{ELECTROMAGNETIC INDUCTION}

Electrical resistivity reconnaissance and detail surveys may be conducted by means of various types of controlled-source EM systems. To map shallow changes in resistivity, low-power and lightweight equipment designed for mineral surveys can be used for profiling. For example, a two-coil moving source-receiver arrangement (Slingram technique) has been used to map shallow resistivity variations in geothermal areas of New Zealand and Chile (Lumb and Macdonald, 1970). In-phase and quadrature components are converted into apparent resistivity values. The technique is faster to apply than shallow galvanic resistivity profiling. However, if shallow resistivity information only is required, it is yet simpler to use a natural field technique, such as the Very Low Frequency (VLF) technique, which requires modest instrumentation and a single operator.

VLF surveying is used primarily for mineral exploration, and there is no mention in the literature of its use in geothermal exploration. VLF transmitters, operating at carrier frequencies of 17 to $25 \mathrm{kHz}$, have been installed at various sites around the world and are used for 
long-range communication to submarines. To exploit these sources for exploration purposes, several manufacturers offer receivers consisting of a pair of small, orthogonal detection coils connected to a circuit that can be selectively tuned to a desired transmitter frequency. The hand-held receiver is operated as a dipmeter; one determines the dip angle of the anomalous magnetic field in the vertical plane containing the receiver location and the electric dipole transmitter. While this mode of operation is useful for detecting near-vertical tabular conductors, at least one instrument gives apparent resistivity directly by means of simultaneous electric and magnetic field measurements. This device can be used to map lateral variations in apparent resistivities, averaged over a shallow depth of 10 to 30 meters.

In most geothermal exploration situations, deeper electrical soundings are necessary, and larger, more powerful systems capable of operation at low frequencies are required. Several such systems are in operation or under development. Only one, the TDEM (Time-Domain Electromagnetic) system developed at the Colorado School of Mines, is in commercial use (R. Furgerson, 1977, personal communication). The TDEM was tested at, among other places, the Kilauea volcano, Hawaii (Jackson and Keller, 1972; Keller and Rapolla, 1974), and in Hualapai Flat and Central Black Rock Desert Area, northwestern Nevada (Grose and Keller, 1975).

A transient electromagnetic field is generated by energizing a long grounded wire (bipole source) with an asymmetric square wave current of about 100 amperes peak-to-peak. The vertical magnetic field at a receiver location is detected by means of a large induction 
loop laid out on the ground, although a three-component Josephson Junction magnetometer has also been used (Ofiafate and Keller, 1976). The loop is connected to a sensitive high-speed chart recorder through a low-pass filter to reject power line noise. In the laboratory, the repeated voltage signals must undergo rather complicated processing involving (1) synchronous stacking to improve signal-to-noise, (2) deconvolution to compensate for recording system characteristics, and (3) further smoothing to reduce uncorrelated noise. The resulting voltage-time plots can be compared to obtain a semi-quantitative estimate of the lateral changes in resistivity. One processing method (Vanyan et al., 1967) involves calculating and plotting a maximum apparent resistivity using the maximum voltage value. A somewhat similar timedomain prospecting device was developed for mineral exploration at the University of Toronto (Lamontagne, 1973, 1975), but the "UTEM" System has not yet been tested for geothermal applications. In the experimental system a large ( $1 \mathrm{~km}$ by $1 \mathrm{~km}$ ) horizontal loop is energized by a precisely-controlled current, triangular in form with a peak amplitude of 5 amperes. The resulting vertical magnetic field is detected by means of a small ferrite-core induction-coil magnetometer. The signal is processed by means of a clock-synchronized receiver which automatically samples and averages ten time segments (channels) of the voltage. Each channel is corrected for source-receiver distance, earth resistivity and topography, and the signal variations along traverse lines are interpreted in terms of model results for the target sought, i.e., a near-vertical tabular conductor. A depth sounding 
interpretation has not been developed for either the TDEM or UTEM techniques.

Among the frequency domain prospecting systems, one of the most advanced is an experimental 14-frequency system developed by the University of Utah and McPhar Geophysics, Toronto, for mineral explorations. Relative to either a vertical or horizontal transmitter loop, the tilt of the major axis and the ratio of minor to major axes of the magnetic field polarization ellipse are measured over the range $10 \mathrm{~Hz}$ to $86 \mathrm{~Hz}$ (Ward et al., 1976). The instrument has been tested

at various places in Utah for geothermal resource studies, and the data have been chiefly useful as a means of comparison with Schlumberger resistivity results (Ward et al., 1976).

More recently, LBL and the University of California began development of a frequency-domain system for geothermal exploration, based on experiments in Grass Valley, Nevada (Jain and Morrison, 1976; Jain, 1977). In these experiments it was shown that EM soundings gave interpreted results that compared well with those from dipole-dipole surveys to depths of the basement at $\mathrm{I}^{+} \mathrm{km}$. The system, which can be expanded to include time-domain measurements, is designed around a horizontal coil transmitter with small diameter $(30 \mathrm{~m})$ but large moment to overcome a number of problems in the galvanic resistivity method and problems with other controlled-source EM systems:

1. Because no ground contact is needed, the system is better suited to areas where contact resistances are high, such as the Dunes areas, California. 
2. A magnetic field detector can be used, thus eliminating the need for long wires to be laid out and retrieved.

3. The transmitter can be placed at any convenient location, an especially helpful feature in rugged terrain where access is limited, and the surrounding area is surveyed by moving the receiver only.

4. Vertical resistivity soundings are made by varying frequency, not transmitter-receiver separation, * and this avoids the interpretational difficulties of galvanic methods which are caused by lateral inhomogeneities.

5. By generating an EM field over a broad range of frequencies $\left(10^{3} \mathrm{~Hz}\right.$ to as low as $\left.10^{-3} \mathrm{~Hz}\right)$ the system provides good resolution of the near-surface as well as better depth penetration than galvanic methods in conductive environments.

6. A smaller field crew is required than in galvanic resistivity measurements.

The transmitter portion of this prototype system is somewhat similar to that used for galvanic resistivity surveys. Current from a $60 \mathrm{~kW}, 400$-cycle, 3-phase motor generator is rectified and applied to the loop through an array of transistorized switches controlled remotely by an operator who manually sets the pulse length of a control voltage. Recently developed transistors, capable of handling large current and voltage, with fast rise times, are used in place of SCR's

\footnotetext{
* Orientation surveys are best performed by repeating measurements at differernt transmitter-receiver separations ( $r$ ) so as to assure oneself that the important range of induction numbers $(\omega \mu \sigma)^{1 / 2} r$, has been completely covered.
} 
for switching because SCR's cannot switch at frequencies over about

$1 \mathrm{~Hz}$ when coupled to an inductive load.

Magnetic field detection is done with a three-component SQUID magnetometer connected to a receiver. The receiver circuitry is designed to digitize each magnetic signal and compare it to the digitized phase reference signal from the transmitter-controller. By means of digital processing, the in-phase and quadrature components of the fundamental frequency are obtained, displayed and stored on a printed tape. The synchronous detector can also receive and process two additional data channels from electric dipoles and thus may also be used as an MT receiver-processor. In the prototype version a hard-wire link is used between transmitter and receiver, but this can eventually be replaced with a telemetry link.

All necessary data processing except for normalization for current is done automatically in the field. Data interpretation is accomplished later by means of a one-dimensional inversion if a depth sounding is desired. However, in geologically complex areas some form of twoor three-dimensional analysis is required. For this, the observed data must be compared to sections calculated for two- or three-dimensional models, similar to the procedure used in galvanic resistivity interpretation. Computer programs for these purposes are being developed by LBL and the University of California, and at the University of Utah.

RESEARCH AREAS FOR CONTROLLED SOURCE METHODS

Several research areas have been identified in the class of controlled source electrical and electromagnetic techniques. These 
areas, listed below, are discussed in the following sections and shown in the Research Matrix, Fig. 7.

- Two-Dimensional Interpretation of Resistivity Data

- Magnetometric Resistivity

- Inductive Coupling Effects in Induced Polarization

- Controlled-Source Electromagnetic Surveying

1. Area I: Two-Dimensional Interpretation of Resistivity Data Problem Statement

The interpretation of apparent resistivity pseudo-sections is most commonly done by comparing observations to an atlas of results for simple two-dimensional models or by a trial-and-error fit of observations to more complex two-dimensional geometries; the latter is made possible by the availability of faster, less expensive computer codes for the forward problem (e.g., Dey and Morrison, 1977; Dey, 1976). Despite recent advances in computer programming, interpretation by means of trial-and-error calculations can be an arduous and expensive exercise. For this reason, we suspect that much of the resistivity data collected by industry has not been adequately interpreted, and that waning interest in electrical resistivity can be partially attributed to the time, cost and difficulties in interpretation.

\section{Solution}

The ease of interpreting electrical resistivity pseudo-sections would be vastly improved by the availability of an automatic inversion code for the two-dimensional problem. While we do not see an easy means for obtaining a generalized two-dimensional inversion, a limited 
RESEARCH AREAS

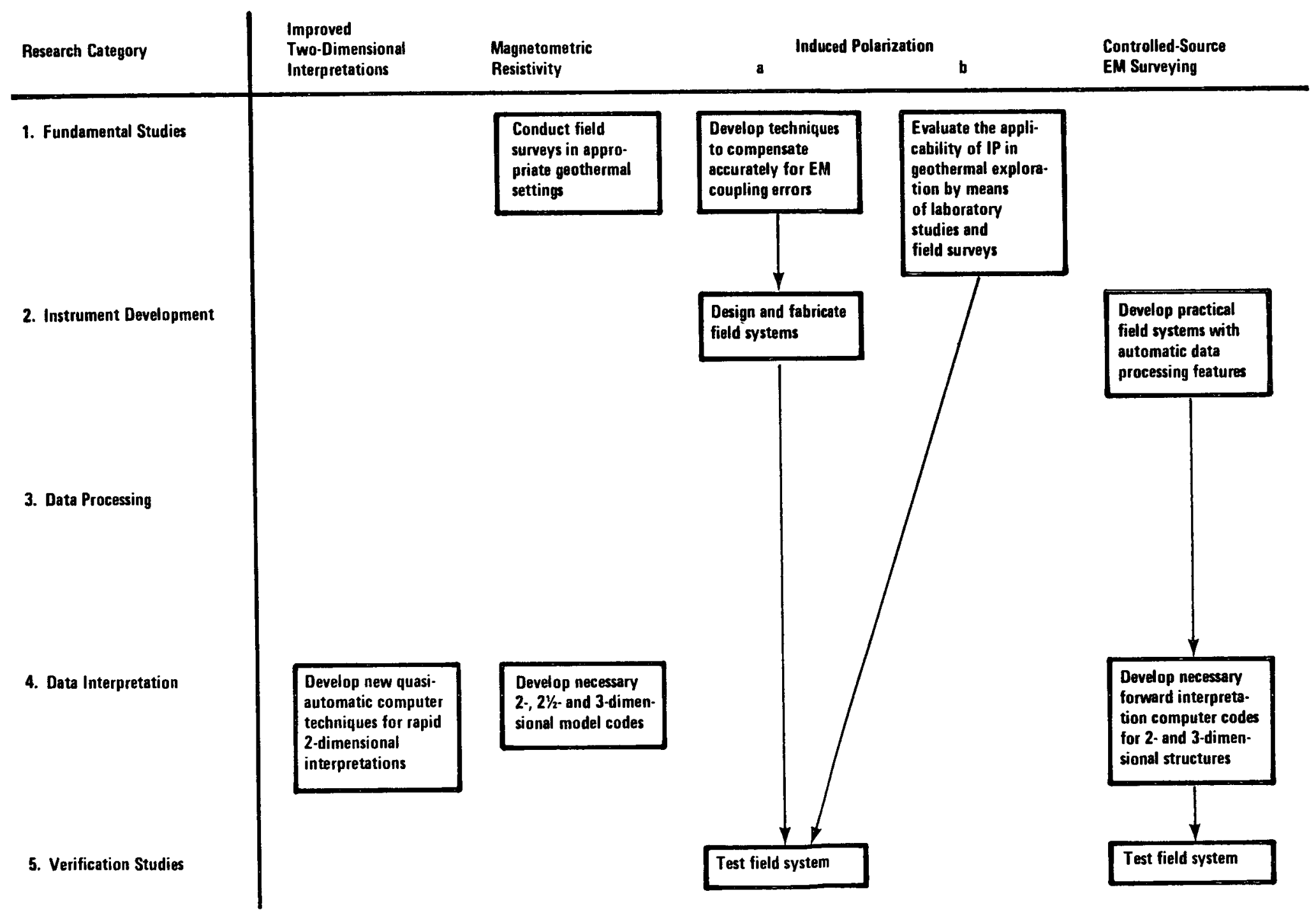

Fig. 7. Research matrix for controlled-source electrical and electromagnetic exploration. 
inversion is possible, as demonstrated by Pelton (1977). He considered the resistivity/IP problem involving a rectangular two-dimensional source lying below a conductive overburden; his model consisted of nine parameters to be resolved. The routine used spline interpolation between 768 stored data sets (dipole-dipole array only), covering the range of parameter combinations expected, to obtain the fast forward problem solution required for ridge regression inversion.

This approach could be extended to the inversion of resistivity data for geothermal surveys once a target class is characterized by a range of model parameters and a data bank is created and stored. Although this is a computationally expensive operation, it does not have to be repeated unless one wishes to recharacterize the geology. Pelton's method has the advantage of speed and low cost, stability of the estimates in the presence of noise, and adaptability of ridge regression inversion to the joint inversion of multiple data sets (e.g., different dipole lengths). The technique could also be extended to accommodate other electrode arrays, in particular, the Schlumberger array.

Alternatively, efforts should be made to develop a more general automatic approach to a two-dimensional inversion,' not limited to a stored data bank of precalculated models. For some data sets, this might be accomplished in three phases:

(a) a preliminary one-dimensional inversion for parts of the the data set where the earth appears layered; 
(b) an interactive procedure to find where vertical boundaries have to be placed in order to match curve shapes in the pseudo-section, and

(c) an iterative procedure to determine resistivity contrasts at each of the vertical boundaries.

\section{Area II: Magnetometric Resistivity}

\section{Problem Statement}

The Magnetometric Resistivity (MMR) has application in flat areas when the target sought is buried beneath a conductive overburden and conventional resistivity cannot provide anomaly resolution. However, there has been little field experience with MMR and computer modeling methods for the generalized two-and-a-half and three-dimensional forward problems have not been extended to the MMR simulations.

\section{Solution}

MMR surveys should be conducted over several geothermal areas in the western United States, where subsurface information has been obtained from surface geophysics and confirmed by drilling. MMR data would be assessed to determine the value of the reconnaissance method or detail surveying in conductive terrains.

At the same time, available two, two-and-a-half, and three-dimensional model codes for the dc cases should be modified to calculate theoretical MMR responses, and such calculations should be done for a range of models.

It is also suggested that magnetometric induced polarization (MIP) be tested and studied to determine the applicability of this 
technique and whether it offers advantages over conventional induced polarization (see Area III).

\section{Area III: Inductive Coupling Effects in Induced Polarization}

\section{Problem Statement}

The ambiguity of some resistivity data might be resolvable by means of Induced Polarization (IP) measurements. However, the potential of IP in geothermal exploration has not been studied because in conductive environments, electromagnetic (EM) coupling errors may be large and impossible to correct and therefore reliable readings are difficult to obtain.

\section{Background}

Resistivity lows may be associated with geological conductors unrelated to the high ionic conductivity of present-day geothermal systems. Among the misleading sources are: a) conductive zones in alluvium, particularly clay-rich rocks, and b) certain sediments such as carbonaceous limestones. Characterization of a resistivity low might be accomplished by means of IP measurements. Not only would the IP measurements indicate the possibility of sulfides, but the IP spectral signature (Zonge, 1972; Sumner, 1976) might help to identify the source of the polarization and hence the source of the resistivity low. The principal limitation of IP, and the main reason why this technique is not used, is the problem of accurately compensating for inductive EM coupling. Various means have been devised for this purpose, but none are known to be sufficiently accurate and precise for surveys involving long wire spreads over conductive surface rocks. Wynn and 
Zonge (1975) discuss this problem and report that they have developed a coupling removal technique that depends heavily on laboratory rock spectra characterization and in situ field measurements. Decoupling is performed using a generalized version of the coupling equations and an iterative, interactive computer optimization routine. The main problem with their technique is that it is difficult to apply, requiring considerable background in rock behavior, interactive computer analysis, and a highly sophisticated field spectrum (magnitude and phase) measuring system.

\section{Solution}

Because EM coupling cannot be totally avoided by the proper choice of electrode array, the use of short wires or choice of survey area, and because coupling cannot be totally or easily compensated for by calculations, the problem must be solved by an accurate in-field determination of the coupling effect, a unique property for each combination of transmitting and receiving dipoles.

The ideal solution would be a procedure whereby the inductive coupling effect could be determined directly at the frequencies of interest for each set-up. This is an extremely difficult problem and we can offer only limited directions toward finding a satisfactory solution. One possibility, which may have application in geologically simpler areas, is similar to the approach outlined by Wynn and Zonge (1975). This calls for an iterative scheme of first interpreting a conductivity section from the dc apparent resistivity data. An electromagnetic response is then calculated for the model at the fre- 
quencies and array parameters used. Finally, the EM response is subtracted from the observed IP response. Programs to calculate the EM response have been developed at the University of Utah and University of California, among other places, and it remains only to design a thorough field and modeling experiment to test the method.

\section{Area IV: Controlled-Source Electromagnetic Surveying}

\section{Problem Statement}

As discussed earlier, controlled-source electromagnetic (EM) techniques have advantages over both dc resistivity and natural field resistivity techniques. In Western countries relatively little work has been done to develop and demonstrate the usefulness of this technique for deep exploration. Difficulties arise in generating and measuring the low-frequency fields, and in interpreting the results when the earth cannot be approximated by layers or simple structures.

\section{Solution}

Advances in technology make it possible now to build a practical EM system for exploration to depths of $5 \mathrm{~km}$, and to interpret results more quantitatively and faster than before. In instrumentation, the development of the Josephson-effect superconducting magnetometer permits three-component magnetic field measurements to $10^{-10} \mathrm{G}$ by means of a lightweight detector that can be handled in the field by one man. The increase in sensitivity (almost two orders of magnitude over induction coils at $10^{-2} \mathrm{~Hz}$ ) permits more accurate measurements and also reduces the source moment needed, thereby reducing some of the field problems related to generating a large primary field. In-field 
processing of the observed magnetic fields by means of a digital synchronous detector in a small, portable package would make it possible to determine directly the amplitude-phase information of each frequency or the transient (time-domain) response of the earth. Finally, the development of new transistors capable of handling large currents and voltages makes it possible to switch current into an inductive load (loop transmitter) at frequencies above $1 \mathrm{~Hz}$. This means that soundings can be made more conveniently, varying frequency (parametric sounding) instead of the transmitter-receiver separation (geometric sounding). However, where lateral inhomogeneities are anticipated, both types of soundings should be made, and thus a portable receiver is needed.

At this time the most practical transmitter would be a relatively small-diameter, multi-turn horizontal loop with a large dipole moment $\left(>10^{6} \mathrm{mks}\right)$. Design considerations show that a 30 -meter diameter loop consisting of five to ten turns of $4 / 0$ wire would be a satisfactory compromise; this loop could be laid out with relative ease, particularly if it is segmented and energized by a 50-60 kW motor-generator. A vertical loop (horizontal dipole) offers a signal-noise advantage over a horizontal loop, because the preferred component for sounding is the vertical, the direction of minimum natural noise. However, a vertical loop with large moment is difficult to set up in the field.

A third type of source, a rotating dc magnet, produces the elliptically polarized field of two dipoles, and may be the theoretically optimum source. A lightweight rotating source with large moment could be obtained with a lossless dc superconducting magnet. A limita- 
tion of this source is rotation velocity; centrifugal forces on the cryostat would probably limit the upper frequency to $10 \mathrm{~Hz}$. However, this source has several advantages over a coil:

a. it may be oriented in any direction--in particular it can be horizontal, which offers a signal-to-noise improvement;

b. the rotating dipole produces an elliptically polarized field at a distant point, a feature that is helpful for resolving two-dimensional resistivity structure;

c. the moment is invariant, and only the rotation velocity needs to be monitored;

d. a rotating system is amenable to sweep frequency operation;

e. there is no joule heating loss, and therefore only a low

power dc source is needed to create the magnet;

f. the source is easily transported; no coils need to be laid out.

Such a system is presently being designed on the Berkeley campus as part of an industry-supported research program on the applications of superconductivity in electromagnetic exploration systems. Interpretation of sounding data obtained with a loop (dipole) transmitter is well in hand for the one-dimensional (layered earth) model. Additional work needs to be done to develop a computer program that calculates the response of an arbitrary two-dimensional resistivity distribution. For simple three-dimensional geometries there already exist integral computer programs. 
REFERENCES--Controlled-Source Electrical and Electromagnetic Methods

Bell, B., 1977, personal communication.

Beyer, J. H., 1977a, Telluric and dc resistivity techniques applied

to the geophysical investigation of Basin and Range geothermal systems, Part II: a numerical model study of the dipole-dipole and Schlumberger resistivity methods: Lawrence Berkeley Laboratory report, LBL-6325,

Feb. 3.

Beyer, J. H., 1977b, Telluric and dc resistivity techniques applied to the geophysical investigation of Basin and Range geothermal systems, Part III: the analysis of data from Grass Valley, Nevada: Lawrence Berkeley Laboratory report, LBL-6325, March 3.

Beyer, J. H., et al., 1976, Geological and geophysical studies in Grass Valley, Nevada, preliminary open file report: Lawrence Berkeley Laboratory report, LBL-5262.

Bowers, R., 1977, personal communication.

Cathles, L. M., 1977, An analysis of the cooling of intrusives by groundwater convection which includes boiling: Econ. Geol., v. 72, p. 804 .

Dey, A., 1976, Resistivity modeling for arbitrarily shaped two-dimensional structure, Part II: user's guide to the FORTRAN algorithm RESIS2D: Lawrence Berkeley Laboratory report, LBL-5283.

Dey, A., and Morrison, H. F., 1976, Resistivity modeling for arbitrarily shaped two-dimensional structures, Part I: theoretical formulation: Lawrence Berkeley Laboratory report, LBL-5233.

Dolan, W., 1977, personal communication. Edmiston, R., 1977, personal communication. 
Edwards, R. N., 1974, The magnetometric resistivity method and its application to the mapping of a fault: Can. J. Earth Sci., v. 11, pp. $1136-1156$.

Edwards, R. N., and Howell, E. C., 1976, A field test for the magnetometric resistivity (MMR) method: Geophysics, v. 41, n.6A, p. 1170 .

Elders, w., 1977, personal communication.

Ellis, A. J., 1969, Present-day hydrothermal systems and mineral deposition: Proceedings, 9th Commonwealth Mining Metallurgical Congress, London.

Espey, H. R., 1977, Geophysical activity in 1976: Geophysics, v. 42, p. 1070 .

Ewers, G. R., and Keays, R. R., 1977, Volatile and precious metal zoning in the Broadlands geothermal field, New Zealand: Econ. Geol., v. 72, no. 7, pp. 1337-1354 .

Furgerson, R., 1977, personal communication.

Furgerson, R., and Keller, G. V., 1974, Computed dipole resistivity effects for an earth model with vertical and lateral contrast in resistivity: Off. Naval Res. Report of Investigations, Colorado School of Mines, Golden, Colorado.

Garcia, D. S., 1975, Geoelectric study of the Cerro Prieto geothermal area, Baja California, Mexico: Proceedings, Second U. N. Symposium on the Development and Use of Geothermal Resources, San Francisco, v. 2 , p. 1003 . 
Grose, L. T. and Keller, G. V., 1975, The Colorado School of Mines geothermal study: Progress Report No. 4, Colorado School of Mines, Golden, Colorado.

Hall, S. H., and Davis, J., 1977, The rotating current dipole method-a field test: Geoph. Prospecting, v. 25, no. 2, p. 308 . Jackson, D. B., and Keller, G. V., 1972, An electromagnetic sounding survey of the summit of Kilauea Volcano, Hawaii: Jour. Geophys. Res., v. 77, p. 4957.

Jain, B., 1978, A low-frequency electromagnetic prospecting system: Ph. D. thesis, University of California, Berkeley, in preparation. Jain, B. and Morrison, H. F., 1976, Inductive resistivity survey in Grass Valley, Nevada: Lawrence Berkeley Laboratory, progress report. Jakosky, J. J., 1933, Method and apparatus for determining underground structure: U.S. Patent 1,986,271.

Jakosky, J. J., 1950, Exploration geophysics, second edition: Trija Publishing Co., Los Angeles, 1195 pp.

Keller, G. V., and Rapolla, A., 1974, Electrical prospecting methods in volcanic areas: Physical Volcanology, ed. L. Civetta et al., Elsevier Scientific, Amsterdam, p. 133.

Keller, G. V., et al., 1975, The dipole mapping method: Geophysics, v. 40, p. 451 .

Lamontagne, Y., 1973, A wide-band, time-domain ground EM system: Sympos. electromag. explor. methods, Geophysics Lab., Physics Department, Univ. of Toronto. 
Lamontagne, Y., 1975, Applications of wide-band, time-domain EM measurements in mineral exploration: $\mathrm{Ph}$. D. thesis, University of Toronto.

Lumb, J. T., and Macdonald, W. J. P., 1970, Near-surface resistivity surveys of geothermal areas using the electromagnetic method: Second U. N. Symposium on the Development and Use of Geothermal Resources, v. 2, p. 311 .

Meidav, T., 1977, personal communication.

Miller, D., Chapman, w., and Dunster, D., 1975, Mark II--A multichannel IP system with minicomputer control and processing: Preprint, 45th Annual International Meeting, SEG, Denver, Colorado.

Morrison, H. F., 1975, The up-down counter: a synchronous signal averager for earth resistivity measurements: The study of Temporal Resistivity Variations on the San Andreas Fault, Technical Progess Report on USGS grant \#14-08-0001-G-124, Engineering Geoscience, University of California, Berkeley.

Ofiafate, O., and Keller, G. V., 1976, Use of two three-component receivers in time-domain electromagnetic sounding: Abs., 46th Annual International Meeting, SEG, Houston, Texas.

Pelton, W. H., 1977, personal communication. Pelton, พ. H., 1977, Interpretation of induced polarization and resistivity data, Ph. D. thesis, University of Utah, $255 \mathrm{pp}$. Ramo, A., 1977, personal communication. Risk, G. F., 1975, Monitoring the boundary of the Broadlands geothermal field, New Zealand: Proceedings, Second U. N. Symposium on the Development and Use of Geothermal Resources, v. 2, p. 1185. 
Snyder, D. D., 1976, Field tests of a microprocessor-controlled electrical receiver: Abs., 46th Annual International Meeting, SEG, Houston, Texas.

Smith, W., 1977, personal communication.

Sumner, J. S., 1976, Principles of induced polarization for geophysical exploration: Elsevier Scientific, Amsterdam, 277 pp.

Swift, C. M., Jr. 1977, personal communication.

Vanyan, L. L. et al., 1967, Electromagnetic depth soundings: Consultants Bureau, New York, $312 \mathrm{pp}$.

Ward, S. A., Smith, B. D., Glenn, W. E., Rijo, L., and Inman, J. R., Jr., 1976, Statistical evaluation of electrical sounding methods, Part II: applied electromagnetic depth soundings: Geophysics, v. 41, pp. $1222-1235$.

Zohdy, A. A. R., 1977, personal communication.

Zohdy, A. A. R. et al., 1973, Resistivity, self-potential, and induced polarization surveys of a vapor-dominated system: Geophysics, v. 38, p. 1130 .

Zonge, R. L., 1972, Electrical parameters of rocks as applied to geophysics: Ph. D. dissertation, University of Arizona, Tucson, and University Microfilms, Ann Arbor, Michigan.

Zonge, K. L., 1975, Field application of minicomputers as used in economic mineral exploration: Abs., 45th Annual International Meeting, SEG, Denver, Colorado.

Zonge, R. L., Sauck, W. A., and Sumner, J. S., 1972, Comparison of time, frequency and phase measurements in induced polarization: Geophys. Prosp., v. 20, pp. 626-648. 
APPENDIX I. GEOPHYSICISTS CONSULTED FOR SEISMIC METHODS

$\begin{array}{ll}\text { Name } & \begin{array}{l}\text { Affiliation } \\ \text { John Bailey }\end{array} \\ \text { Shawn Biehler } & \text { University of California, Riverside, CA } \\ \text { David Butler } & \text { MicroGeophysics, Golden, CO } \\ \text { Jim Combs } & \text { University of Texas, Dallas, TX } \\ \text { Gary Crosby } & \text { Phillips Petroleum, Del Mar, CA } \\ \text { Dick Dondanville } & \text { Union Oil, Los Angeles, CA } \\ \text { Robert Greider } & \text { Chevron Oil, San Francisco, CA } \\ \text { H. M. Iyer } & \text { U. S. Geological Survey, Menlo Park, CA } \\ \text { Lewis Katz } & \text { Seismic Exploration, Salt Lake City, UT } \\ \text { Arthur Lange } & \text { Amax Exploration, Golden, Co } \\ \text { Alfred Liaw } & \text { University of California, Berkeley, CA } \\ \text { Ernest Majer } & \text { University of California, Berkeley, CA } \\ \text { Thomas McEvilly } & \text { University of California, Berkeley, CA } \\ \text { Amos Nur } & \text { Stanford University, Stanford, CA } \\ \text { Robert Smith } & \text { University of Utah, Salt Lake City, UT } \\ \text { Howard Taylor } & \text { Sun Oil, Dallas, TX }\end{array}$


APPENDIX II. GEOPHYSICISTS CONSULTED ON ELECTRICAL AND ELECTROMAGNETIC METHODS

Tellurics

1. Harry Beyer
2. Gary Crosby
3. Don Hoover
4. Gene Humphreys
5. Alan Lattanner
6. John Maas
7. Aldo Mazella
8. H. Frank Morrison
9. Gary Oppliger
10. James Pritchard
11. John Saarlos
12. Suhli Yungul

Magnetotellurics

\section{Affiliation}

University of California, Berkeley, CA Phillips Petroleum Co., Del Mar, CA U.S. Geological Survey, Denver, Co University of California, Riverside, CA Union Oil Company, Los Angeles, CA Phillips Petroleum Co., Del Mar, CA Terraphysics, Albany, CA University of California, Berkeley, CA University of California, Berkeley, CA Electrodyne Survey Services, Reno, NV Lawrence Berkeley Laboratory, Berkeley, CA Chevron Resources, San Francisco, CA

University of Texas, Austin, TX Senturion Sciences, Inc., Tulsa, OK Phillips Petroleum Co., Del Mar, CA Senturion Sciences, Inc., Tulsa, OK University of California, Berkeley, CA University of California, Berkeley, CA University of New Mexico, Albuquerque, NM Amax Exploration Inc., Denver, CO Union Oil Co., Los Angeles, CA University of California, Berkeley, CA Geonomics, Inc., Berkeley, CA University of California, Berkeley, CA University of California, Berkeley, CA Geonomics, Inc., Berkeley, CA Scintrex, Inc., Toronto, Canada U. S. Geological Survey, Denver, Co Chevron Resources, San Francisco, CA Shell Oil Co., Houston, TX Macquarie University, Sydney, Australia (on sabbatical at U. C. Berkeley)

Geonomics, Inc., Berkeley, CA University of Texas, Austin, TX University of Utah, Salt Lake City, UT U. S. Geological Survey, Denver, co U. S. Geological Survey, Denver, Co Lawrence Berkeley Laboratory, Berkeley, CA Geonomics, Inc., Berkeley, CA Electrodyne Survey Services, Reno, NV 
Resistivity

1. Bruce Bell

2. Roger Bowers

3. William Dolan

4. Robert Edmiston

5. Tsvi Meidav

6. Alan Ramo

7. Bill Smith

8. Charles Swift
Affiliation

Phoenix Geophysical Surveys, Tucson, Az Hunt Energy Corporation, Dallas, TX Amax Exploration, Inc., Denver, CO Chevron Resources, San Francisco, CA Geonomics, Inc., Berkeley, CA

Sun Oil Co., Dallas, TX

Republic Geothermal, Santa Fe Springs, CA Chevron Resources, San Francisco, CA 


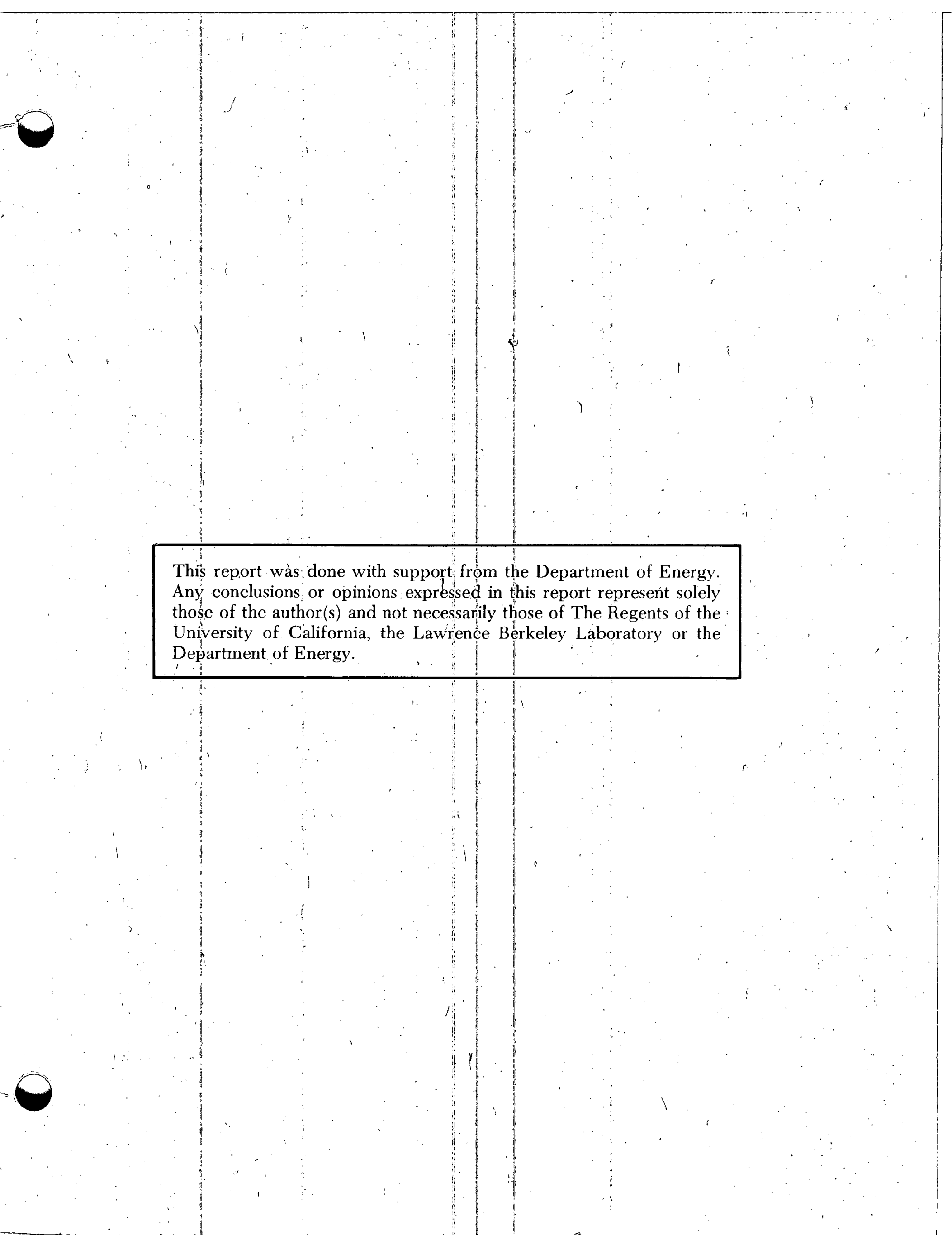


TECHNLAL INFORMATION DEPARTMENT LAWRENCE BERKELEY LABORATORY UNIVERSITY OF CALIFORNIA BERKELEY, CALIFORNIA 94720 